\title{
Growth and Characterization of Amorphous Multicomponent Nitride Thin Films
}

\author{
Hanna Fager
}

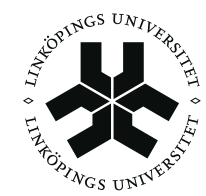

\section{Linköping University}

Thin Film Physics Division

Department of Physics, Chemistry and Biology, (IFM)

Linköping University

SE-581 83 Linköping, Sweden

Linköping 2014 
The cover of the thesis illustrates a two-dimensional amorphous network consisting of atoms with corresponding relative atomic radii. Hf atoms in red (1.55 $\AA$ ), yellow Ti atoms $(1.40 \AA)$, green $\mathrm{Al}$ atoms $(1.25 \AA)$, Si atoms in purple $(1.10 \AA)$, blue $\mathrm{B}$ atoms $(0.85 \AA)$, and grey $\mathrm{N}$ atoms $(0.65 \AA)$.

The radii are taken from J.C. Slater. Atomic Radii in Crystals.

The Journal of Chemical Physics, 41:3199,1964.

(C) Hanna Fager

ISBN 978-91-7519-337-3

ISSN 0345-7524

Typeset using $\mathrm{HT}_{\mathrm{E}} \mathrm{X}$

Printed by LiU-Tryck, Linköping 2014 
Till alla systrar 



\begin{abstract}
This thesis explores deposition of amorphous thin films based on the two transition metal nitride systems, TiN and HfN. Additions of $\mathrm{Si}, \mathrm{Al}$ and $\mathrm{B}$ have been investigated using three different deposition techniques: dc magnetron sputtering, cathodic arc evaporation, and high power impulse magnetron sputtering (HIPIMS). The effect of elemental composition, bonding structure, growth temperature, and low-energy ion bombardment during growth has been investigated and correlated to the resulting microstructure and mechanical properties of the films. The thermal stability has been investigated by annealing experiments.

Deposition by cathodic arc evaporation yields dense and homogeneous coatings with essentially fully electron-diffraction amorphous structures with additions of either $\mathrm{Al}+\mathrm{Si}, \mathrm{B}+\mathrm{Si}$ or $\mathrm{B}+\mathrm{Al}+\mathrm{Si}$ to $\mathrm{TiN}$. The $\mathrm{B}$-containing coatings have unusually few macroparticles. Annealing experiments show that Ti-Al-Si-N coatings have an age hardening behavior, which is not as clear for B-containing coatings. Compositional layering, due to rotation of the sample fixture during deposition, is present but not always visible in the as-deposited state. The layering acts as a template for renucleation during annealing. The coatings recrystallize by growth of TiN-rich domains.

Amorphous growth by conventional dc magnetron sputtering is possible over a wide range of compositions for Ti-B-Si-N thin films. The Ti content in the films is reduced compared to the content in the sputtering target. Without $\mathrm{Si}$, the films consist of a BN onion-like structure surrounding TiN nanograins. With additions of Si the films eventually grows fully amorphous. The growth temperature has only minor effect on the microstructure, due to the limited surface diffusion at the investigated temperature range $\left(100-600{ }^{\circ} \mathrm{C}\right)$. Ion assisted growth leads to nanoscale densification of the films and improved mechanical properties.

Ti-B-Si-N thin films are also deposited by a hybrid technique where dc magnetron sputtering is combined with HIPIMS. Here, the Ti:B ratio remains equal to the target composition. Films with low Si content are porous with $\mathrm{TiN}$ nanograins separated by BN-rich amorphous channels and have low hardness. Increasing Si contents yield fully electron-amorphous films with higher hardness.

Finally, Hf-Al-Si-N single-layer and multilayer films are grown by dc magnetron sputtering from a single Hf-Al-Si target. Amorphous growth is achieved when the growth temperature was kept at its minimum. Low-energy substrate bias modulation is used to grow nanocomposite/nanocolumnar multilayers from the single Hf-Al-Si target, where the layers has essentially the same composition but different $\mathrm{Si}$ bonding structure, and different degree of crystallinity.
\end{abstract}





\section{Populärvetenskaplig sammanfattning}

Människan har i alla tider använt material som hon hittat i naturen och bearbetat dem för att de ska kunna fungera som verktyg, som vapen eller kanske för utsmyckning. Tidigare har vi varit begränsade till att bearbeta de material som funnits naturligt tillgängliga. Men den tekniska utvecklingen under framförallt nitton- och tjugohundratalet har gjort det möjligt att tillverka material som tidigare inte fanns. De senaste hundra åren har vi också börjat förstå i detalj hur olika material fungerar ända ner på atomnivå, vilket öppnat upp för ett helt nytt tankesätt kring material och hur vi kan skapa dem.

Vi har utvecklat nya tekniker för att tillverka material, bland annat de ytbeläggningstekniker som använts i det här arbetet. Dessa tekniker har kommit att bli en global succé, en miljardindustri och faktiskt en förutsättning för det moderna liv som vi känner det idag.

Anledningen till att vi har produkter som surfplattor och smarta mobiltelefoner idag beror till stor del på utvecklingen av tunna filmer, skikt, eller beläggningar som de också kallas. Idag är beläggningarna ofta inte tjockare än någon eller några mikrometer, vilket motsvarar en eller några tusendelars millimeter, och de är omöjliga att se med blotta ögat. Beläggningar i sig är inget nytt påfund, människan har använt sig av dem i tusentals år, till exempel för glasering av kärl för förvaring och transport av vatten, men de senaste decennierna har de blivit mer och mer tekniskt avancerade. Samma grundtanke finns dock kvar, nämligen att kombinera egenskaperna hos två eller flera olika material där det ena utgör ett tunt lager ovanpå det andra. På så sätt kan man utnyttja de olika materialens bästa egenskaper. Exempelvis kan vi tänka oss en bil där karossen är gjord av metall som är hårt men relativt lätt att forma. För att bilen ska stå emot väder och vind målar vi den så att den skyddas mot rostangrepp men också får en vacker färg.

Inom verktygsindustrin har beläggningar gjort det möjligt att öka produktiviteten genom att förlänga verktygens livslängd. Detta gäller inte bara skruvmejslar och borr som du och jag köper för hemmabygget, utan framför allt för verktyg för metallbearbetning i tillverkningsindustrin. För att vara användbara inom detta område måste beläggningarna vara hårda och slitstarka så att de håller för de stora påfrestningar i form av värme och tryck som uppstår då man borrar, fräser, svarvar eller på annat sätt bearbetar ett material.

Idag används olika tekniker där grundämnena man vill ha i sitt skikt eller beläggning fås från en fast eller flytande materialkälla. Atomerna förångas eller stöts ut ur materialkällan och bildar ett moln, eller en ånga, som består av atomer, elektroner och joner. Om objektet som ska beläggas, till exempel ett borr, är i kontakt med atomångan kondenserar atomerna på ytan och skiktet växer atom för atom.

Inne i skiktet ordnar sig atomerna i särskilda mönster, kristallstrukturer. Grupper av atomer växer till kristaller som utgör själva skiktet. Storleken 
på kristallerna påverkar egenskaper som bland annat hårdhet, slitstyrka och seghet. Mellan kristallerna, eller kornen, bildas så kallade korngränser där atomerna sitter slumpmässigt placerade. Eftersom atomerna inte sitter ordnade i något särskilt mönster så säger man att de är amorfa - saknar ordning. Hur stor andel amorft material man får kan bestämmas genom tillverkningsprocessen.

Det är också möjligt att tillverka skikt som är helt amorfa, det vill säga att atomerna sitter slumpmässigt placerade genom hela skiktet. Dock är det en stor utmaning att tillverka amorfa skikt som är så pass hårda och slitstarka att de är intressanta för verktygsindustrin. Mitt mål har varit att skapa så mycket oordning som möjligt i skikten, utan att de förlorar de egenskaper som krävs för att vara användbara för till exempel verktyg.

Tillverkningen av skikten har skett både i labbskala på universitetet och i industriella system hos en företagspartner, vilket ställer olika krav på materialval och tillverkningsprocess. I de skikt som tillverkats blandas övergångsmetaller, till exempel titan eller hafnium med icke-metaller som kisel och bor för att tillsammans med kväve bilda nitrider som tillhör en klass av material som kallas keramer. Keramer har många attraktiva egenskaper, bland annat är de hårda och har hög smältpunkt.

Tillverkningsprocessen gör det möjligt att styra hur atomerna rör sig när de landat på objektets yta. Om de har en tendens att bilda kristaller så kommer de att försöka hitta rätt plats för att göra det. Men hur mycket och hur snabbt atomerna kan röra sig på ytan beror på vilken energi de har, som i sin tur bland annat beror på vilket temperatur det är vid ytan. Om temperaturen är låg rör sig atomerna långsamt. Om beläggningshastigheten samtidigt är hög så hinner de inte flytta på sig innan nästa lager träffar ytan och täcker dem. Det går också att göra det svårare för atomerna att hitta sina favoritgrannar genom att blanda många olika grundämnen. Genom att välja grundämnen som föredrar olika grannar och olika kristallstrukturer kan man se till att de hindrar varandras framfart på ytan.

I det här arbetet har det varit viktigt att atomerna har lagom mycket energi och rörlighet när de träffar ytan. Om de fastnar direkt så finns det risk att materialet får stora håligheter och blir poröst vilket gör att det inte är lika hårt som det skulle kunna vara. Samtidigt får inte rörligheten vara för bra, för då bildas kristaller.

I den här avhandlingen visar jag att vi kan tillverka helt amorfa skikt baserade på material som tidigare i princip alltid tillverkats med en stor andel kristaller. Mina skikt är fortfarande väldigt hårda, och har visat sig mer tåliga mot sprickbildning än vissa kristallina material. Eftersom mina skikt är väldigt täta och saknar korn, och därmed korngränser, kan de vara intressanta i helt nya applikationer där korngränserna är de svagaste länkarna i materialet. 


\section{Preface}

This thesis is the result of my doctoral studies in the Thin Film Physics Division at the Department of Physics, Chemistry, and Biology (IFM) at Linköping University between 2009 and 2014.

Parts of the results are published in scientific journals, and the introductory chapters are based on, and expanded from, my licentiate thesis, Growth and Characterization of Amorphous TiAlSiN and HfAlSiN Thin Films, Linköping Studies in Science and Technology Licentiate Thesis No. 1542 (2012).

The major part of the work has been carried out in the Thin Film Physics Division at Linköping University, but I have also been working at Frederick Seitz Materials Research Laboratory and Materials Science Department at University of Illinois at Urbana-Champaign.

The work has been financially supported by The Swedish Research Council (VR) and the Swedish Foundation for Strategic Research (SSF) project Designed Multicomponent Coatings - Multifilms. 



\section{Acknowledgments}

I would like to start by thanking my supervisor Prof. Lars Hultman for giving me the opportunity to join the Thin Film Physics Division. It has been a great experience to work with you and I want to thank you for your endless support and enthusiasm, for giving me a great deal of freedom, and for providing me the opportunity to travel all over the world, not only to study, but also to share with others what I have learned. Finally, I would like to thank you for proofreading the thesis. All remaining errors are of course mine.

During my time as a PhD student I have spent quite some time at UIUC. I am very grateful to Prof. Ivan Petrov for inviting me, and for taking such good care of me during my stays. Working with you has been very rewarding, and together with Prof. Joe Greene you have made a significant contribution to my work. Thank you, both of you!

I would also like to acknowledge a few others at UIUC that made my stays so memorable. First of all my great friend Dr. Brandon Howe from whom I've learned so much about life in general and about science in particular. I hope our paths in life will cross again, and I very much look forward to that day! M.Sc. Antonio Mei and M.Sc. Allen Hall are acknowledged for always making me feel welcome in the lab. Every time I've come back, it has felt as if I never left. Thank you!

I have also spent some time at Seco Tools in Fagersta, and I would like to thank everyone who has helped me during my stays, and made my experiments successful. A special thanks to Dr. Jon Andersson. It has been a pleasure to work with you!

Writing scientific research papers is a team effort and none of the papers in this thesis would have been published without my skilled colleagues and coauthors. A big thank you goes to all of you for your hard work and valuable input. In addition, I would like to thank those who should always be acknowledged and without whom, nothing would work. So thank you Thomas Lingefelt for fixing everything I have ever destroyed, and to Kirstin Kahl, Inger Eriksson, and Therese Dannetun for helping me out with the administrative stuff.

Inevitably, after a few years some of your colleagues turn into close friends. M.Sc. Hanna Kindlund not only has the best of names, but is also a great travel companion. Some of the memories from our travels to Japan and to the US I will surely carry with me for the rest of my life. I can hardly believe that it's true, but we made it!

I would also like to mention Dr. Emma Björk and Dr. Carina Höglund. You have not only guided me in science-related issues, but also supported me when life outside the university has been tough, and for that I am truly grateful!

Other colleagues have contributed in big and small and I am thankful to all of you; Dr. Olle Hellman (for providing me with a nice looking, and wellfunctioning LTEX-template), Dr. Olof Tengstrand (for being the best office mate 
anyone, who gets disturbed by anything, could ever dream of), M.Sc. Christopher Tholander (for a nice travel to Los Angeles), and M.Sc. Annop Ektarawong (for ditto to Boston), Dr. Fredrik Eriksson (for all the help in the lab), Dr. Per Eklund (for being a really good friend and for never saying no to raggmunk), Lic. Sit Kerdsongpanya (for taking our thai/swedish-cooking sessions so seriously), and finally Dr. Anders Eriksson (for patiently helping me out with all OriginLab-related questions when all I did was to yell in sheer frustration).

I would like to thank my friends, some of you who have been around since we were kids, and some that I have met more recently. We have had much fun over the years and I hope we will keep that up in the future. You have all contributed to this work in one way or another. So, a big thank you goes to Jonas Birgersson, Stina Källbäck, Ylva Jung, Ulrika Pettersson, Sofia Fahlvik Svensson, Karl Granström, Jonas Callmer, Martin Skoglund, and Oskar Leufvén.

I am very lucky to have a family that supports me in everything I do. Mamma, pappa och Nils, you are more important to me than anything, and I love you!

Finally, Björn. Just because of you, it was worth it!

Hanna Fager

Linköping, April 2014 


\section{CONTENTS}

Acronyms xv

1 Introduction 1

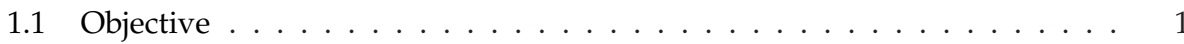

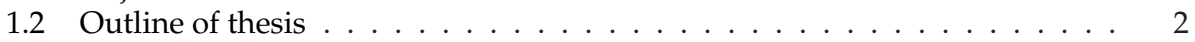

2 Amorphous solids and films 3

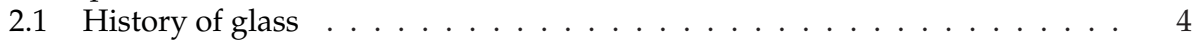

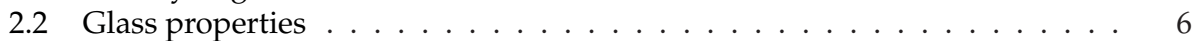

2.3 Bulk metallic glasses . . . . . . . . . . . . . . . . . . 7

2.4 Thin film metallic glasses . . . . . . . . . . . . . . . . . . . . 8

2.5 Amorphous thin films . . . . . . . . . . . . . . . . . 9

3 Methods for thin film synthesis 11

3.1 DC magnetron sputtering . . . . . . . . . . . . . . . . . . 11

3.2 High power impulse magnetron sputtering - HIPIMS . . . . . . . . . . . . 17

3.3 Cathodic arc evaporation . . . . . . . . . . . . . . . . . . . . 19

3.4 Plasma characterization . . . . . . . . . . . . . . . . . . . 21

4 Bonding and crystal structures 27

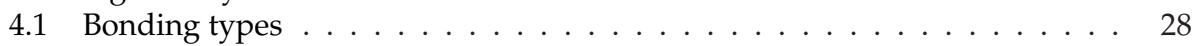

4.2 Bonding and properties . . . . . . . . . . . . . . . . . . . . . 29

4.3 Binary parent compounds . . . . . . . . . . . . . . 30

5 Phase stability and metastable phases 35

5.1 Nucleation and growth . . . . . . . . . . . . . . . . . . 35

5.2 Thin film growth . . . . . . . . . . . . . . . . . . 38

6 Characterization techniques 43

6.1 X-ray diffraction . . . . . . . . . . . . . . . . . . . 43

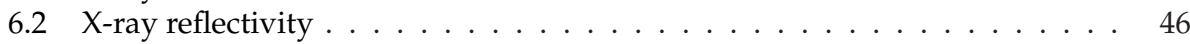

6.3 Electron microscopy . . . . . . . . . . . . . . . . . . . . . . 48

6.4 Chemical and elemental analysis . . . . . . . . . . . . . . . . 55

6.5 Mechanical characterization . . . . . . . . . . . . . . . . . 61

7 Summary of results and contributions to the field 67

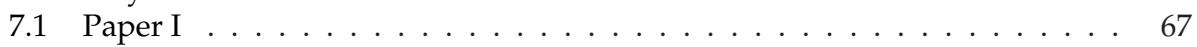

7.2 Paper II . . . . . . . . . . . . . . . . . . . . . . . . . 68

7.3 Paper III . . . . . . . . . . . . . . . . . . . . . . . . . . . . 69

7.4 Paper IV . . . . . . . . . . . . . . . . . . . . . . . . . . . 69

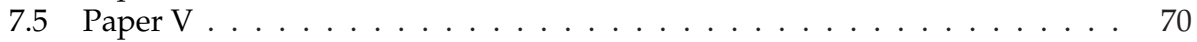

Bibliography 75

List of figures 89 
List of papers and my contributions 92

\section{Paper I 93}

Growth of hard amorphous Ti-Al-Si-N thin films by cathodic arc evaporation

\section{Paper II 113}

Reactive DC magnetron sputtering of amorphous $\left(\mathrm{Ti}_{0.25} B_{0.75}\right)_{1-x} S i_{x} N_{y}$ thin films from $\mathrm{TiB}_{2}$ and Si targets

\section{Paper III 135}

Thermal stability and mechanical properties of amorphous arc evaporated Ti-B-Si-N and $\mathrm{Ti}-\mathrm{B}-\mathrm{Si}-\mathrm{Al}-\mathrm{N}$ coatings grown by cathodic arc evaporation from $\mathrm{Ti}_{2}, \mathrm{Ti}_{33} A \mathrm{Al}_{67}$, and $\mathrm{Ti}_{85} \mathrm{Si}_{15}$ cathodes

\section{Paper IV 161}

Growth and properties of amorphous Ti-B-Si-N thin films deposited by hybrid HIPIMS/DC-magnetron co-sputtering from $\mathrm{TiB}_{2}$ and Si targets

\section{Paper V 181}

Hf-Al-Si-N multilayers deposited by reactive magnetron sputtering from a single $H f_{0.6} \mathrm{Al}_{0.2} \mathrm{Si}_{0.2}$ target using high-flux, low-energy modulated substrate bias: film growth and properties 


\section{ACRONYMS}

bcc body centered cubic

BF bright field

BMG bulk metallic glasses

CVD chemical vapor deposition

DCMS dc magnetron sputtering

DF dark field

EDX energy dispersive $x$-ray spectroscopy

ERDA elastic recoil detection analysis

fcc face centered cubic

FWHM full width at half maximum

GFA glass-forming ability

hcp hexagonal close packed

HIPIMS high power impulse magnetron sputtering

HR high resolution

PVD physical vapor deposition

RBS Rutherford backscattering spectrometry

SAED selected area electron diffraction

SEM scanning electron microscopy

STEM scanning transmission electron microscopy

SYA sputter yield amplification

SZD structure zone diagram

TEM transmission electron microscopy

TFMG thin film metallic glasses

UHV ultra high vacuum

XPS X-ray photoelectron spectroscopy

XRD $\quad$-ray diffraction

XRR x-ray reflectivity 



\section{INTRODUCTION}

Thin films, or coatings, are technologically extremely important. Thin film materials is a multi-billion dollar industry that keeps growing. One reason for that is that thin films are everywhere around us. We get in contact with them every day; most of the time without even realizing their presence.

They are used in the microelectronics and on the scratch-resistant glass screen of our smart phones, on non-stick frying pans, as protective coatings in milk cartons, and as anti-reflective coatings on glasses, just to name a few examples that are commonly encountered. Even though most of the examples are inventions of the twentieth century, the idea of coating an object with a thin film to change its properties is not new. Mankind has used coatings for thousands of years, for example glaze on stoneware to make it water-tight or for decorative purposes.

Many applications of thin films passes unnoticed by for people like you and I, since they are mainly used in industrial applications never noticed by the end consumer. An example of such applications are tools for cutting, turning, drilling, and forming in the automotive and aerospace industry. In this industry section, thin films have made it possible to increase productivity by extending tool life as the coatings keep getting better and better, and more advanced to meet the needs in specific applications.

The first commercially available coated cutting tool was developed and produced by Sandvik Coromant in the late 1960s. The tool consisted of a cemented carbide insert that was coated with fine-grained TiC. ${ }^{1}$ The insert itself already provided good toughness, but lacked in wear resistance. With the coating, the wear resistance was increased radically. After the first coated cutting tool, a number of improved coatings have found their way into the market during the last decades. The area has expanded greatly since the 1960s, and the development is still ongoing.

\section{Objective}

Many transition metal nitride systems have been widely studied for decades, with extensive focus towards tool industry applications. Nevertheless, areas remain that are not fully understood or even explored yet. One of these areas concerns the amorphous transition metal nitrides.

The main objective of this work is to study amorphous transition metal nitride-based thin films. The goal has been to investigate the conditions under which they can be synthesized, and to determine some of their properties, in hope of finding properties that cannot be provided by their crystalline counterparts. 


\section{Outline of thesis}

Following this brief introduction, Chapter 2 aims to put the work into broader perspective with a description of amorphous solids in general, a summary of the history of silicate glasses, characteristic properties of glasses, and a presentation of some technologically important amorphous materials.

In Chapter 3, I present the deposition techniques that I have used, including considerations specific for this work. Chapter 4 treats different types of bonding mechanisms, and the thermodynamically stable parent compounds of the elements of relevance for this work is presented. Chapter 5 continues with a description of phase transformations, both liquid-to-solid and vapor-to-solid ones, including nucleation and growth of thin films, and effects on microstructure evolution.

The thin films are characterized using several different analysis techniques, each described in Chapter 6.

Finally, I summarize the results from the papers in Chapter 7 together with my contributions to the field, followed by the appended papers. 


\section{AMORPHOUS SOLIDS AND FILMS}

Very generally speaking, solid materials can be divided into crystalline or amorphous ones. A crystalline material has translational symmetry and is characterized by its unit cell, which when extended in three dimensions gives the structure of the material. Unlike crystalline solids, the term amorphous solid has no defined structural meaning, but Kittel describes it as not crystalline on any significant scale. ${ }^{2}$ In condensed matter physics, an amorphous solid refers to a material that lacks the long-range order that is characteristic for crystals. The word amorphous comes from the Greek, and is a combination of the word $a$, which means without, and the word morphe, which translates into shape or form.

Even though amorphous materials lack long-range order, they have a structure that exhibits short-range order in regions where the placement of the atoms can be predicted. ${ }^{3}$ This means that the atom positions are not totally uncorrelated as in an ideal gas, where each atom may be located anywhere, but there is a local correlation where each atom has its nearest-neighbor atoms at almost the same distance to it. Also, the bond angles are similar to those in the corresponding crystalline phase. ${ }^{4}$

For a long time, it was thought that only a limited number of materials could be prepared in the form of amorphous solids, and amorphous metals were not believed to exist. But in the mid-1950s pure metal Ga and Bi films were produced, ${ }^{3}$ and soon it was realized that there were no specific glass-forming solids. Rather, it is a question of how the solids are produced, and Turnbull expressed it as: ${ }^{4}$

Nearly all materials can, if cooled fast enough and far enough, be prepared as amorphous solids.

However, until the end of the 20th century, it was mainly the crystalline materials which got the attention of the scientific community. It was believed that, due to the disordered nature of the amorphous materials, they would not find technological applications.

The words amorphous and glass, or glassy, are often used synonymously in literature to describe disordered materials. In a more precise form, the term glass or glassy is used for materials which can be quenched from supercooled liquids and exhibit a glass transition, while the term amorphous usually refers to non-crystalline materials which are prepared as thin films by deposition on substrates which are kept sufficiently cool to prevent crystallisation. $^{5}$

The oldest and most famous amorphous solid that has been manufactured by man is glass. Glass is, however, not a single material, but an array of materials with similar properties. To put the work in this thesis in some historical perspective, I will start with a brief summary of the history of glass. 


\section{History of glass}

The word glass stems from the Roman empire and the late-Latin word glesum, which probably originates from a Germanic word for a transparent, lustrous substance. ${ }^{6}$

The art of glassmaking can be traced back to 3500 BCE in Syria, Mesopotamia or Ancient Egypt, but naturally occurring glass, obsidian, which is a volcanic glass that solidifies from lava, has been used by societies since the Stone Age. ${ }^{7}$ Obsidian is very hard and brittle, and therefore fractures with very sharp edges, making it useful for knives and arrowheads, etc. ${ }^{8}$

The first objects that were produced out of glass were beads. It is believed that the glass for the beads was produced unintentionally in by-products of metal working or during the production of faience. ${ }^{7}$

During the Late Bronze Age, i.e. 1550-1200 BCE, glass making technology developed in Egypt, and findings from that time include both colored glass ingots, vessels, and beads. The first vessels were cone-shaped, formed by winding a rope of molten glass around a clay template. The glass was fused by repeated heating sequences, and after solidification, the template was removed. Glass was a luxury material, and the vessels were used for storage of expensive goods like oils, perfume, and ointments. The vessels were trade goods, and Egyptian vessels have been found in archeological finding in Turkey, Italy and Spain. ${ }^{6}$

In the 9th century BCE techniques for producing colorless, socalled aqua-glass, were developed. ${ }^{6}$ The aqua-glass commenced the use of glass for architectural purposes, and glass windows started to appear in the most important buildings in Rome, Herculaneum, and Pompeii. Window glasses as large as $70 \times 70 \mathrm{~cm}^{2}$ have been found in archeological sites in Pompeii.

Glass blowing was discovered, or invented, about 2000 years ago in Syria. ${ }^{7}$ The glass blowing completely revolutionized the glass industry. Glass vessels now became inexpensive, and a large number of glass works spread through the Roman empire. The most skilled glass makers lived in Belgium, Cologne, and Normandy.

The art of glass making spread, and glass was extensively used during the Middle Ages. In archeological excavations in England, glass has been found in both cemetery and settlement sites. ${ }^{6}$ Sometime around 1000 CE a group of Normandy glass makers moved to Italy, where they continued their development and production of glass, which over the nextcoming 400 years received a great reputation around the world. The production of glass in Italy was concentrated to the island Murano, outside Venice, which came to be the center for luxury Italian glassmaking. ${ }^{7}$

Glass became more readily available, and found widespread use as stained glass windows in churches and cathedrals. In 
the 11th century a new technique developed in Germany, where sheet glass was formed by first blowing spheres. The spheres were shaped into cylinders and cut open while they still were warm, and flattened. This technique, and the similar crown glass technique, were the dominating ones until the 19th century.

In 1843, Bessemer patented an early type of float glass process. This technique was, however, not very successful since it was so expensive, ${ }^{6}$ so the sheet glass technique continued to be the most commonly used.

In the early 1900s, another process took over and spread globally, namely the Fourcault process in which a thin sheet of glass is drawn vertically from the melt and held at the edges by rollers that simultaneously cools and shapes the glass. To make the glass clear, extensive grinding and polishing was needed.

The float glass, however, made a grandiose comeback in the mid 20th century, when Pilkington and Bickerstaff invented and launched their own float glass technique in $1959,{ }^{9}$ which had superior quality compared to the glass produced by the Fourcault process. In the Pilkington float glass technique, molten glass is allowed to float on top of a bath of molten tin or other metal, which gives the glass sheet a uniform thickness and very flat surface. Once the glass is floating, the temperature of the metal bath is gradually lowered until the glass sheet can be lifted away. ${ }^{9}$

In the later part of the 20th century, new types of glasses were developed, including laminated glass, reinforced glass and glass bricks for use as building materials, all based on the conventional silicate glass. But during the last 50 years or so, interests for other type of glasses and amorphous solids have evolved in the scientific community. These include the metallic glasses, but also oxide, flouride, phosphate, borate, and chalcogenide glasses. Especially the chalcogenide glasses have become important in modern technology for use as fiber-optic wave guides in communication networks. Some chalcogenide glasses also exhibit thermally driven amorphous-crystalline phase changes, which make them useful for encoding binary information. Applied as thin films, they form the basis of rewritable optical discs. ${ }^{10}$

The advances in thin film processing techniques, has made it possible to synthesize an almost infinite number of new amorphous materials. The bulk metallic glasses and their thin film counterparts have been extremely important for the advances in other types of amorphous thin film development. The metallic glasses will be described in greater detail below, but to fully understand their development, we first need to understand some basic properties of glass. 


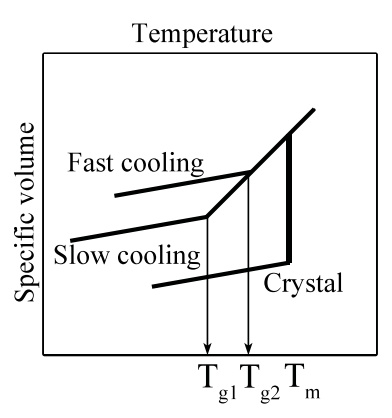

FIGURE 2.1: Change in specific volume as a glass is cooled through $T_{g}$. After Barsoum. ${ }^{12}$

\section{Glass properties}

The two most important properties of glass are the glass transition temperature, $T_{g}$, and the viscosity, $\eta$. They are not only of fundamental importance for glass manufacturers, but also holds scientific interest. In Science, P.W. Andersson refers to the nature of glass and the glass transition as: ${ }^{11}$

The deepest and and most interesting unsolved problem in solid state theory...

\section{THE GLASS TRANSITION}

The glass transition is a reversible transition from a hard and relatively brittle state into a molten or rubber-like state of the material. Most materials that are cooled from the liquid state will abruptly solidify in a crystalline manner at a well-defined temperature, their melting point, $T_{m}$. However, some materials form amorphous solids instead, and they typically do not exhibit a very specified melting temperature.

The transformation of a liquid into a crystalline solid most often occurs via the formation of a nuclei and its growth, a process that requires some time. If the thermal energy is removed by a rate that is higher than the time needed for crystallization, a glass will form. ${ }^{12}$ From this follows that every liquid, if cooled fast enough, should be able to form a glass.

For amorphous solids, the change in specific volume and configuration entropy with respect to the temperature is more gradual than for crystalline ones. The properties follow the liquidus line to a temperature, where the slope of the specific volume or entropy versus temperature curve is drastically decreased, see Figure 2.1. The point at which the slope breaks is known as the glass transition temperature, $T_{g}$, and is the temperature at which a glass-forming liquid transforms into a glass. In the temperature range between $T_{m}$ and $T_{g}$, the material is said to be a supercooled liquid. However, it should be noted that not all supercooled liquids form amorphous solids! A supercooled liquid can in some cases crystallize almost instantly if a crystal is added as a core for nucleation.

The atomic structure of a glass is similar to the structure in a supercooled liquid, but glass behave as a solid below its $T_{g}$. A supercooled liquid, on the other hand, behaves as a liquid, even though it is below its freezing temperature.

$T_{g}$ is not a discrete material dependent constant temperature. It has been experimentally shown that $T_{g}$ is a function of the cooling rate, with $T_{g}$ shifting to lower temperatures with decreasing cooling rates. ${ }^{12}$ If the atoms have more time to rearrange, a denser amorphous solid will result. This implies that the glass transition temperature is not a thermodynamic quantity, but rather a kinetic one. 


\section{VISCOSITY}

Viscosity is another important property of glass that can be influenced by additions to the glass melt. The viscosity of the glass melt is of course temperature dependent.

The viscosity $\eta$ is a measure of the ratio of the applied shear stress to the flow rate $\nu$ of a liquid. If the liquid would be confined between two parallel plates with area $A$, separated by a distance $d$, and subjected to a shear force $F$, the viscosity is given by: ${ }^{12}$

$$
\eta=\frac{F d}{A \nu}=\frac{\tau_{s}}{\dot{\varepsilon}},
$$

where $\varepsilon$ is the strain rate $\left(\mathrm{s}^{-1}\right)$ and $\tau_{s}$ is the applied shear stress (Pa). The viscosity of a crystalline solid changes abruptly over an extremely narrow temperature range during crystallization. For silicate glasses, following fitting of a large number of experimental data, the most accurate dependence of viscosity on temperature is given by the Vogel-Fulcher-Tammann equation: ${ }^{13}$

$$
\ln \eta=A+\frac{B}{T-T_{0}},
$$

where $A, B$, and $T_{0}$ are temperature-independent adjustable parameters and $T$ is the temperature.

For silicate glasses, the viscosity can be lowered by addition of basic oxides (such as $\mathrm{Na}_{2} \mathrm{O}$ or $\mathrm{CaO}$ ) that will break the silicate network. As a result, the number of $\mathrm{Si}-\mathrm{O}$ bonds that needs to be broken during viscous flow decreases and a shear process becomes easier. The viscosity of a glass is a measure of the diffusivity, i.e. the atom mobility in the glass, which is one of the crucial parameters for glass formation. At $T_{g}$, the viscosity of a glass is of the order of $10^{15} \mathrm{~Pa} \cdot \mathrm{s}$, which means that the atomic mobility is quite low. ${ }^{12}$

\section{Bulk metallic glasses}

The first metallic glass was discovered in 1960 by Klement et al. by rapid quenching $\left(10^{5}-10^{6} \mathrm{~K} / \mathrm{s}\right)$ of a $\mathrm{Au}_{80} \mathrm{Si}_{20}$-liquid. ${ }^{14} \mathrm{~A}$ few years later, Chen et al. managed to produce amorphous spheres of the ternary Pd-Si-N ( $\mathrm{N}=\mathrm{Ag}$, $\mathrm{Cu}$ or $\mathrm{Au}$ ) systems. ${ }^{15}$ Continuous work on the Pd-based system led to the discovery of materials where the supercooled regime could be extended to $40 \mathrm{~K}$, which made it possible to study the crystallization process in metallic glasses.

The work of Chen, Turnbull and co-workers showed similarities between metallic glasses and other non-metallic glasses such as silicates, ceramic glasses, and also polymers. The glass transition was found to occur at a rather narrow temperature range for metallic glasses (or bulk metallic glasses (BMG), to distinguish them from their thin film counterparts), in contrast to the case in 
e.g. silicate glasses, and $T_{g}$ was found to only vary slightly if the cooling rate was changed. ${ }^{16}$

Turnbull set up a criterion for the glass-forming ability (GFA) and still today it is considered to be the best rule-of-thumb for predicting GFA of any liquid. ${ }^{17}$ The criterion relates the glassforming ability to the ratio of the glass transition temperature and the melting temperate, saying that $T_{g} / T_{m} \leq 2 / 3$ gives a liquid which can only crystallize within a very narrow temperature range, and is thereby easier to prepare as an amorphous solid.

The work on bulk metallic glasses was focused on increasing the critical size and to decrease the needed cooling rate. In 1974 a thickness of $1 \mathrm{~mm}$ was reached, and the cooling rate was only $10^{3} \mathrm{~K} / \mathrm{s} .{ }^{18}$ Ten years later, the critical size had been increased to $10 \mathrm{~mm}$, while the cooling rate had been further decreased into the $10 \mathrm{~K} / \mathrm{s}$ region. ${ }^{19,20}$

In the late 1980s the group of Inoue studied bulk metallic glasses based on rare-earth materials with additions of $\mathrm{Al}$ and found exceptional glass-forming ability in La-Al-Ni and La-Al-Cu alloys. ${ }^{21}$ Later they expanded their work to include Zr-based bulk metallic glasses and found that they had high glass-forming ability and high thermal stability. ${ }^{16}$ By this time, the critical thickness had been increased to $15 \mathrm{~mm}$. In 1993 a group of researchers from Caltech developed a pentanary Zr-Ti-Cu-Ni-Be alloy which is most known under the commercial name Vitreloy $1 .{ }^{22}$ Its thickness was several centimeters and Vitreloy 1 is the most studied BMG today. The group of Inoue took up the work with Pd-based systems and in 1997 they developed a Pd-Cu-Ni-P alloy with critical casting size of $72 \mathrm{~mm}$, and the highest glass-forming ability known to date. ${ }^{23}$

Bulk metallic glasses are almost exclusively multicomponent alloys. Some specific elements act to decrease the liquidus temperature and thus improve glass formation. In addition, elements of different size and with different valence electron configuration hinder crystalline formation in the metallic glasses. ${ }^{24}$ Bulk metallic glasses are manufactured and sold commercially today. The applications include sporting goods, cases for electronic products, cell phone cases, and medical devices. ${ }^{25}$

\section{Thin film metallic glasses}

Simultaneous with the work on bulk metallic glasses, other groups started to investigate thin film metallic glasses (TFMG). This, of course, made sense since the metallic glasses from the beginning only were available as thin ribbons, and much of the struggle during the first years of research on BMGs was to actually produce bulk samples.

In the 1980s and 90s most of the work in the field of thin film metallic glasses concerned sputtering of immiscible binary sys- 
tems, often $\mathrm{Cu}$ - or Fe-based. Thin film metallic glasses were also produced by solid-state amorphization of multilayer films. ${ }^{26,27}$

A great benefit with thin films is that if prepared by vaporto-solid deposition, they are expected to be farther from thermodynamic equilibrium than the corresponding glasses that are prepared by liquid-to-solid melting and casting processes. This means that the glass-forming ability of vapor-to-solid deposited materials is larger, and that amorphization can be reached over a wider compositional range.

Quite ironically, today it seems like there are more possible applications for thin film metallic glasses than for their bulk counterparts. One reason for this might be the brittle nature of bulk metallic glasses, something that does not necessarily have to be a problem for thin film applications, since ductility can be achieved by the right choice of substrate material.

Among the proposed applications, usage in MEMS devices is one, due to the good corrosion resistance and wear properties of thin film metallic glasses. ${ }^{28,29}$ Due to their glassy structure, TFMGs have a fascinating ability to recover from e.g. scratches and indents, upon annealing below $T_{g}$. This has been demonstrated following nanoindentation, where atomic force microscopy (AFM) images reveal a decrease in the size of the residual indent after annealing. The film surface also became smoother, and the pile-up decreased. ${ }^{27}$

Thin film metallic glasses, especially $\mathrm{Cu}$ - and Ag-containing ones, have been suggested as coatings on door handles and other hand-contact regions, e.g. in hospitals, since they have lower surface roughness and are more hydrophobic than stainless steel. They have also shown to have antimicrobial properties. ${ }^{30}$

\section{Amorphous thin films}

Amorphous thin films does not exclusively concern thin film metallic glasses. Various amorphous oxide, carbide, and nitride thin films have also found widespread interest in the scientific community, and have been investigated for a number of applications.

Thin film amorphous oxides have been heavily investigated for the use as thin film transistors (TFT). ${ }^{31}$ TFTs are used in several type of displays and imaging devices, including liquid crystal displays (LCD), in which they are integrated to each sub-pixel in order to monitor the amount of light that reaches the eyes of the viewer. Here, amorphous transparent conductors are attractive because the low processing temperature makes it possible to grow on plastic substrates. In 2010 an estimated $30-40 \%$ of all flat panel displays contained amorphous transparent conducting oxides. $^{32}$

Among the carbide thin films, $\mathrm{SiC}$ is the most studied amorphous material, and can be used in a great variety of applications. Amorphous $\mathrm{SiC}$ devices are used in optoelectronics, e.g. 
in solar cells and in LEDs, as well as in coatings for extreme UV optics. $^{33,34}$

Much work on thin film carbides have been going hand-inhand with thin film nitrides. Due to their extensive use as wear protective coatings on cutting tools, major interest has been towards nanocrystalline films and nanocomposites. Recently, amorphous transition metal carbides have been studied in more detail, including both the binary $\mathrm{Cr}-\mathrm{C}$ system ${ }^{35,36}$ and the ternary $\mathrm{Zr}-\mathrm{Si}$ C system. ${ }^{37,38}$

For the nitrides, amorphous thin films were heavily investigated for the use as diffusion barriers mainly during the 1990s. Examples are Ti-Si-N, Ta-Si-N, Mo-Si-N and W-Si-N. ${ }^{39}$ 


\section{METHODS FOR THIN FILM SYNTHESIS}

Thin films can be grown in numerous ways, where two of the main deposition techniques are chemical vapor deposition (CVD) and physical vapor deposition (PVD). Both of these techniques require vacuum to avoid reactions with the atmosphere, but also for control of composition and microstructure of the films.

In CVD, the film is grown by allowing deposition species, supplied in the gas phase, to react and form bonds with atoms at the substrate surface at conditions near thermal equilibrium. This process generally needs to take place at high temperatures $\left(\sim 1000{ }^{\circ} \mathrm{C}\right)$, which limits the use of heat-sensitive substrates. In CVD, all areas in contact with the gas will be coated, which make this technique very well suited for coating of complex shapes. Today, CVD is the most commonly used technique in hard coatings industry, even though the fraction of coatings deposited by PVD is steadily increasing.

In general terms, PVD can be described as a process where a coating material is vaporized from a solid or liquid source material, travels through a plasma, and condensates on the substrate. PVD can only deposit films line-of-sight, but generally operates at much lower temperatures than CVD, which in combination with high deposition rates enables the formation of metastable structures, as the atoms may not have time and energy to rearrange in the most energetically favorable positions. This is crucial, e.g., for the formation of amorphous thin films.

Among the available PVD techniques, the two most important methods are evaporation and sputtering. The difference between these two types of PVD processes is that in sputtering, atoms are dislodged from the target surface by impact of gaseous ions, while in evaporation, the atoms are removed by thermal means. ${ }^{3}$

In this thesis, two different sputtering techniques; dc magnetron sputtering, and high power impulse magnetron sputtering (HIPIMS), and one evaporation technique; cathodic arc evaporation, have been employed, all described in detail below.

\section{DC magnetron sputtering}

\section{BASICS OF SPUTTERING}

Figure 3.1 shows a schematic of the sputtering process. In its simplest configuration a sputtering system consists of a vacuum chamber, a so-called target connected to a voltage supply, a substrate, a vacuum pump, and an inlet for the sputtering gas.

By applying a negative voltage to the target, in this case a dc voltage, an electric field will form. A sputtering gas (in this case $\mathrm{Ar}$ ) is let into the chamber. A small amount of ions and electrons 


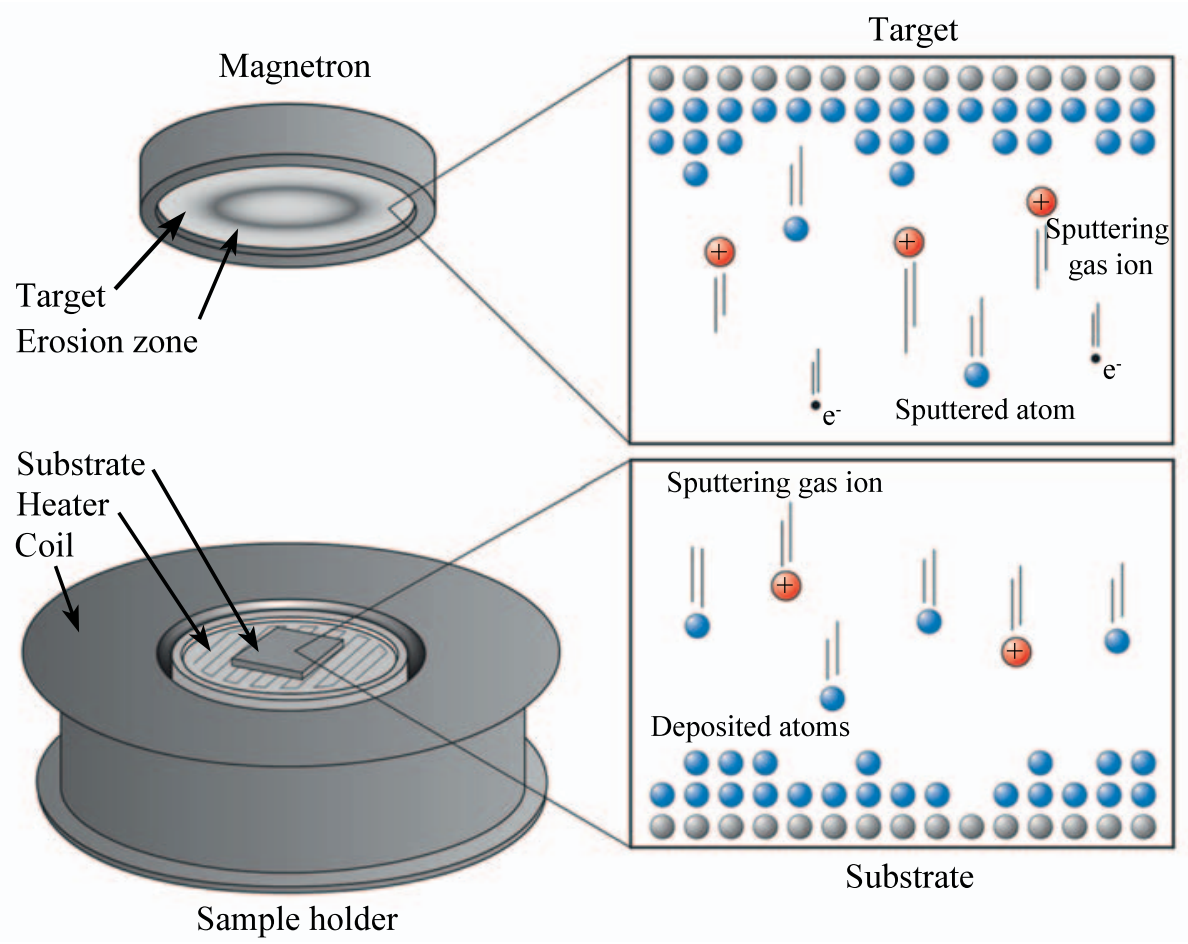

FIGURE 3.1: Schematic illustration of a magnetron sputtering process on the target and substrate side. Image courtesy of Fredrik Eriksson. will always be present in the chamber, and these will be affected by the electric field. The electrons are repelled by the negatively charged target, and if they gain enough energy from the electric field, they will cause ionization of the sputtering gas.

The positively charged Ar ions will be attracted towards the target, where they collide with the target surface causing numerous collisions to take place. Mainly neutral target atoms are removed by momentum transfer, but other particles such as secondary electrons, reflected ions and neutrals, and photons, are also scattered from the surface. The neutral target atoms travel

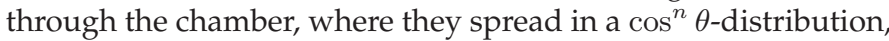
meaning that most of the target atoms will be sputtered in the forward direction, where the substrate holder should be placed so that most atoms will condense on the substrate and form the thin film. Some of the target atoms, however, will be ionized and they will travel through the plasma, hitting both the grounded chamber walls and the substrate holder.

The secondary electrons are accelerated away from the target surface. These electrons help sustain the glow discharge by ionization of the sputtering gas atoms, which in turn bombard the target and release more secondary electrons in an avalanche process. When the number of generated electrons is high enough 
to produce ions that in turn regenerate the same number of electrons, the discharge is self-sustaining and the gas begins to glow. The light emitted is characteristic of both the target material and the incident ions.

\section{REACTIVE SPUTTERING}

Reactive sputtering refers to the process where a reactive gas is introduced in the chamber. Adding a reactive gas makes it possible to form complex compounds between the sputtered target atoms and the reactive gas molecules. This was done in Paper $\mathrm{V}$, where Hf-Al-Si-N thin films were deposited by reactive sputtering from a $\mathrm{Hf}_{0.6} \mathrm{Al}_{0.2} \mathrm{Si}_{0.2}$ target in a $\mathrm{N}_{2}$-Ar gas mixture, and in Paper II and Paper IV where Ti-B-Si-N films were grown in a $\mathrm{N}_{2}$-Ar gas mixture from $\mathrm{TiB}_{2}$ and $\mathrm{Si}$ targets. Nitrogen is a common reactive gas, but also oxygen is used, as well as $\mathrm{C}_{2} \mathrm{H}_{2}$ and $\mathrm{CH}_{4}$ for synthesizing carbides. The sputtering gas does not necessarily have to be Ar. Other noble gases as $\mathrm{Ne}, \mathrm{Kr}$, and $\mathrm{Xe}$ can also be used, even though $\mathrm{Ar}$ is the most common one. It is also possible to sputter in the pure reactive gas, without any addition of a sputtering gas.

\section{MAGNETRON SETUP}

Glow discharges are relatively inefficient ion sources. There is a high risk that the electrons will hit the grounded chamber walls, leaving the system, instead of colliding with the sputter gas atoms and ionize them. Only a few percent of the gas atoms in a glow discharge are actually ionized. By applying a magnetic field close to the target, using a so-called magnetron, the time the electrons spend in the vicinity of the target can be multiplied and the plasma is much easier maintained. This was first discovered by Penning in $1936,{ }^{40}$ and further developed by Kay and others. ${ }^{41,42}$

a)

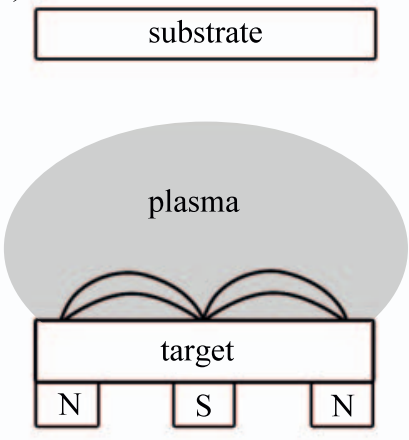

b)

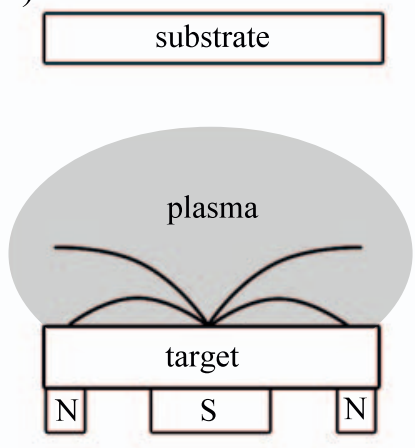

FIGURE 3.2: Schematic of three different planar magnetron configurations with the magnetic field lines indicated. a) balanced magnetron, $b$ ) unbalanced type I, and c) unbalanced type II. c)

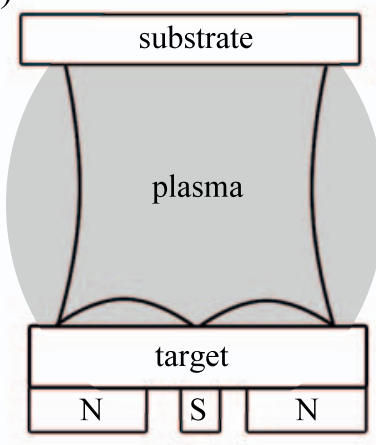


FIGURE 3.3: Schematic image illustrating the effect on the plasma of superimposing an external magnetic field $B_{\text {ext }}$ which a) opposes, and b) reinforces the field of the outer permanent magnets in the magnetron. After Petrov et al. ${ }^{44}$
By 1975, the magnetron sputtering technique was commercially used. ${ }^{43}$

Several different geometries can be used for the magnetron, including the planar type that was used in this study. The magnets are placed so that there is at least one closed path or region in front of the target surface, where the magnetic field is normal to the electric field.

There are three types of magnetron configurations available: balanced magnetrons, unbalanced type I, and unbalanced type II, see Figure 3.2. In a balanced magnetron, the inner and outer magnets have the same strength, which confines the plasma and electrons close to the target surface. In unbalanced mode, the inner and outer magnets have different strength, where type I refers to a stronger inner magnet, whereas type II has stronger outer magnets.

In Paper V, a modified type II unbalanced magnetron was used. This system was developed and characterized by Petrov et al. ${ }^{44}$ It is a regular ultra high vacuum (UHV) planar magnetron system with a pair of external Helmholtz coils that enables application of a variable magnetic field $B_{\text {ext }}$. This external magnetic field is superimposed on the permanent magnetic field of the magnetron.

The external magnetic field can be negative or positive with respect to the outer permanent magnets in the planar magnetron. If the external field is negative, the field between the target and the substrate will have the same sign as the central pole, meaning that the electrons will be steered away from the substrate a)
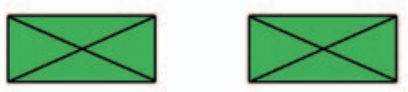

substrate
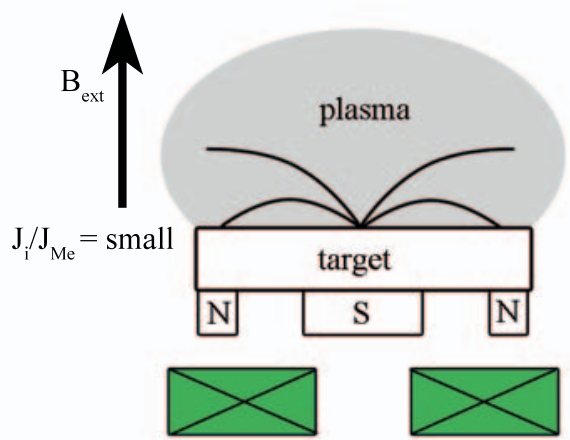

external magnets b)
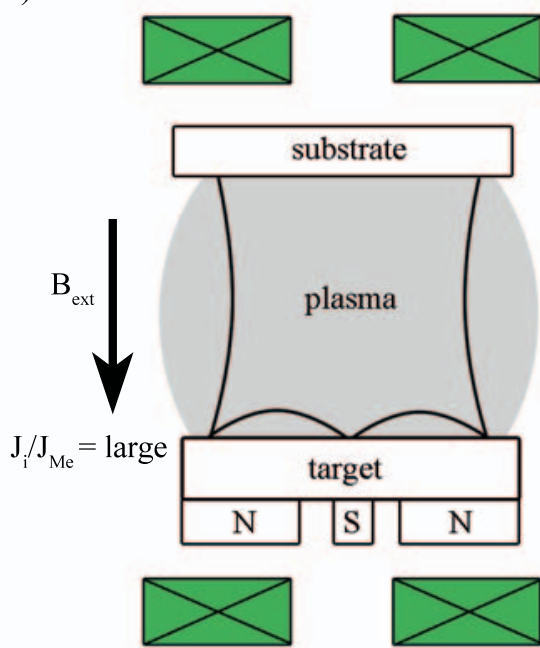

external magnets 
towards the walls of the chamber, reducing the plasma density near the substrate, and thus reduce the ion-to-metal-flux ratio, $J_{i} / J_{M e}$, on the growing film, see Figure 3.3. A positive field leads to an increased fraction of electrons that escape the trap over the target, and they are channeled towards the substrate. This increases the plasma density close to the substrate and enhances the ion flux incident at the growing film. In this system, the ion-to-metal-flux ratio, $J_{i} / J_{M e}$, has been shown to vary with $B_{\text {ext }}$, without any significant effect on the ion energy, $E_{i}$. This enables independent control of the ion flux and the ion energy, meaning that it is possible to control the degree of unbalancing of the magnetron.

\section{THE EFFECT OF SUBSTRATE BIAS VOLTAGE}

Negative substrate bias voltages can be applied from an external power source, and the growing film will then be subjected to positive ion bombardment. Other energetic particles, such as secondary electrons, ions that have been reflected from the sputtering target and are now neutrals, and photons are also irradiating on the growing film.

By introducing a bias voltage, the electric fields near the substrate are modified in order to vary the energy of the incident particles. The application of a bias voltage can change the film properties in several ways; it affects residual stresses, film morphology, density, grain size and preferred crystallographic orientation; improves adhesion to the substrate; increases oxidation resistance in optical films; enables control of magnetic anisotropy; increases the probability for dopant incorporation; and enables control of film composition, among other. ${ }^{3,45}$

Applying a substrate bias voltage is an effective way of tailoring film properties by quite simple means. When energetic particles bombard the substrate surface during film formation this leads to higher surface mobility of adatoms and elevated film temperatures, which has consequences for atomic reactions and interdiffusion rates, and is of special importance for amorphous film formation.

For controlling the growth kinetics and the physical properties of thin films, low-energy $\left(E_{i}<100 \mathrm{eV}\right)$ ion bombardment has been shown to be useful. ${ }^{45}$

\section{SPUTTER YIELD AMPLIFICATION}

The term sputter yield amplification (SYA) was introduced by Berg and Kartadjiev. ${ }^{46}$ It is based on preferential resputtering of lighter species during ion bombardment of alloys, leading to enhanced sputter yields of lighter elements as compared to the elemental ones.

The sputter yield is defined as the number of atoms ejected from the target surface per incident ion. ${ }^{47}$ It is one of the most 


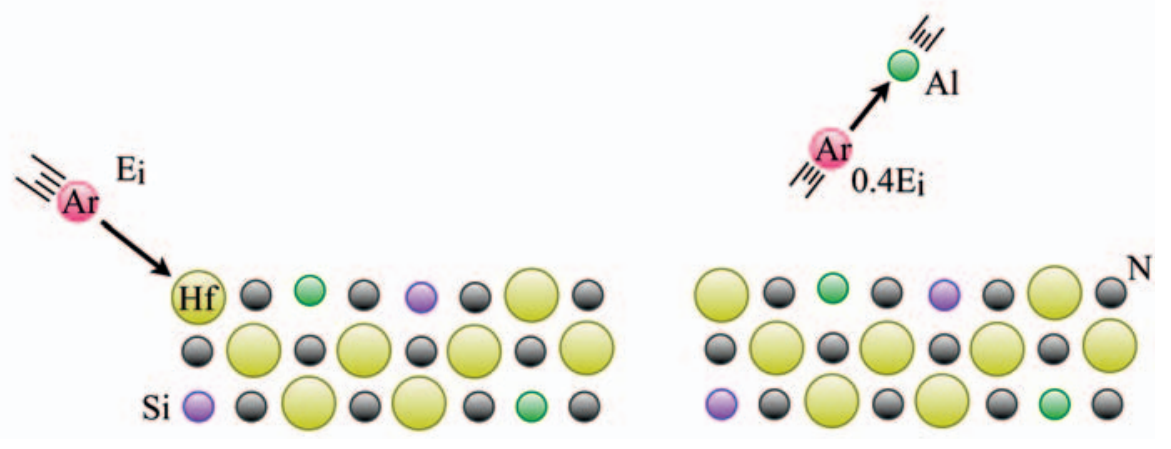

FIGURE 3.4: Illustration of how an energetic Ar atom impinges on a heavy $\mathrm{Hf}$ atom in the growing film, recoils and resputter a light $\mathrm{Al}$ atom on its way out. fundamental parameters of the sputtering process, but still not all effects that contribute to the sputter yield are fully understood. The sputter yield of an element increases with increasing incident ion energy, but also increases with increasing mass and $\mathrm{d}$-shell filling of the incident ion. ${ }^{48,49}$ Sputter yields for many elements can be found in the literature, but the sputter yield for an element can vary substantially if it is sputtered from a pure elemental target or from an alloy. For the elements used in this study ( $\mathrm{N}$ and $\mathrm{B}$ excluded), the sputter yield at $300 \mathrm{eV} \mathrm{Ar}{ }^{+}$bombardment is 0.65 for $\mathrm{Al}, 0.31$ for $\mathrm{Si}, 0.33$ for Ti, and 0.48 for $\mathrm{Hf}^{50}$

When sputtering from an alloy target, the initial bombardment will cause the element with highest sputter yield to be removed first. The target will then be enriched in the material with lower sputter yield. At steady state, the composition of sputtered species is equal to the target composition. ${ }^{51}$

SYA describes the compositional enhancement of an element with higher mass $m_{h}$ as compared to an element with lower mass $m_{l}$ due to bombardment by ions with intermediate mass $m_{\text {int }}$. The films deposited in Paper $\mathrm{V}$ consist of elements with large difference in mass ( $\mathrm{Hf}=178.5 \mathrm{amu}, \mathrm{Al}=27 \mathrm{amu}$, and $\mathrm{Si}=28 \mathrm{amu}$ ) as compared with the mass of $\mathrm{Ar}=40 \mathrm{amu}$.

Even though a $5 \%-\mathrm{N}_{2} /$ Ar gas mixture was used, single charge $\mathrm{Ar}^{+}$ions are the primary energetic species that hit the growing film, which was shown by mass spectroscopy experiments carried out under similar deposition conditions. ${ }^{52}$ The Ar ions will have energies:

$$
E_{i}=e V_{s}=e\left|\left(V_{b}-V_{p}\right)\right|,
$$

where $e$ is the electron charge, $V_{p}$ is the plasma potential, and $V_{b}$ is the applied substrate bias potential. The energy transfer from an impinging Ar ion to the growing film will have a maximum energy transfer for $180^{\circ}$ backscattering collisions. If the ion collides with a Hf atom, the energy transfer can be estimated as: ${ }^{53}$

$$
\frac{4 \cdot m_{H f} \cdot m_{A r}}{\left(m_{H f}+m_{A r}\right)^{2}} E_{i} .
$$


This means that $\sim 0.6 E_{i}$ is transferred to the Hf atom, and the $\mathrm{Ar}$ ion is backscattered with an energy $E_{b} \approx 0.4 E_{i}$. If the Ar ion instead collides with an $\mathrm{Al}$ or $\mathrm{Si}$ atom it will transfer about 96$97 \%$ of its energy and is reflected with $E_{b} \approx 0.03-0.04 E_{i}$.

This extremely efficient energy transfer to lighter elements, leads to resputtering of $\mathrm{Al}$ and $\mathrm{Si}$ as an $\mathrm{Ar}$ ion first collides with a $\mathrm{Hf}$ atom in the film, is backscattered, and collides with an $\mathrm{Al}$ or $\mathrm{Si}$ atom on the way out. However, the energy of the backscattered ion, $E_{b}$, must be high enough for preferential resputtering of $\mathrm{Al}$ and $\mathrm{Si}$, but below the Hf sputtering threshold.

In Paper $\mathrm{V}$ this effect was used to vary the composition of the films by changing the incoming ion energy, $E_{i}$. In addition, it was discovered that the change in ion energy also affects the Si bonding in the films, where Si in films grown with low ion energy is mainly Si-Si or Si-Hf bonded, while higher ion energies promotes $\mathrm{Si}-\mathrm{N}$ bonding.

\section{High power impulse magnetron sputtering - HIPIMS}

High power impulse magnetron sputtering (HIPIMS), also called HPPMS (high power pulsed magnetron sputtering), is a PVD method similar to dc magnetron sputtering, from which it developed. In conventional dc magnetron sputtering, increased ion flux can be achieved, as previously mentioned, by unbalancing the magnetrons, strengthening the magnetic field by external coils, or by increasing the substrate bias voltage. Increasing the substrate bias voltage will, however, mainly increase the ion energy which can lead to undesired implantation of sputter gas ions.

Another option would be to increase the number density of ionized particles in the plasma, as most of the sputtered material in conventional dc magnetron sputtering is neutrals. Ionization could, basically, be increased by increasing the power density to the target and thereby increase the plasma density and ionize more of the sputtered material, but this would also lead to target melting, or the need for extreme cooling. The idea to instead apply very short high-power pulses to the target was investigated by several groups of researchers during the 1990s, ${ }^{54,55,56}$ but the final breakthrough came with the paper by Kouznetsov et al., published in $1999 .{ }^{57}$

By applying short pulses, typically 5-200 $\mu s$, with frequencies ranging from tens of $\mathrm{Hz}$ to several $\mathrm{kHz}$ and power densities in the $\mathrm{kW} / \mathrm{cm}^{2}$-regime, dense and highly ionized plasma is generated in front of the target. ${ }^{58,59,60}$ To keep the target temperature down, the duty cycles are low, i.e. the pulse time in relation to the cycle time is only a few percent. This leads to a low average power to the target, similar to the case for conventional dc magnetron sputtering. 
The electron density is in the range of $10^{18}-10^{19} \mathrm{~m}^{-3}$, which is 2-4 orders of magnitude higher than for conventional dc magnetron sputtering, ${ }^{61,62}$ leading to a reduction of the mean ionization distance from typically $50 \mathrm{~cm}$ in conventional dc magnetron sputtering ${ }^{63}$ to only a few $\mathrm{cm}$, thus increasing the probability of ionization of the sputtered species. ${ }^{64,65}$ The degree of ionization depends on the discharge characteristics, but also on the target material itself, and values from $\sim 5 \%$ for $\mathrm{C}$ to $90 \%$ for Ti has been reported. ${ }^{58,66}$

HIPIMS has been shown to have a number of merits over conventional dc magnetron sputtering, including increased film density, ${ }^{66,67,68}$ due to the increased adatom mobility on the substrate.

In addition, the lack of target poisoning is an attractive advantage of HIPIMS compared to dc magnetron sputtering. ${ }^{69}$ Target poisoning drastically reduces the deposition rate, and is a common problem during reactive sputtering, especially of metals. ${ }^{70}$ It is not certain why target poisoning is unusual in HIPIMS, but one explanation might be rarefaction of the reactive gas, i.e. the gas is more dissociated during the HIPIMS pulse since the gas is heated by energetic sputtered species. ${ }^{71,72}$ Another explanation is that a high erosion rate of the target, following the high power loads, act as effective cleaning of the target, which in combination with low plasma activity between the pulses prevents compound formation at the target surface. ${ }^{69,73}$

Another advantage of HIPIMS over conventional dc magnetron sputtering is that the high degree of ionization of the sputtered species make the process less affected by the limiting lineof-sight deposition. The charged species in the plasma can be steered by applying electrical and magnetic fields, making it possible to deposit homogeneous coatings of quite complex shaped objects, to a much further extent than possible with dc magnetron sputtering. ${ }^{74}$

In comparison to cathodic arc evaporation, which also benefits from the high degree of ionization, HIPIMS has the advantage of producing coatings free from macroparticles, leading to a much smoother surface and improved scratch resistance. ${ }^{75,76}$

Some of the drawbacks of HIPIMS are the often mentioned low deposition rates compared to conventional dc magnetron sputtering for the same average target power. ${ }^{60,73}$ It should, however, be noted that deposition rates compared to conventional dc magnetron sputtering varies greatly, ranging from $15-120 \%$ depending on the material, even though $25-35 \%$ are more typically reported values. ${ }^{60,76}$

The reasons behind the lower deposition rates is not fully understood, but one explanation is that metal ions are being attracted back to the target. ${ }^{77}$ These ions can participate in the sputtering process, but since the self-sputtering yield is typically lower than the sputter gas yield, ${ }^{78}$ the deposition rate will be de- 
creased. In addition, these ions are not available for film growth since they are confined at the target side, further reducing the growth rate. Other explanations include weakening of the magnetic confinement of the magnetron, ${ }^{54,79}$ and a non-linear energetic dependence of the sputter yield to the deposition rate. ${ }^{80} \mathrm{In}$ conventional dc magnetron sputtering the process operates under conditions where the sputter yield has an almost linear relationship to the ion energy of the impinging ions. The higher cathode voltages typically used in HIPIMS may push the process into a non-linear regime, so that a power increase will not lead to corresponding increased sputter yield.

In Paper IV $\left(\mathrm{TiB}_{2}\right)_{1-x} \mathrm{Si}_{x} \mathrm{~N}$ thin films were deposited reactively in a hybrid coating system by operating the $\mathrm{TiB}_{2}$ target in HIPIMS mode, and the elemental Si target in conventional dc magnetron sputtering mode. To our knowledge, this is the first report on $\mathrm{TiB}_{2}$-targets operated in HIPIMS mode.

\section{Cathodic arc evaporation}

As already stated; in evaporation techniques the atoms are removed by thermal means. Both evaporation and sputtering techniques derive from the mid-nineteenth century. The development of better vacuum-pumping equipment and heating sources, spurred the process of evaporation techniques, even though sputtering was also used on an industrial scale meanwhile. ${ }^{3}$ Until the late 1960s, evaporation was the preferred deposition technique, due to high deposition rates, good vacuum, and the possibility to deposit all kind of materials.

In arc evaporation a discharge between two electrodes is used to melt and evaporate the material. The cathode corresponds to the target in sputtering, and consists of the material that will be deposited. The high current, low voltage discharge melts a small spot on the cathode surface creating a plasma discharge. A current flows from the small spot, the so-called cathode spot. At the local spot the temperature is high enough to melt the target material and neutral atoms, electrons, and ions, are evaporated. There can be one or more active arc spots on the cathode surface, but due to heating of the cathode at the local spot, the resistivity increases. If several spots are active at the same time, the newer spot will be preferred due to its lower resistance.

To start the process the arc has to be ignited. A common way is to let a mechanical trigger create a short circuit on the cathode side which gives a short, high-voltage pulse. Since the cathode and the anode are largely separated in the system, a conductive ionized gas, a so-called plasma, is created. The plasma make the process self-sustained since the electrical current that flows between the cathode and the anode is transported by the plasma. ${ }^{81}$

The electrons are attracted by the electric field, and they collide with evaporated atoms and ionize them. The ions are then

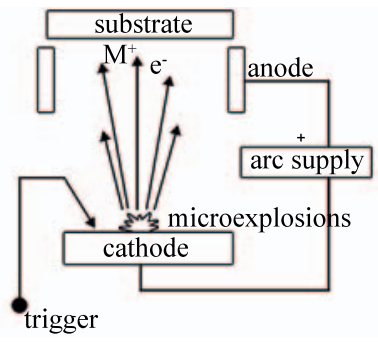

FIGURE 3.5: Schematic image illustrating the arc evaporation process. 
a)
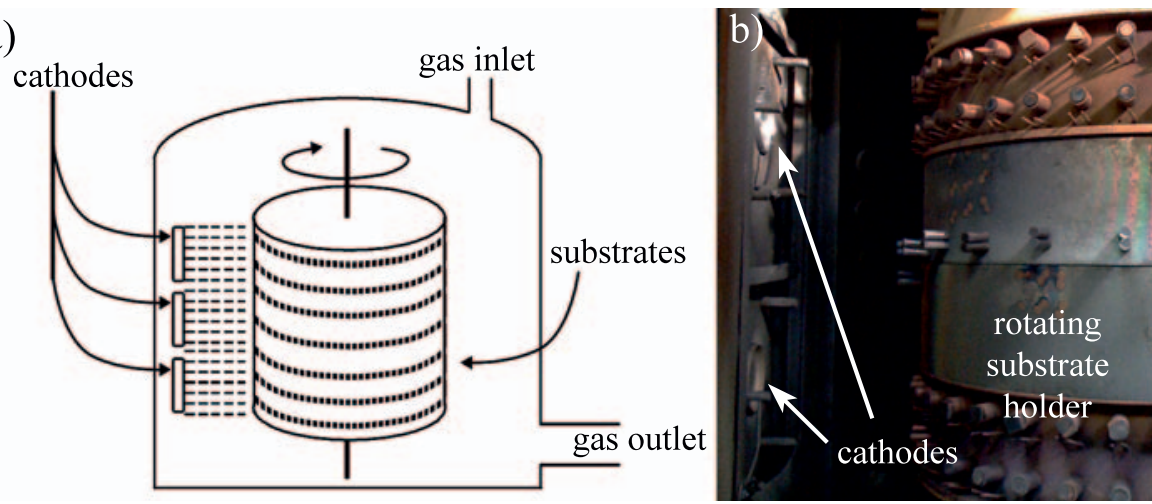

FIGURE 3.6: a) Schematic image of an industrial cathodic arc evaporation system with b) corresponding photograph of the system used in Paper I and Paper III. transported to the substrate surface where they condensate to form the growing film. Figure 3.5 shows a schematic illustration of the arc process.

In contrast to the case in magnetron sputtering, the plasma is highly ionized in arc evaporation. Close to the cathode spots the degree of ionization is nearly $100 \%{ }^{81}$ The plasma can be manipulated using electric and magnetic fields. ${ }^{82}$ This can be used to change the stoichiometry of the films when growing from a compound or alloy target, since different elements have different degree of ionization. Ions with high degree of ionization will impinge on the film surface with higher energy, thus penetrating deeper into the film and cause preferential re-sputtering of light elements in the growing film. A high degree of ionization also provides high deposition rates, which makes it possible to grow dense films with good adhesion. ${ }^{83}$

In the same way as in reactive magnetron sputtering, reactive cathodic arc evaporation can be performed by introducing a reactive gas into the chamber. Light elements like carbon, oxygen or nitrogen are often introduced in the gas phase, but they can also be introduced via the cathode. ${ }^{84}$ Compound and alloy cathodes can be used to control and vary the composition of the films.

In industrial arc evaporation systems, there is usually room for several cathodes. Figure 3.6 shows a schematic illustration of the industrial system used in Paper I and Paper III. In this system, cathodes can be placed both left and right of the chamber door, but also on the door itself. The substrates are mounted on a rotating drum in the center of the system.

By using cathodes of different composition, and aligning them vertically on the wall of the deposition chamber, it is possible to achieve variations in the film compositions depending on the position of the substrates in relation to the cathodes. By arranging the cathodes vertically, the plasma generated from each cathode will partly overlap. This can be used to grow films with a wide range of compositions during one deposition. But if the drum 
holding the substrates is rotating, this can cause compositional modulation that is visible as layering in the films. This layering effect was seen in both Paper I and Paper III. This effect is described in detail by Eriksson et al. ${ }^{85}$

When the material is melted and evaporated, larger particles, so-called droplets, are ejected. These droplets are incorporated in the growing film. The droplets hinder the growing film, and they can serve as nucleation sites for differently shaped grains that can grow large in size. The presence of these macroparticles increases the surface roughness. In Paper I a regular amount of droplets were observed in the Ti-Al-Si-N coatings. The Ti-B-Si-N and Ti-B-Al-Si-N coatings in Paper III, on the other hand, were surprisingly featureless. A few droplets were observed, but to a much lesser extent than what is usual for many arc evaporated coatings. The same was observed by Knotek et al. in a study where they evaluated the arc evaporation behavior, and resulting coating properties, of $\mathrm{TiB}_{2}$ cathodes with different manufacturing characteristics. ${ }^{86}$

\section{Plasma characterization}

To control the growth of thin films there are several process parameters that have to be monitored, among which the most important ones include the ion energy, ion flux, and the substrate temperature.

In this work, electrostatic probes were used to determine the characteristics of the plasma, and changes in ion energy, $E_{i}$, and the ion-to-metal flux ratio, $J_{i} / J_{M e}$, with respect to the substrate bias voltage, $V_{b}$, and applied magnetic field strength, $B_{\text {ext }}$, were investigated. Thermal probes were used to determine the substrate temperature, $T_{s}$.

The basic operation principles and theoretical considerations of these probes are discussed below.

\section{ELECTROSTATIC PROBES}

A magnetron glow discharge can be described as a region of relatively low temperature and low pressure gas. ${ }^{87}$ In a homogeneous plasma, the number of particles that crosses a unit area per unit time is given by: ${ }^{88}$

$$
\Gamma=\frac{1}{4} n \bar{v},
$$

where $n$ is the particle number density, and $\bar{v}$ is the mean particle speed. We assume that we only have single charged ions (this is most likely not the case for the deposition with HIPIMS in Paper IV, but a valid approximation for the case in Paper V). In addition we assume that the number density of electrons is approximately the same as the number density of ions, $n_{e} \approx n_{i}$, and that the electron temperature, $T_{e}$, and ion temperature, $T_{i}$, are comparable in 
FIGURE 3.7: Real experimental data showing typical I-V characteristics for a Langmuir probe, with the ion and electron saturation regions, and the electron retarding field, indicated in the figure.

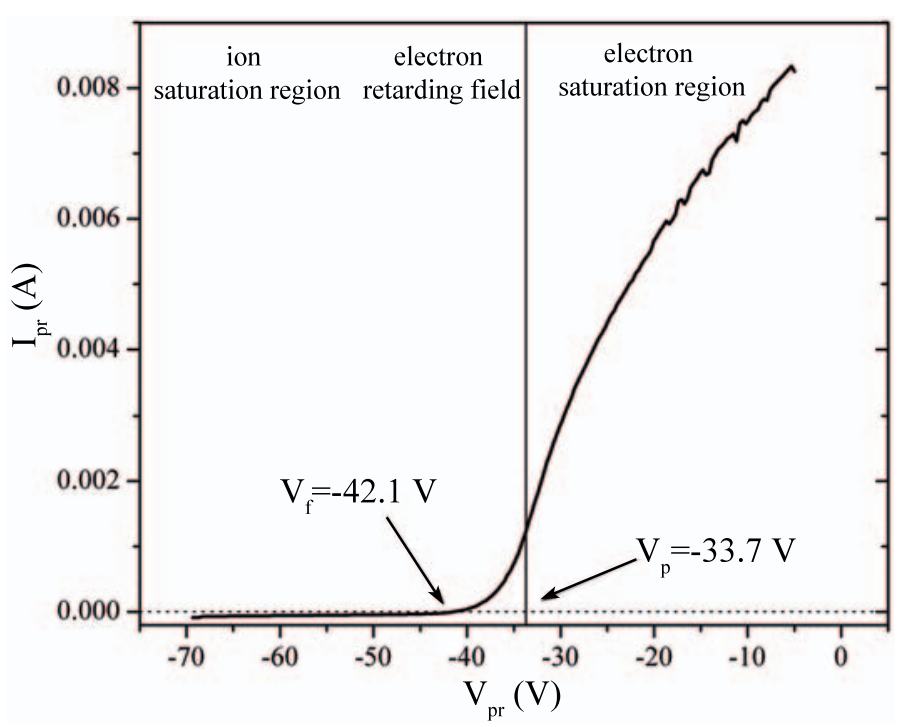

size. Since electrons are much lighter than ions, the mobility of electrons is much higher (at least 100x). If we insert a probe with area $A$ in the plasma, so that the plasma remains unperturbed, the electric current $I$ drawn through the probe would then be dominated by electrons:

$$
I=-e A\left(\frac{1}{4} n_{i} \bar{v}_{i}-\frac{1}{4} n_{e} \overline{v_{e}}\right) \approx \frac{1}{4} e A n_{e} \bar{v}_{e} .
$$

This gives the plasma a small positive potential and it is said to be in a quasineutral state. ${ }^{89}$ The electric potential in the plasma, without any probe, is denoted $V_{p}$.

The high velocity of the electrons creates a charge-depleted zone close to any surface facing the plasma. This zone is called dark space, and for typical magnetron sputtering conditions the thickness of the dark space is of the order of mm. ${ }^{89}$ The ions that are transported through the plasma are accelerated towards the substrate at the edge of the dark space, and if their mean-free path is larger than the width of the dark space, the energy $E_{i}$ of the ions impinging of the film surface can be determined using Equation 3.1:

$$
E_{i}=e V_{s}=e\left|\left(V_{b}-V_{p}\right)\right|
$$

In order to estimate the ion flux, it is necessary to know the ion number density, $n_{i}$ (or the electron number density since $n_{e} \approx$ $\left.n_{i}\right)$, and the electron energy distribution function $f(E)$. The energy distribution function in conventional dc glow discharges is assumed to be of Maxwellian form, and it is then possible to approximate $f(E)$ to a value of the electron temperature, $T_{e}$.

Electrostatic probes are usually the best instruments for measuring and characterizing the plasma and determine values of $T_{e}$ 
and also $V_{p}$. The electrodes have to be small in order to minimize perturbation of the plasma during measurement.

In this work, single-probe electrodes were biased relative to a larger reference electrode (the discharge anode). Two different types of probes were used, here described for the measurements in Paper V, but a similar setup was used also in Paper II.

The first one, a so-called Langmuir probe, consists of a 2-mmlong, 0.4-mm-diameter cylindrical tungsten probe mounted in a ceramic tube, placed approximately $5 \mathrm{~mm}$ above the regular substrate position, whereas the second one was a planar probe. The planar probe is a 6-mm-diameter stainless-steel disc mounted in the center of a specially designed substrate holder. The planar probe was placed in the regular substrate position facing the target and was electrically isolated from the surrounding holder plate by a gap of $0.25 \mathrm{~mm}$.

The operation principle is simple; a voltage, $V_{p r}$, is applied to the probe with respect to the anode. The total probe current, $I_{p r}$ is measured, and so-called I-V curves are recorded. Figure 3.7 shows a typical I-V curve measured for a $\mathrm{Hf}_{0.6} \mathrm{Al}_{0.2} \mathrm{Si}_{0.2}$-target in Paper V. The curve can be divided into three parts: ${ }^{90}$

1. $V_{p r}<V_{f}$. This is the ion saturation region. Towards more negative probe potentials, the total current is increasing part ion current until only ions are collected and the ion saturation current is reached.

2. $V_{p r}<V_{p}$. This region is called the electron retarding field, and the probe is negative with respect to the plasma. Here, electrons are repelled according to the Boltzmann relation, until $V_{p r}=V_{f}$, where the total probe current is zero. At this potential, the so-called floating potential, an insulating probe which cannot draw current will float.

3. When $V_{p r}>V_{p}$ the electron saturation region is reached. The total current is increasingly electron current with increasing probe potential. Eventually the electron current cannot increase any more, since all arriving electrons are collected by the probe. At $V_{p r}=V_{p}$, the probe is at the same potential as the plasma and it mainly draws current from electrons since they are more mobile than ions.

The total probe current, $I_{p r}$, is a sum of the electron current $I_{e}$ and the ion current $I_{i}$ :

$$
I_{p r}=I_{e}+I_{i}
$$

In an ideal case, the ion and electron saturations currents, $I_{i}^{*}$ and $I_{e}^{*}$, respectively, can be written as:

$$
I_{i, e}^{*}=\frac{e n_{i, e} A}{4} \sqrt{\frac{8 k_{B} T_{i, e}}{\pi M_{i, e}}},
$$


FIGURE 3.8: The plasma potential, $V_{p}$, and the electron saturation current, $I_{e}^{*}$ are determined using the tangent method. The electron temperature, $T_{e}$, is determined using the slope of the linear part of the $\ln I_{p r}$-curve.

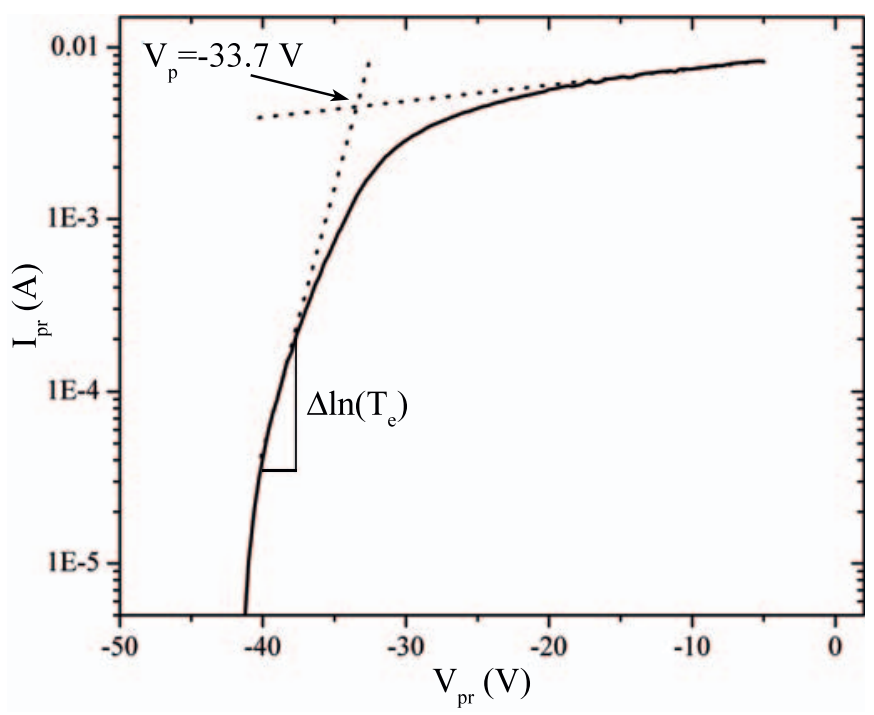

where $e$ is the electron charge, $k_{B}$ is the Boltzmann constant, $A$ is the probe area and $M_{i, e}$ are the ion and electron masses, respectively. The expressions can be used to determine $n_{i}$ and $n_{e}$ after measuring the ion and electron saturation currents. The problem, however, is that the ion saturation current, $I_{i}^{*}$ cannot be directly determined from the I-V curves, so first $I_{i}^{*}$ has to be determined using an alternative procedure (see below).

The I-V curves can, however, be used to determine the electron temperature, $T_{e}$. To do that, the electron retarding field is used. Here, the probe potential is negative with respect to the plasma potential which means that the ion current has the value $I_{i}^{*}$. Only those electrons that have energies high enough to overcome the potential difference $V_{p r}-V_{p}$ are collected, according to:

$$
I_{e}=I_{p r}-I_{i}^{*}=I_{e}^{*} \exp \left(-e \frac{V_{p r}-V_{p}}{k_{B} T_{e}}\right)
$$

By this, the electron temperature can be calculated from the slope of the linear part of the dependence $\ln \left(I_{e}\right)$ on $V_{p r}$. Equation 3.7 also allows for determination of the plasma potential, $V_{p}$, and the electron saturation current, $I_{e}^{*}$, by the so-called tangent method. The interception point of the tangent to the slopes give $\ln I_{e}^{*}$ and $V_{p}$, see Figure 3.8.

To determine $I_{i}^{*}$, the recorded data from the ion saturation region can be used in the method of Laframboise, where a theoretical dependence between $I_{p r}$ and $I_{i}^{*}$ is used, followed by an iterative procedure to determine $I_{i}^{*}$ and $T_{e} \cdot{ }^{91}$ Another option is to use a planar probe, which was used in this thesis.

The planar probe measures the actual current densities reaching the substrate. ${ }^{92}$ The measured current, $\mathrm{I}_{p r}$, is used to calcu- 
late the ion flux $J_{i}$, i.e. the ion current drawn through the probe, by dividing the measured current, $I_{p r}$, with the electron electric charge, the probe area, and the deposition time, $t$, according to:

$$
J_{i}=\frac{N_{i}}{A t}=\frac{I_{p r}}{e A t} .
$$

Using the deposition rate, $r$, the density of the film, $\rho$, and the molar mass, $M$ of the metal atoms, the metal atom flux, $J_{M e}$, can be determined by:

$$
J_{M e}=\frac{N_{M e}}{A t}=\frac{\rho N_{A} r}{M},
$$

where $N_{A}$ is the Avogadro constant. $N_{M e}$ can also be taken from RBS measurements, which was done in Paper V. Using Equations 3.8 and 3.9, the ion-to-metal flux ratio can be calculated:

$$
J_{i} / J_{M e}=\frac{I_{p r} M}{\rho N_{A} r e A t} .
$$

\section{TEMPERATURE MEASUREMENTS}

The substrate temperature is of profound importance for the film growth and resulting film properties. The temperature at the substrate is a combination of the plasma heating and the applied external heating. The resulting temperature at the substrate is affected also by the thermal conductivity of the substrate material itself. In this work, the substrate temperature has been measured by a combination of thermocouples and pyrometers.

\section{Thermocouple}

For measurement of the substrate temperature, the thermocouple is placed on top of a dummy sample and mounted in the regular substrate position, see Figure 3.9.

The operation principle of a thermocouple is based on the thermoelectric effect, or the so-called Seebeck effect. A conductor that is subjected to a thermal gradient generates a voltage. To measure the voltage, another conductor has to be connected to the wire that experiences the thermal gradient. This second conductor will, of course, also experience a thermal gradient and generate a voltage opposite to the first one. By using wires of different material, giving rise to slightly different voltages, it is possible to measure the voltage difference generated by the two wires.

For most measurements, it is enough to assume that the output voltage increases linearly with the temperature difference, $\Delta T$, but for more accurate measurements and measurements outside the range where linearity applies (depending on the thermocouple type), the non-linearity must be corrected for. Correction 


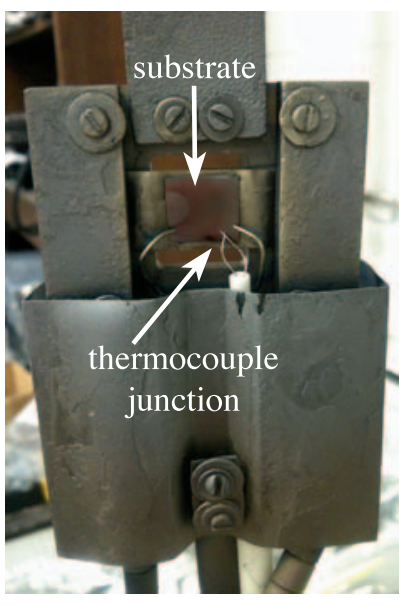

FIGURE 3.9: A thermocouple mounted in the substrate holder for temperature measurements in Paper V. coefficients can be found online from National Institute of Standards and Technology (NIST). ${ }^{93}$

A thermocouple for use in deposition systems is a rather simple construction, basically just two wires that are spark welded together in a so-called hot junction or thermocouple junction. The two wires are then connected to a voltmeter outside the chamber where the voltage difference is recorded and translated into a temperature.

In this work a 0.51-mm-diameter K-type thermocouple was used, in which the wires are chromel (90\% nickel and 10\% chromium) and alumel (95\% nickel, 2\% manganese, 2\% aluminum and $1 \%$ silicon). The $\mathrm{K}$-type is a very common thermocouple since it can measure over a wide range of temperatures from $200{ }^{\circ} \mathrm{C}$ to $+1250{ }^{\circ} \mathrm{C}$.

\section{Pyrometer}

A pyrometer is a non-conducting device that translates the thermal radiation from an object into a temperature. This give pyrometers a great advantage in that they do not require contact with the object they are measuring. Pyrometers consist of an optical system and a detector. The measured temperature is related to the thermal radiation or irradiance $j^{\star}$ of the object, according to the Stefan-Boltzmann law:

$$
j^{\star}=\varepsilon \sigma T^{4},
$$

where $\varepsilon$ is the emissivity of the object, $\sigma$ is a proportionality constant (the Stefan-Boltzmann constant), and $T$ is the temperature. Single wavelength pyrometers can operate over a wide range of temperatures, but require knowledge of the sample's emissivity.

There are also dual wavelength pyrometers, also called ratio pyrometers. They detect the emitted energy at two different wavelengths and calculates the temperature based on the ratio of the two values. This is called two-color technique, and give reliable values even if the signal is weakened by dust or dirty glass lenses along the sight path.

The dual wavelength pyrometers assume that the emissivity is the same at both wavelengths, known as the gray body assumption. Dual wavelength pyrometers became very popular when they were introduced to the market, and it was later realized that the gray body assumption does not apply for all materials, which causes measurement errors.

Today, there are also multi-wavelength pyrometers available, that more accurately can measure the temperature of objects with changing or unknown emissivities. ${ }^{94}$

A major drawback with pyrometers is that most of them do not work well at temperatures $<600{ }^{\circ} \mathrm{C}$. The substrate temperature $T_{s}$ in most of the studies in this work has been kept at $\sim 400{ }^{\circ} \mathrm{C}$, and pyrometers have been used together with thermocouples to control the temperature settings. 


\section{BONDING AND CRYSTAL STRUCTURES}

The properties of solid materials are closely related to how the atoms are arranged, which in turn is primarily determined by the bonds that hold the atoms together. Bonds are generally divided into two groups: strong primary bonds such as ionic, metallic and covalent bonds, and weaker secondary bonds such as van der Waals bonds and hydrogen bonds.

For ceramics, three factors are decisive for the structure. ${ }^{12}$ The first one is the stoichiometry, which limits the type of structure the atoms can assume by the demand that the sum of all charges must be zero.

The second factor is the cation to anion radius ratio. The lowest energy state is attained if the ions maximize their attraction at the same time as the repulsions are minimized. Since the negatively charged anions generally are larger than the positively charged cations, the structure is determined by the largest number of anions that is possible to pack around the cations without any cations or anions touching. The ratio is given by $r_{c} / r_{a}$, where $r_{c}$ and $r_{a}$ are the cation and anion radii, respectively. The critical ratio varies with coordination number. To predict the structure, the size of the ions must be known. It is possible to determine the distance between atoms by $\mathrm{x}$-ray diffraction, but for ions it is of course almost impossible to determine where one ion ends and the other begins. ${ }^{2}$ There are a number of compilations of atomic and ionic radii available, where the atomic radii for the elements of relevance in this work are $r_{H f}=1.55 \AA, r_{T i}=1.40 \AA, r_{A l}=1.25 \AA$, $r_{S i}=1.10 \AA, r_{B}=0.85 \AA$, and $r_{N}=0.65 \AA$, given by Slater. ${ }^{95}$

Finally, the third factor is a measure of the likelihood for covalency and tetrahedral coordination. Some compounds crystallize in tetrahedrally coordinated structures such as zinc-blende or wurtzite even though the radius ratio suggests otherwise. This typically happens in structures where the covalent character of the bond is enhanced or in structures that favor $s p^{3}$-hybridization, such as $\mathrm{Si}, \mathrm{Ge}$, and C. ${ }^{12}$

Figure 4.1 shows the chemical bonding for some common hard materials. Bonding in $\mathrm{TiN}, \mathrm{HfN}$ and $\mathrm{TiB}_{2}$ are characterized by their metallic bonding, whereas $\mathrm{Si}_{3} \mathrm{~N}_{4}, \mathrm{BN}$ and AlN exhibit more covalent type of bonding. However, the division can not be made razor sharp, since transition metal nitrides involves simultaneous contributions of metallic, covalent and ionic bonding, ${ }^{96,97}$ and no ceramics are purely covalently or ionically bonded. ${ }^{12}$ 
FIGURE 4.1: Hard materials, classified after chemical bonding, adapted from Mayrhofer et al. 98

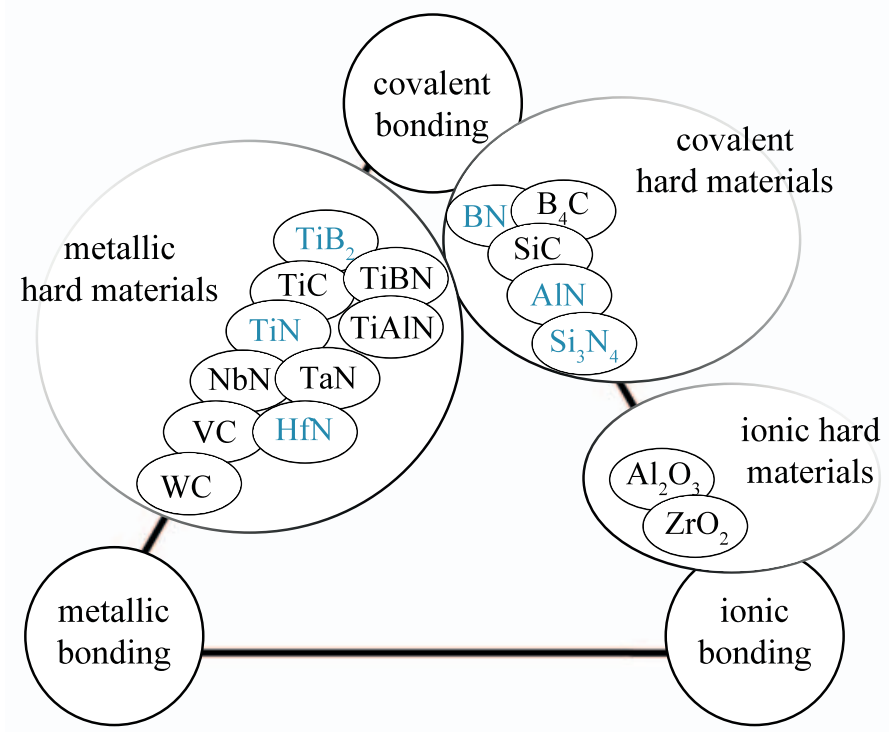

Bonding types

IONIC BONDING

Ionic bonding is formed in materials with charged particles, where the electrostatic interaction between the positive cations and negative anions holds the solid together. In the most simple model of ionic solids the ions are considered as impenetrable charged spheres. The solid are held together by the electrostatic attraction between spheres with negative and positive charge. ${ }^{2,99}$ Generally, ionic bonds form between metallic elements and non-metals. There is always a range of mixed bonding going from ionic bonding to covalent bonding, except for homopolar bonds which are purely covalent (e.g. $\mathrm{H}_{2}$ ). Covalent bonding only occurs if ionic bonding is unfavorable.

\section{COVALENT BONDING}

The covalent type of bonding is characterized by the sharing of electron pairs between atoms, and there is a stable balance of attractive and repulse forces between the atoms. ${ }^{12}$ The electronic distribution it not very different from metallic bonding, except there are no partially filled bands, and that the distribution of electronic densities are not uniform and not fully delocalized. ${ }^{99}$ Covalent bonds are usually formed by two electrons, one from each atom, that is connected through the bond. The electrons are localized in the region between the two atoms instead of being close to their own nuclei. 
As previously mentioned, elements like $\mathrm{Si}, \mathrm{Ge}$, and $\mathrm{C}$ have strong covalent tendencies. Ceramics which are predominantly covalently bonded, like silicon nitride in this work, are composed of $\mathrm{Si}$ atoms that are simultaneously bonded to four $\mathrm{N}$ atoms in a tetrahedral arrangement. The ground state configuration of $\mathrm{Si}$ is $3 p^{2}$ which suggests that only two primary bonds should form. This is, however, not the case and is explained by the hybridization between $s$ and $p$ orbitals. In $\mathrm{Si}$ the $s$-orbital can hybridize with one $p$-orbital forming an $s p$-orbital, with two $p$ orbitals forming a trigonal $s p^{2}$-orbital, or hybridize with all three $p$-orbitals and form a tetrahedral $s p^{3}$-orbital. Each one of the orbitals belong to one electron, making it possible for every $\mathrm{Si}$ atom to bond to four other atoms in the $s p^{3}$-configuration. ${ }^{12}$ The same type of hybridization occurs in $\mathrm{BN}$ where h-BN and r-BN are $s p^{2}$ hybridized, whereas c-BN and $\mathrm{w}$-BN are $s p^{3}$-hybridized. ${ }^{100,101,102}$

\section{METALLIC BONDING}

The last type of primary bonds are the metallic ones, which are formed due to attractive forces between positively charged metal ions and negatively charged fully delocalized electrons. In metals and solids characterized by metallic bonding there is quite a large number of electrons that are free to move (1-2 per atom). ${ }^{2}$ They are called conduction electrons and are gathered in an electron cloud that moves freely across the material. One could consider the metallic bonding as a covalent bond that has expanded until the density of electrons covers the interstitial regions and there is band overlap in k-space. ${ }^{99}$ In the transition metals, such as Ti and Hf, there is additional binding contributions from inner electron shells present, and their large d-electron shells lead to high binding energies. ${ }^{2}$ Metals and ceramics with metallic binding tend to crystallize in close-packed structures such as $h c p, b c c$, and $f_{c c}$.

\section{Bonding and properties}

The type of bonding strongly influences material properties. A solid with strong bonds, like ionic ones, have high melting points, exhibit high stability, but are also brittle and poor electrical and thermal conductors. ${ }^{12,103}$ The covalent bond is also strong, comparable to the ionic one, ${ }^{2}$ and have strong directional properties. Covalently bonded solids are not as good insulators as ionic ones and as thin film materials they are characterized by high hardness, high strength, but poor adhesion to the substrate. ${ }^{98}$ Increasing the covalent character reduces the number of bonds that have to be broken during melting, which reduces the melting point. However, this is also dependent on the melt structure, where for example many polymers do not require bond breaking for melting, which in reality means low melting points despite the high 


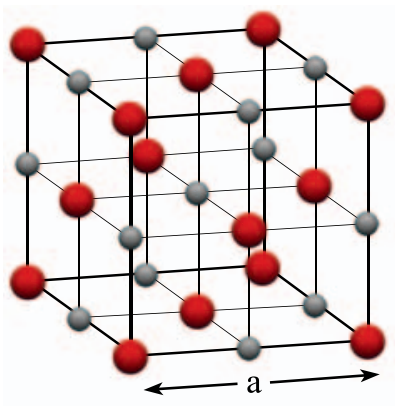

FIGURE 4.2: $\mathrm{NaCl}$-structure of $\mathrm{TiN} / \mathrm{HfN}$ where Ti or Hf atoms occupy octahedral sites, coordinating six $\mathrm{N}$ atoms. degree of covalency. Some covalent ceramics to not melt, but decompose at high temperatures. ${ }^{12}$ Metallic bonded materials have high ductility, good adhesion when applied as coatings or thin films, but suffer from lower hardness. ${ }^{98}$

Mayrhofer et al. ${ }^{98}$ showed that transition metals nitrides (TaN, TiN, and HfN) have covalent components between the transition metal and nitrogen, whereas for $\mathrm{TiB}_{2}$ the main covalent component is between the $\mathrm{B}$ atoms. AlN also has covalent components between $\mathrm{Al}$ and $\mathrm{N}$, but shows no metallic components at all.

In addition to the strong primary bonds described here, also other type of bonds play a major role for the properties of solids. In h-BN the structure is primarily covalent within the atomic planes (B and $\mathrm{N}$ are covalently bonded) while the layers are held together by weak van der Waals bonds. This causes anisotropy of most properties of h-BN, where for example hardness and electrical and thermal conductivity are much higher within the planes than perpendicular to them.

\section{Binary parent compounds}

\section{TITANIUM NITRIDE}

TiN is one of the most well known and most studied thin film materials, and it has been commercially available as a wear resistant coating on cutting tools since the 1970s. Despite the development of coatings with improved properties, e.g., better oxidation resistance and higher hardness, $\mathrm{TiN}$ is still common. It can also be found in a variety of other applications, e.g., as a diffusion barrier, ${ }^{104,105}$ and for decorative purposes. ${ }^{106} \mathrm{TiN}_{x}$ is thermodynamically stable over a wide range, $0.6<x<1.2 .{ }^{96,107}$ Thin film TiN has a reported hardness value ranging from $\sim 20 \mathrm{GPa}$ for single-crystal films ${ }^{108}$ to $26-30 \mathrm{GPa}$ for polycrystalline ones. ${ }^{109,110}$ A drawback with $\mathrm{TiN}$ is that it starts to oxidize at $\sim 550{ }^{\circ} \mathrm{C}$, which limits the use for high-temperature applications. ${ }^{111,112}$

$\mathrm{Ti}$ and $\mathrm{N}$ form a compound with rock-salt structure (often also called $\mathrm{NaCl}$ ) with Strukturbericht designation B1 and unit cell parameter $a=4.24 \AA .{ }^{113}$ The rock-salt structure can be described as two $f c c$ Bravais lattices where one is filled with nitrogen atoms and the other with metal atoms, offset by $a / 2$. In the structure, pictured in Figure 4.2, the metal atoms occupy the octahedral sites, and each metal atom is coordinating six nitrogen atoms.

\section{HAFNIUM NITRIDE}

HfN is a much less studied binary nitride than TiN. It has been investigated for the use as a diffusion barrier, ${ }^{114}$ and $\mathrm{HfN}$ is known to be the most refractory of all known nitrides, with a melting point of $\sim 3300{ }^{\circ} \mathrm{C}$ and hardness of $25 \mathrm{GPa} .{ }^{115,116} \mathrm{HfN}_{x}$ forms the rock-salt structure with $0.8<\mathrm{x}<1.2 .{ }^{117,118}$ For nitrogen substo- 
ichiometry, $\mathrm{HfN}$ is an insulator with a bandgap of $2-3 \mathrm{eV} .{ }^{119} \mathrm{Un}-$ der high temperature and high pressure conditions it is also possible to synthesize cubic $\mathrm{Hf}_{3} \mathrm{~N}_{4}$ in the $\mathrm{Th}_{3} \mathrm{P}_{4}$-structure in which the $\mathrm{Hf}$ atoms are eightfold coordinated with $\mathrm{N} .{ }^{120} \mathrm{HfN}$ has a unit cell parameter, $a=4.53 \AA .{ }^{121}$

\section{ALUMINUM NITRIDE}

Aluminium nitride is a wide band gap $(6.2 \mathrm{eV})^{122}$ semiconductor that is used in optical and microelectronic device applications. AlN is stable at high temperatures with a melting point $>2800{ }^{\circ} \mathrm{C}$, but in air AlN oxidizes at $700{ }^{\circ} \mathrm{C}$ and forms a protective surface layer that is stable up to $1370{ }^{\circ} \mathrm{C} .{ }^{123}$ The hardness of $\mathrm{AlN}$ is $20 \mathrm{GPa} .{ }^{124,125}$

AlN forms the wurtzite structure which belongs to the hexagonal crystal family. In the wurtzite structure the atoms have tetragonal coordination, and the tetrahedra are arranged in such a way that each $\mathrm{Al}$ atom is bonded to four $\mathrm{N}$ atoms (and vice versa) with equal bond lengths. The metal-to-nitrogen ratio has to be close to unity. The wurtzite structure can be described as two hexagonal close packed ( $h c p$ ) lattices, one with metal atoms, and one with nitrogen atoms, that are stacked on top of each other, and one is displaced in relation to the other. The nitrogen atoms are placed so that they occupy half of the available tetrahedral sites in the metal atom lattice. The wurtzite structure of AIN is shown in Figure 4.3. The unit cell parameters are: $a=3.11 \AA$ and $c=4.98 \AA .{ }^{126}$

In addition, there is a metastable zinc-blende AlN phase, ${ }^{127}$ as well as a metastable rock-salt AlN phase at high temperates and high pressures. Rock-salt AlN has also been observed as an intermediate phase during spinodal decomposition. ${ }^{128}$ The zincblende structure is cubic, and named after the mineral zincblende (sphalerite) and is also called ZnS or B3 from its Strukturbericht designation. In the same way as in the rock-salt structure, it can be seen as consisting of two $f_{c c}$ lattices stacked on top of each other, but shifted relative another. The atoms are tetrahedrally coordinated, in the same way as in the wurtzite structure.

\section{SILICON NITRIDE}

Silicon nitride is a hard ceramic that has an unusually high fracture toughness. It is most used in high temperature applications such as gas turbines, car engine parts, and bearings, but also on cutting tools. Silicon nitride does not melt, but decomposes at $\sim 1850{ }^{\circ} \mathrm{C} .{ }^{129}$ The hardness of silicon nitride is much dependent on both phase and synthesis technique. For amorphous $\mathrm{Si}_{3} \mathrm{~N}_{4}$, hardness values between 9-23 GPa have been reported, and a theorectical value as high as $31.5 \mathrm{GPa}$ is predicted. ${ }^{130}$ For the cubic silicon nitride phase, a hardness of $35 \mathrm{GPa}$ is reported. ${ }^{131}$

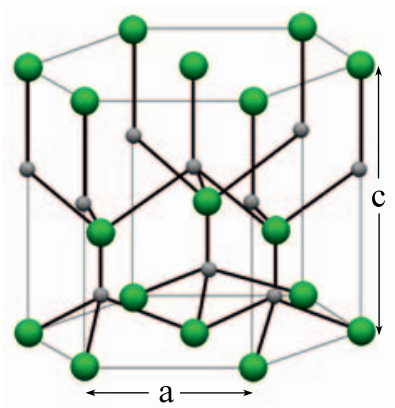

FIGURE 4.3: Wurtzite structure of AIN where each $\mathrm{Al}$ atom coordinates four $\mathrm{N}$ atoms and vice versa. 


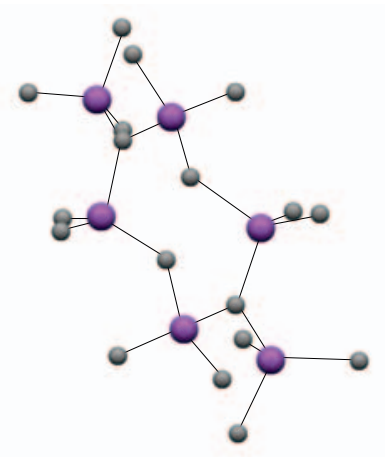

FIGURE 4.4: Network of silicon nitride tetrahedra in which each Si atom coordinates four $\mathrm{N}$ atoms and each $\mathrm{N}$ atom coordinates three Si atoms.
$\mathrm{Si}$ and $\mathrm{N}$ form the stable compound $\mathrm{Si}_{3} \mathrm{~N}_{4}$. The two most common phases are the trigonal $\alpha$-phase and the hexagonal $\beta$ phase. ${ }^{132}$ The cubic spinel $\gamma$-phase can only be synthesized under high-pressure and high-temperature conditions. ${ }^{133}$ In addition, $\mathrm{Si}_{3} \mathrm{~N}_{4}$ also forms an amorphous polymorph. This is the most common structure for $\mathrm{Si}_{3} \mathrm{~N}_{4}$ thin films, due to the strong covalent bonding between $\mathrm{Si}$ and $\mathrm{N}$ that suppresses crystallization. ${ }^{134}$

The building block in $\mathrm{Si}_{3} \mathrm{~N}_{4}$ is based on the $\mathrm{SiN}_{4}$-tetrahedron. The tetrahedra are arranged in such a way that every $\mathrm{Si}$ atom coordinates four $\mathrm{N}$ atoms and every $\mathrm{N}$ atom coordinates three $\mathrm{Si}$ atoms, see Figure 4.4. The tetrahedra are stacked so that they form alternating layers of silicon and nitrogen with a sequence $\mathrm{ABAB}$ for the hexagonal $\beta$-phase and $\mathrm{ABCDABCD}$ for the trigonal $\alpha$-phase. The layers $\mathrm{A}$ and $\mathrm{B}$ are the same in both phases, and the $C$ and $D$ planes are related to the layers $A$ and $B$ by c-axis glide planes. The unit cell parameters are $a=7.75 \AA$ and $c=5.62 \AA$ for the $\alpha$-phase ${ }^{135}$ and $a=7.61 \AA$ and $c=2.91 \AA$ for the $\beta$-phase. ${ }^{135}$

In the cubic spinel-type $\gamma-\mathrm{Si}_{3} \mathrm{~N}_{4}$ the silicon atoms are both four-and six-fold coordinated with nitrogen, so that two silicon atoms coordinate six nitrogen atoms octahedrally, and one silicon atom coordinates four nitrogen atoms tetrahedrally. To reflect this relationship an alternative notation, $\mathrm{Si}\left[\mathrm{Si}_{2} \mathrm{~N}_{4}\right]$, has been suggested. The unit cell parameter is $a=7.80 \pm 0.08 \AA .{ }^{133}$

\section{TITANIUM BORIDE}

The most technologically important Ti-B compound is titanium diboride, $\mathrm{TiB}_{2}$. It has attracted much interest as a wear-resistant coating due to its high hardness, $33 \mathrm{GPa},{ }^{136,137}$ but is also used as a base material for cutting tool inserts. It has a high melting temperature $\left(\sim 3200{ }^{\circ} \mathrm{C}\right)$, high thermal conductivity and is resistant to oxidation in air up to $1100{ }^{\circ} \mathrm{C} .{ }^{138} \mathrm{TiB}_{2}$ is also used in the aluminum industry as a grain refiner, since it has low solubility in molten aluminum. ${ }^{139}$

In $\mathrm{TiB}_{2}$, Ti and B form in a hexagonal close packed $(h c p)$ structure, the so-called $\mathrm{AlB}_{2}$-structure, where the $\mathrm{B}$-atoms form graphitic like sheets with alternating layers of $\mathrm{Ti}$, see Figure 4.5. The basis is a tetrahedra where each Ti atom coordinates three $\mathrm{B}$ atoms. The unit cell parameters are $a=3.03 \AA$, and $c=3.23 \AA .{ }^{140}$ Other possible crystal structures for Ti-B has also been reported: orthorombic $\mathrm{TiB}$ (FeB-type), ${ }^{141}$ orthorombic $\mathrm{Ti}_{3} \mathrm{~B}_{4}\left(\mathrm{Ta}_{3} \mathrm{~B}_{4}\right.$-type), ${ }^{142}$ and cubic $\mathrm{TiB}$ (NaCl-type). ${ }^{143}$

\section{ALUMINUM BORIDE}

Aluminum boride includes two compounds - $\mathrm{AlB}_{2}$ (aluminium diboride) and $\mathrm{AlB}_{12}$ (aluminium dodecaboride). Aluminium diboride forms in the same hexagonal close packed structure as 
$\mathrm{TiB}_{2}$. $\mathrm{AlB}_{12}$ is used instead of diamond dust in grinding operations. Aluminium diboride on the other hand is considered to be hazardous since it reacts with acids and hydrogen gas to produce toxic gases, e.g. borane. The unit cell parameter for $\mathrm{AlB}_{2}$ is $a=3.00 \AA$, and $c=3.25 \AA .{ }^{144}$

The exact number of crystalline forms of $\mathrm{AlB}_{12}$ is not certain. The low temperature modification is the tetragonal $\alpha$-phase. In addition, $\mathrm{AlB}_{10}, \beta-\mathrm{AlB}_{12}$, and $\gamma-\mathrm{AlB}_{12}$ have been reported, but there has been a debate on whether these structures are stable or not. ${ }^{139}$ Nevertheless, the structures are very similar to the $B_{12}$ and $\mathrm{B}_{20}$ units, that builds up a three-dimensional network. ${ }^{145}$

\section{BORON NITRIDE}

Boron nitride exists in several different polymorphs, with fundamentally different properties, and thus different areas of application. The most stable structure is the hexagonal form, $\alpha$-BN or h-BN, which is similar to graphite. It is the softest of all BN polymorphs and is used as a lubricant. The lubricating properties of $\mathrm{BN}$ is not reliant on water or gas molecules being trapped in the structure, and therefore it can be used as a lubricant also in vacuum. In addition, h-BN also has widespread use in cosmetic products. ${ }^{146}$

The hexagonal structure consists of mixed B and $\mathrm{N}$ layers, where the atoms within each layer are bound by strong covalent bonds, while the layers are held together by weaker van der Waals bonds. ${ }^{100}$ The layers are stacked in such a way that each B atom is on top of a $\mathrm{N}$ atom, and vice versa. The unit cell parameters for h-BN are $a=2.55 \AA$, and $c=4.22 \AA .{ }^{147}$

The other thermodynamically stable phase of $\mathrm{BN}$ is the cubic phase, c-BN or $\beta$-BN, which is formed in the zinc-blende structure. Due to its similarity with diamond, c-BN exhibits extreme hardness, ${ }^{148}$ but shows superior thermal and chemical stability properties compared to diamond. Cubic $\mathrm{BN}$ is produced by treating h-BN at high temperatures and high pressures. Thanks to the excellent thermal and chemical stability c-BN is widely used for high-temperature equipment, including cutting tool inserts.

There is also a rare wurtzite structure of $\mathrm{BN}(\gamma-\mathrm{BN}$ or $\mathrm{w}-\mathrm{BN})$, which also is synthesized from h-BN at high temperatures and high pressures. ${ }^{102}$ In both c-BN and $\mathrm{w}-\mathrm{BN}$ the $\mathrm{B}$ and $\mathrm{N}$ atoms are grouped into tetrahedra. During synthesis of $\mathrm{w}-\mathrm{BN}$, the basal planes split into two planes, one containing $B$ atoms and one containing $\mathrm{N}$ atoms.

Rhombohedral BN (r-BN) is $\mathrm{sp}^{2}$-bonded, ${ }^{149}$ but has a stacking sequence of three layers instead of two as for h-BN. BN can also form in less-defined structures including amorphous, ${ }^{150,151,152}$ fullerene-like, ${ }^{153,154,155}$ and a turbostratic polymorph ${ }^{156,157}$ that was observed in Paper II.

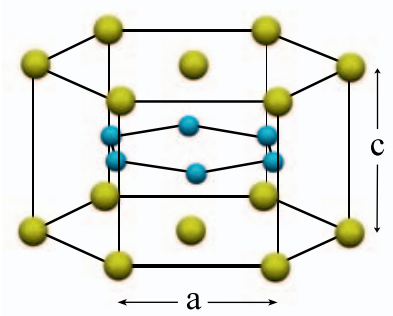

FIGURE 4.5: $\mathrm{AlB}_{2}$-structure with alternating layers of $B$ and Al or Ti.

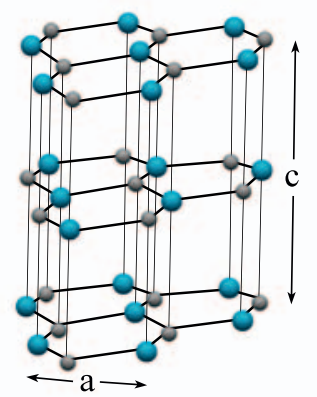

FIGURE 4.6: Hexagonal BN structure with mixed $\mathrm{B}$ and $\mathrm{N}$ layers stacked so that each B is on top of a $\mathrm{N}$ atom and vice versa. 



\section{PHASE STABILITY AND METASTABLE PHASES}

The thin films in this work are metastable. Metastability refers to a state where the system is locally stable and might be unaffected by small fluctuations (like variations in temperature and/or pressure), but where a global minimum in free energy exist, at which the system is in equilibrium. An illustration of this can be found in Figure 5.1. At point $A$, the system is at a local minimum. If the system can overcome the energy barrier at $\mathrm{B}$ it can achieve its most energetically favorable state at position $\mathrm{C}$, where the global minimum is.

This can also be realized for an alloy system by studying the free energy diagram for a hypothetical alloy, $\mathrm{A}_{1-x} \mathrm{~B}_{x}$, shown in Figure 5.2. To construct these diagrams one draws the molar free energy curves for each phase, $\alpha$, and $\beta$. Since there are variations in entropy and in electronic binding energy that vary with composition, also the molar free energy will vary. From the curve it is fairly straight-forward to see that for an A-rich alloy the $\alpha$-phase will have lowest free energy, and for a B-rich alloy the $\beta$ phase is most favorable. In the region near point $Z$, the total energy might be minimized if the atoms separate into two phases. For this separation, or decomposition, to take place the atoms need to diffuse over considerable distances, and this will only happen at high enough temperatures, even if there are no other barriers for separation. The low deposition temperatures employed in PVD techniques make it possible to deposit metastable alloys far from thermodynamical equilibrium conditions.

\section{Nucleation and growth}

In solid materials, most phase transformations are a result of diffusional nucleation and growth. ${ }^{158}$ For the hypothetical alloy system in Figure 5.2, phase $\beta$ at composition $X$ could lower its free energy if it could transform itself into phase $\alpha$ instead. This transformation can occur and it begins by formation of small particles, nuclei, with different phase than that of the matrix that surrounds them. The nuclei have to form interfaces to the matrix phase. This requires energy, meaning that the energy gain by reducing the system energy must be larger than the energy needed for forming the interfaces. When the nuclei have reached a critical size the gain in binding energy is larger than the loss in surface energy and the nuclei will start to grow. Eventually, the material will only consist of the lower-energy phase.

The nucleation process occurs during the most early stages of phase change. For thin films, the nucleation process is of uttermost importance, since the grain structure that develops is 


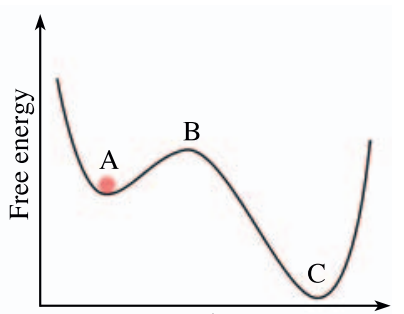

Reaction way

FIGURE 5.1: Schematic illustration of metastability. Point $A$ is a local minimum where the system is in a metastable state, whereas point $C$ shows a global minimum corresponding to a stable configuration. The energy barrier $B$ must be overcome to achieve the most energetically favorable state.

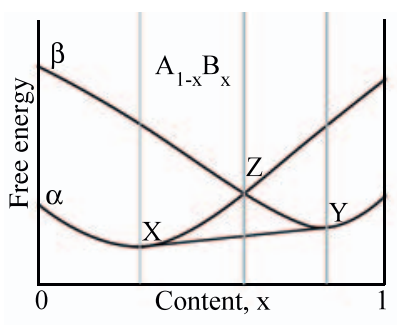

FIGURE 5.2: Free energy diagram of a hypothetical alloy $\mathrm{A}_{1-x} \mathrm{~B}_{x}$. strongly influenced by what happens during film nucleation and subsequent growth. ${ }^{3}$

Nucleation occurs either homogeneously or heterogeneously. Homogenous nucleation means that the nucleation occurs without presence of any heterogeneities, whereas heterogeneous nucleation start at heterogeneities, which can be, e.g., the walls of the container, insoluble particles or free surfaces. ${ }^{12}$ Heterogeneous nucleation is most commonly occurring, but is not as well understood as homogenous nucleation.

\section{HOMOGENEOUS NUCLEATION}

The change in free energy per mole of a system is given by:

$$
\Delta G=\Delta H-T \Delta S
$$

where $\Delta H$ is the change in enthalpy, $\Delta S$ the change in entropy, and $T$ is the temperature. If we assume that a liquid is at its melting point, $T=T_{m}$, the change in free energy that is associated with the transformation from solid-to-liquid is zero $(\Delta G=0)$, the corresponding changes in enthalpy, $\Delta H$, and entropy, $\Delta S$, is given by: ${ }^{12}$

$$
\Delta S=\frac{\Delta H}{T_{m}} .
$$

If the temperature is lower than $T_{m}$, the system will lower its energy by forming a solid. The change in free energy for the transformation is given by the difference in energy between the supercooled liquid and the solid phase. If we assume that a small supercooling does not influence the changes in the entropy and enthalpy, it follows that: ${ }^{12}$

$$
\Delta G_{v}=\Delta H-T \Delta S \approx \Delta H-T \frac{\Delta H}{T_{m}}=\Delta H\left(\frac{\Delta T}{T_{m}}\right),
$$

where $\Delta G_{v}$ is the free-energy change of the transformation. This means that the driving force for nucleation increases linearly with increasing supercooling.

The energy changes that affect homogeneous nucleation include the volume free energy that is released as a result of the liquid-to-solid transformation, the surface energy required for formation of new surfaces, and the strain energy that results from volume changes.

If we omit any strain effects, and assume that spherical nuclei form in the liquid, with interfacial energy $\gamma$, and radius $r$, the energy gained from their formation, is given by: ${ }^{12}$

$$
\text { volume free energy }=-\frac{4}{3} \pi r^{3} \frac{\Delta G_{v}}{V_{m}}=-\frac{4}{3} \pi r^{3} \frac{\Delta H_{f}}{V_{m}}\left(\frac{\Delta T}{T_{m}}\right),
$$


where $V_{m}$ is the molar volume of the solid phase. The energy required for formation of the nuclei is given by:

$$
\text { surface energy }=4 \pi r^{2} \gamma \text {. }
$$

The sum of the volume free energy and the surface energy is called the excess free-energy, and is a measure of the total energy change in the system when a nucleus is formed. Since the energy that is needed for formation of new surfaces scales with $r^{2}$, whereas the volume energy term scales with $r^{3}$, the excess freeenergy function goes through a maximum at a certain radius, called the critical radius, $r_{c}$. This means that when the radius of a cluster is smaller than $r_{c}$ the energy of the system is locally increased. These small clusters are more likely to dissolve, than to grow. However, sometimes the clusters becomes large enough and form a nucleus which has equal probability of growing or decaying. ${ }^{3,158}$

The rate of the homogenous nucleation is dependent on the kinetic and thermodynamic barriers to nucleation. The latter is, in turn, dependent on $\Delta G_{c}$, which is the energy barrier the system has to overcome to form a nuclei, see Figure 5.3. $\Delta G_{c}$ is reduced as the supercooling increases, but at the same time the atomic mobility is reduced, so that the thermodynamic barrier goes through a maximum as a function of the supercooling. ${ }^{158}$ The kinetic term is related to the frequency of successful atom jumps across the nucleus-liquid interface, a parameter that, of course, is difficult to measure. However, the frequency of successful jumps is related to the viscosity, which was mentioned in Chapter 2 as an important property of a glass, and is possible to measure experimentally. ${ }^{12}$

\section{HETEROGENEOUS NUCLEATION}

The other type of nucleation is the heterogeneous one, which is much more common. The majority of nucleation is heterogeneous and occurs at defects such as the previously mentioned container walls, but also at dislocations, interfaces or grains. This is utilized in industry where insoluble particles are added to a melt where they act as nucleation sites, and reduces the grain size of the solid material. These sites are regions of higher free energy, and they tend to reduce the interfacial energy, which means that nucleation occurs at smaller supercoolings, where homogeneous nucleation is unlikely.

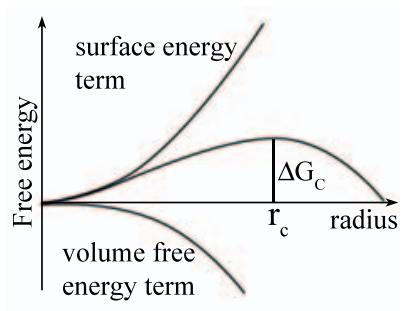

FIGURE 5.3: Free energy change vs. the radius of a spherical nucleus in homogeneous nucleation. 


\section{CRITERIA FOR GLASS FORMATION}

For a liquid to solidify as a glass, a few criteria must be fulfilled. ${ }^{12}$ These include:

- a low nucleation rate for the possible crystalline phase,

- a high viscosity near the melting point of the glass,

- and absence of nucleating heterogeneities.

Based on the first two criteria it has been experimentally shown that the atom mobility, reflected in the viscosity at the melting point, is the by far most important factor. ${ }^{12}$

\section{Thin film growth}

Thin film growth is also a phase transformation, however, not a liquid-to-solid one but a vapor-to-solid transformation. In thin film growth, vaporized atoms condensate on an object and form a solid film, involving a nucleation and growth process.

When the sputtered or evaporated species arrive at the substrate, they move on the substrate surface and gather to form small clusters or islands. These islands are more or less evenly distributed over the surface. Impinging atoms are drawn to the islands that grow larger and increase in density. The coalescence of the islands decreases their density and creates uncovered areas on the substrate where nucleation can continue. ${ }^{3}$ Finally the islands merge into a film.

\section{MICROSTRUCTURE EVOLUTION}

The mobility of the adatoms on the surface determines the microstructure of the growing film. If the surface diffusivity is high, the adatoms are able to travel greater distances and form large grains. If the surface diffusivity is low, the adatoms will be trapped at low-energy lattice positions, creating many nucleation sites at the substrate. These nucleation sites will grow individually and form a columnar structured film. A way of illustrating the effect of deposition parameters on the resulting structure is often done in a so-called structure zone diagram (SZD). These diagrams were developed for evaporation in $1969,{ }^{159}$ and for sputtering in 1974. ${ }^{160}$ A diagram for plasma-based depositions was presented more recently, ${ }^{161}$ see Figure 5.4.

The structure zone diagram for plasma-based depositions describes the microstructure as a function of the generalized temperature $T^{\star}$, the normalized energy $E^{\star}$, and the net film thickness $t^{\star}$. The generalized temperature includes both the homologous temperature $T_{h}$, which is the ratio of the substrate temperature $T_{s}$ over the melting temperature $T_{m}$ in $\mathrm{K}$, and a temperature 


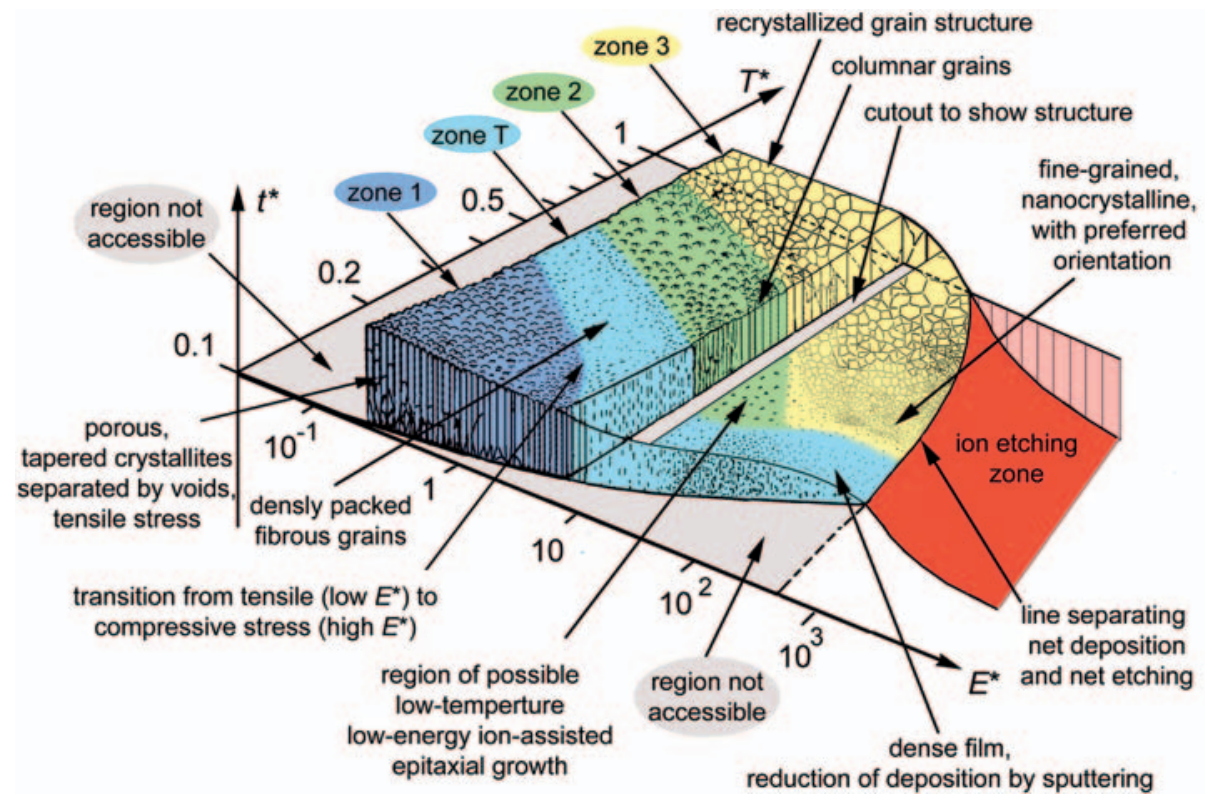

shift that is caused by the potential energy of the particles arriving on the surface. The normalized energy $E^{\star}$ describes the displacement and heating effects that are caused by the kinetic energy of particles bombarding the surface, e.g., when the substrate is biased. The net film thickness illustrates the microstructure of the films as they grow, and also show the effect of densification of the films, as well as possible ion etching.

The diagram suggested by Anders ${ }^{161}$ is divided into four zones, where zone 1 represents growth at low temperatures and low energy. Here, the adatom mobility is low which favors growth of textured porous films. Zone $\mathrm{T}$ is a transition zone, where the surface diffusivity is improved compared with zone 1, but it is limited over grains boundaries, which lead to V-shaped grains. In zone 2, the surface diffusivity is higher and not limited by grain boundaries, thus leading to uniform columnar grain growth. Zone 3 involves high temperature and high energy, where bulk diffusion is allowed and recrystallization and densification of large grains occur.

The awake reader now realizes that amorphous films are not represented in the SZD in Figure 5.4. This very well illustrates that most interest in this field, until now, has been focused towards crystalline thin films. Growth of amorphous films is highly dependent on the deposition rate and the substrate temperature, and in very general terms it can be said that high substrate temperatures and low deposition rates is associated with large grains or single crystals. And the other way around; low substrate tem-
FIGURE 5.4: Structure zone diagram for plasma-based thin film deposition from Anders. 161 (c) 2010 Elsevier B.V. Reprinted with permission. 


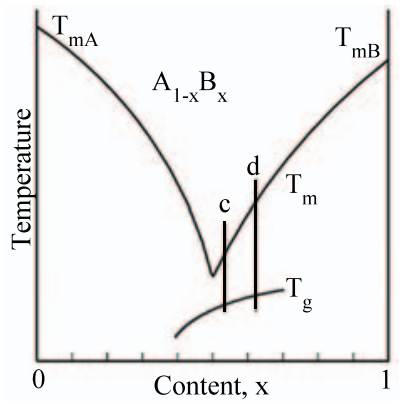

FIGURE 5.5: A simplified binary phase diagram of a hypothetic alloy $\mathrm{A}_{1-x} \mathrm{~B}_{x}$ with a deep eutectic point. peratures and high deposition rates yield polycrystalline or even amorphous films.

According to most structure zone diagrams a necessary (but not sufficient) condition for formation of amorphous phases is that $T_{h}$ is smaller than 0.3. These films are expected to be porous, but in this work I have shown that it is possible to grow amorphous films that also are dense.

\section{FORMATION OF AMORPHOUS THIN FILMS}

As already mentioned, for amorphous solids it becomes a profound practical problem of realizing extremely fast cooling rates (from $1 \mathrm{~K} / \mathrm{s}$ for oxides to $>10^{6} \mathrm{~K} / \mathrm{s}$ for elemental metals ${ }^{158}$ ) for a given volume. For thin films, fast cooling rates are not a concern since the film condensate from the vapor phase. On the other hand, for growing amorphous thin films, the atoms need to be hindered from finding their equilibrium positions in the lattice. This requires high deposition rates and low substrate temperatures. Low substrate temperatures freezes the impinging adatoms on the substrate and prevents them from diffusing and finding equilibrium lattice sites. High deposition rates mean that the atoms will not have time to move far on the substrate to find such favored positions before yet another adatom arrives at the surface. The atoms will thus be trapped in unfavorable positions and are covered in the growing film. There are ways to affect the growth, not only by lowering the deposition temperature. Large doses of implanted ions on the growing film can also, by momentum transfer, dissociate any emerging crystallites.

In general, the formation of amorphous phases is promoted in alloy systems where: ${ }^{162,163}$

1. The heat of mixing is strongly negative, hence in systems with strong tendency for compound formation.

2. There are large differences $(>10 \%)$ in atomic size.

3. The phase diagram contains deep eutectic points.

The trend is that the glass-forming ability tend to be larger for binary materials than for elemental ones. The components in a binary alloy hinder the mobility of each other, but this effect is also attributed to the relation between the glass transition temperature $T_{g}$, and the melting temperature $T_{m}$, as previously mentioned. Figure 5.5 shows a phase diagram for a binary system, $\mathrm{A}_{1-x} \mathrm{~B}_{x}(0<\mathrm{x}<1)$. For the alloy, the liquid is stabilized and the melting point $T_{m}$ is lowered as compared with the single-element end points $x=0$ and $x=1$. There is a eutectic composition at $x=0.5$ at which the melting point $T_{m}$ is minimized. Near the eutectic composition, at point $c$ in the figure, the liquid is much more readily quenched to the glass phase than at a composition corresponding to point $d$, since the distance between $T_{m}$ and $T_{g}$ is 
much larger at $d$ than at $c$. The distance is even smaller at the eutectic composition, meaning that this composition would be favored for formation of amorphous solids.

\section{SPINODAL DECOMPOSITION}

Growth by PVD makes it possible to create systems where the components normally are immiscible. It is even possible to create systems where there is no free energy barrier for nucleation. Such systems are stabilized only by diffusion barriers and are thermodynamically unstable since any local compositional fluctuations will be amplified if the films are exposed to high temperatures, for example during annealing experiments or cutting operations. This is called spinodal decomposition and means that there will be areas in the film with different composition and also different physical properties. For most crystalline solid solutions, a difference in composition comes with a variation in lattice parameter, and in order to retain the lattice structure so-called coherency strains are introduced in the material.

Figure 5.6 shows a free energy curve and corresponding phase diagram for a system with immiscible components. Alloys within the unstable, spinodal, region will undergo spinodal decomposition without any preceding nucleation. ${ }^{164}$

\section{AGE HARDENING}

Age hardening is a hardening phenomenon that occurs when precipitates form in a material, for example when it undergoes phase decomposition during annealing. An example of this is found during spinodal decomposition of TiAlN, ${ }^{165}$ where cubic TiAlN decomposes into c-TiN and c-AlN, and the later finally into h-AlN. The first transformation is attributed to an increased hardness that is lost when hexagonal AlN is formed.

The small particles, or precipitates, hinder defect formation and dislocation movement in the material, leading to increased hardness. If precipitates are present in the matrix, dislocations will be arrested, go around, or cut right through them, which is, irrespective of which, more difficult than traveling through a homogeneous matrix. Introducing precipitates with the right size in a material is a difficult process, and in the case of too little diffusion - under aging - the particles will be to small to hinder dislocations effectively. Too much diffusion will cause formation of large precipitates that are dispersed and interact within most dislocations.

An example of age hardening in this work is found in Paper I, where initially x-ray amorphous $\left(\mathrm{Ti}_{0.26} \mathrm{Al}_{0.46} \mathrm{Si}_{0.28}\right) \mathrm{N}_{1.17}$ thin films show a linear increase in hardness with increasing annealing temperature up to $1000{ }^{\circ} \mathrm{C}$, due to formation of nanocrystals in the films.

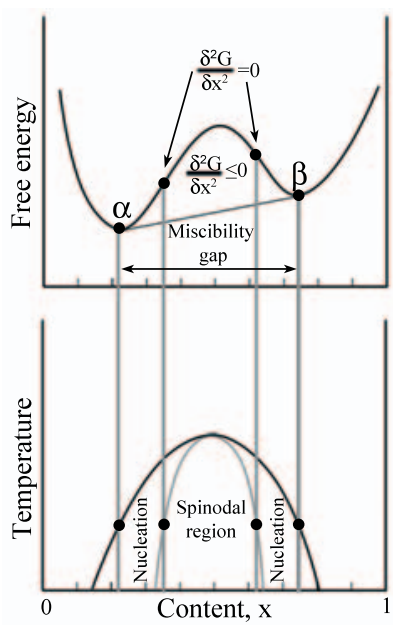

FIGURE 5.6: Free energy curve and corresponding phase diagram for a system with immiscible components. 



\section{CHARACTERIZATION TECHNIQUES}

Several different analysis techniques and instruments are needed to determine the nature of a thin film. In this thesis a combination of $\mathrm{x}$-ray diffraction (XRD), x-ray reflectivity (XRR), analytical transmission electron microscopy (TEM), scanning electron microscopy (SEM), energy dispersive x-ray spectroscopy (EDX), Rutherford backscattering spectrometry (RBS), elastic recoil detection analysis (ERDA), x-ray photoelectron spectroscopy (XPS), and nanoindentation, was used to determine composition, microstructure, and mechanical properties of the films.

\section{$X$-ray diffraction}

X-rays were detected by the German physicist Wilhelm Conrad Röntgen in 1895, for which he was awarded the first Noble Prize in Physics in 1901.

X-rays are electromagnetic waves with a wavelength of 0.01 $10 \mathrm{~nm}$, which was discovered in 1912 by Max von Laue. This, together with the discovery that atoms are periodically ordered in crystals and that they can scatter x-rays, made him the Nobel laureate in Physics in 1914. The wavelengths of x-rays are in the same order of magnitude as the interatomic spacing in crystals (0.15-0.4 nm), which make them suitable for characterization of crystal structures. ${ }^{166}$

$\mathrm{X}$-ray diffraction (XRD) is a non-destructive technique that is much used, since there is no need for complicated sample preparation, and the evaluation is often quick and straight-forward. It is a versatile technique that can be used for characterization of crystal structures, detection of phase transformations, measurement of residual stress, thickness measurement, etc.

$\mathrm{XRD}$ is based on the principle of scattering. When x-rays enter condensed matter they scatter in all directions, giving rise to constructive and destructive interference. This phenomena was first described by William Lawrence Bragg in 1912, which earned him the Nobel Prize in Physics in 1915 (jointly awarded to him and his father William Henry Bragg "for their service in the analysis of crystal structure by means of X-rays"). ${ }^{167}$ The relationship is called Bragg's law:

$$
2 d \sin \theta=n \lambda,
$$

where $d$ is the lattice plane distance, $\theta$ is the scattering angle, $\lambda$ the wavelength of the x-rays, and $n$ is an integer. Bragg's law states an intensity maximum for an integer number of wavelengths, see also Figure 6.1. In the case of constructive interference, intensities add up and show as peaks, while in destructive interference x-rays cancel each other.

In an x-ray tube electrically charged particles are accelerated towards an anode plate from where the x-rays are emitted. Com- 


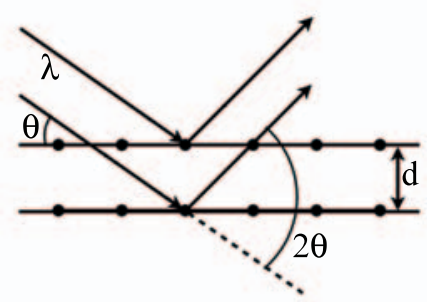

FIGURE 6.1: Schematic illustration of x-ray diffraction according to Bragg's law, Equation 6.1.
FIGURE 6.2: A typical diffractogram showing Ti-Al-Si-N films that are a) nanocrystalline, and b) x-ray amorphous. Peaks underneath the grey areas correspond to the substrate. mon anode materials are high purity metals such as copper, chromium, or molybdenum. ${ }^{166}$ Different elements give rise to slightly different wavelengths. In this thesis, diffractometers with $\mathrm{Cu}$ anodes have been used exclusively. By using a Ni filter at the exit of the x-ray tube, $\mathrm{Cu} \mathrm{K} \mathrm{K}_{\beta}$-radiation is filtered out, and only $\mathrm{Cu} \mathrm{K} \alpha$ with a wavelength of $1.54 \AA$ is left.

In symmetric $\theta-2 \theta$ scans the incident beam angle changes at half the rate of the outgoing beam, which gives peaks at characteristic $2 \theta$ values, so-called Bragg angles. The incident and outgoing beams have equal angles with respect to the sample surface, thus the scattering vector is always normal to the sample surface, meaning that only reflections from lattice planes parallel to the sample surface contribute to the peaks. Not only the peak positions, but also the shape of the peaks can give valuable information. If the sample is textured, i.e., has preferred growth in one specific lattice direction, it will change the relative height of the peaks. Also, crystalline grain size affects the peak width and it is possible to estimate the crystallite grain size using Scherrer's equation:

$$
D=\frac{K_{s} \lambda}{\beta \cos \theta},
$$

where $D$ is the crystalline grain size, $K_{s}$ is a geometrical shape factor, $\lambda$ the wavelength of the x-rays, $\beta$ is the peak width (integral breadth or full width at half maximum (FWHM)), and $\theta$ is the scattering angle. In Paper I, FWHM was used to calculate the crystalline grain size. Small grain sizes will give broad and diffuse peaks, and if the sample consist of randomly oriented crystallites smaller than 2-5 nm, it may not be possible to detect them due to severe peak broadening. A sample like that is regarded $x-$ ray amorphous. Figure 6.2 shows an example of a diffractogram with a crystalline and an x-ray amorphous sample.

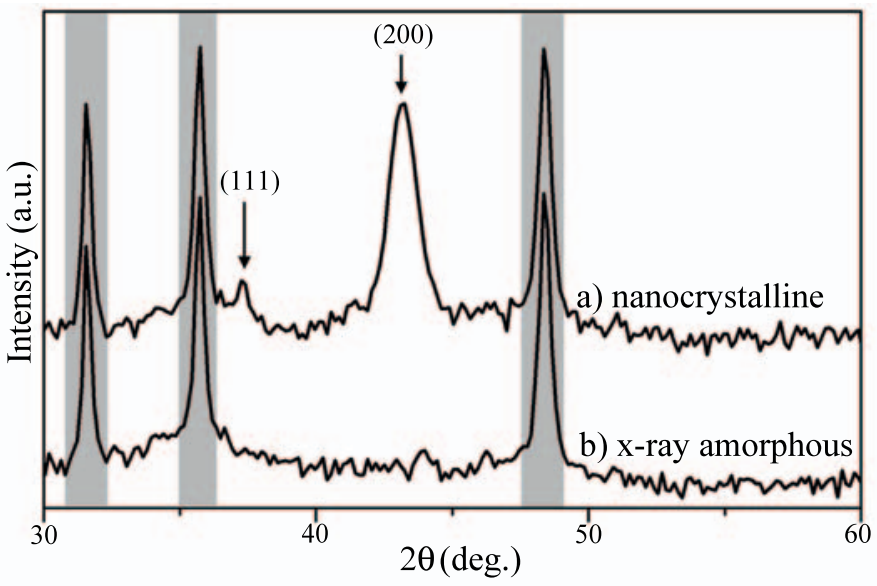


STRESS MEASUREMENTS - THE $\sin ^{2} \Psi$-METHOD

X-ray diffraction can be used for measurement of residual stress in coatings and thin films, which was done in Paper I.

The determination of stress $(\sigma)$ is based on the measurement of strain $(\varepsilon)$, where the strain is a measure of the average amount of elastic deformation, and is given by the difference in lattice plane spacing $(d)$ compared to the unstrained lattice spacing $\left(d_{0}\right)$ :

$$
\varepsilon=\frac{d-d_{0}}{d_{0}} .
$$

The relationship between stress and strain is given by Hooke's law ${ }^{166,168}$

$$
\varepsilon_{i j}=\frac{1+\nu}{E} \sigma_{i j}-\delta_{i j} \frac{\nu}{E} \sum_{k} \sigma_{k k},
$$

where $E$ is the elastic modulus, and $\nu$ is Poisson's ratio. See, Figure 6.3 for definitions of the stress components for a thin film on a substrate. The stress components, $\sigma_{i j}, i \neq j$, are the shear components.

Using XRD, it is possible to measure the strain by rotating and tilting the sample during measurement. Strain in the film will introduce a shift in the lattice plane spacing, $d_{\Phi \Psi}$, that changes with the tilt angle $\Psi$ and the azimuth angle $\Phi$ (see Figure 6.4 for definition of angles). The strain measured in the $z z$-direction, can now be written as: ${ }^{168}$

$$
\begin{aligned}
\varepsilon_{\Phi \Psi}=\left(\frac{1+\nu}{E}\right) & {\left[\left(\sigma_{x x} \cos ^{2} \Phi+\sigma_{y y} \sin ^{2} \Phi+\sigma_{x y} \sin 2 \Phi\right) \sin ^{2} \Psi\right.} \\
& \left.+\left(\sigma_{x z} \cos \Phi+\sigma_{y z} \sin \Phi\right) \sin 2 \Psi+\sigma_{z z} \cos ^{2} \Psi\right] \\
& \left.+\left(\frac{-\nu}{E}\right)\left(\sigma_{x x}+\sigma_{y y}\right)+\sigma_{z z}\right] .
\end{aligned}
$$

For thin films, it can be assumed that the stress state is biaxial. This means that the strain is only in the in-plane direction, i.e. parallel to the film-substrate interface. Due to symmetry along the growth direction, the in-plane stress components can be simplified to $\sigma_{x x}=\sigma_{y y}=\sigma$, and the out-of-plane componenet $\sigma_{z z}=0$. Biaxial stress assumes zero shear stress components $\left(\sigma_{x y}=\sigma_{x z}=\right.$ $\sigma_{y z}=0$ ), and that the stress has no dependence on the rotation angle $\Phi$. The strain can now be expressed as:

$$
\varepsilon_{\Psi}=\frac{d_{\Psi}-d_{0}}{d_{0}}=\frac{1+\nu}{E} \sigma \sin ^{2} \Psi-2 \frac{\nu}{E} \sigma .
$$

The in-plane stress can either be compressive $(\sigma<0)$ or tensile $(\sigma>0)$. A compressive stress means that there is a contraction of the lattice plane spacing in the in-plane direction, while a tensile stress means an elongation in the in-plane direction. Compressive stress states are common for arc evaporated coatings grown on cemented carbide substrates.

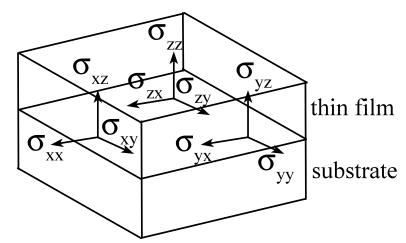

FIGURE 6.3: Definition of sample-related stress tensor $\sigma_{i j}$.

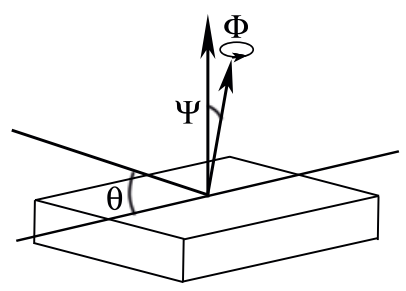

FIGURE 6.4: The rotation angle $\Phi$, and the tilt angle, $\Psi$, for diffraction in the $\theta-2 \theta$ configuration. 
By scanning $\Psi$ over both positive and negative values for a selected Bragg diffraction peak in the $\theta-2 \theta$-configuration, the changes in lattice plane spacing, $d_{\Psi}$, can be recorded. High-angle diffraction peaks give rise to larger peak shifts for different $\Psi$ angles. Therefore it is recommended to use the highest possible diffraction peak when recording the change in lattice plane spacing. In some cases, e.g., for nanocrystalline materials, the highangle peak may have too low intensity to be accurately determined in position, and a low-angle peak must be chosen instead. This was the case in Paper I, when the residual stress was determined using the TiN (002) peak. Using a low-angle peak will increase the error of the measurement.

Plotting $d_{\Psi}$ vs. $\sin ^{2} \Psi$ gives a linear relationship, where the slope of the curve is equal to:

$$
\frac{d_{0}(1+\nu)}{E} \sigma
$$

In order to check for shear stress components $\left(\sigma_{x y}, \sigma_{x z}\right.$, and $\left.\sigma_{y z}\right)$, the sample is tilted to both positive and negative $\Psi$-angles. Nonzero shear stress components will cause a split in the $d_{\Psi}$ vs. $\sin ^{2} \Psi$ data, with different slopes for positive and negative $\Psi$-angles, respectively.

The $\sin ^{2} \Psi$-method provides a simple and straight-forward method to measure the in-plane stress in a thin film. One should, however, be aware that the result is affected by a number of approximations and simplifications. First of all, Equation 6.7 assumes that the unstrained lattice plane spacing $d_{0}$ is known. This value varies even with small compositional changes and is often taken as the lattice plane spacing when $\Psi=0$, even though it in most cases is not a correct approximation. Furthermore, the elastic constants can be anisotropic, i.e. $E$ and $\nu$ are dependent on the orientation. Also, it is often the case that $E$ and $\nu$ are not known for the material under investigation. For most ternary and multicomponent nitrides there are no reliable values reported in literature. In Paper I, values for TiN ( $E=450 \mathrm{GPa}$, and $\nu=0.22$, as given by Sue et. $\mathrm{al}^{169}$ ) was used for determination of residual stress in Ti-Al-Si-N thin films. Other issues include stress gradients and texture anisotropy. Nevertheless, the $\sin ^{2} \Psi$-method gives a useful estimate of the residual stress.

\section{$X$-ray reflectivity}

X-ray reflectivity or x-ray reflectometry (XRR) has been used in this work to determine deposition rates and density in Paper II, density in Paper IV, and multilayer thickness in Paper V. XRR is a surface-sensitive technique, that is based on reflections of $\mathrm{x}$-rays from surfaces and interfaces. It was first described by Parratt in 1954 for the study of thin layers of copper on glass substrates. ${ }^{170}$ 
$\mathrm{XRR}$ is not a diffraction technique, and hence not reliant on the interatomic spacing of atom layers, but only on the difference in refractive index of different media. Therefore, $\mathrm{XRR}$ is an excellent technique to use for all kind of sample morphologies, including amorphous ones.

The measurement is performed in a symmetric $\theta-2 \theta$-configuration, where the reflected angle is equal to the incident angle. The scattering angles are small, usually not exceeding $5-6^{\circ}$. The pathway difference of the x-rays that have been scattered at the substrate and the film surface gives rise to constructive interference that shows as intensity maxima in the recorded scan. For a monolayer film, a modified version of Bragg's law can be deduced as

$$
n \lambda=2 D \sin \theta \sqrt{1+\frac{\eta^{2}-1}{\sin ^{2} \theta}},
$$

where $n$ is an integer, $\lambda$ is the wavelength of the x-rays, $D$ is the film thickness, $\eta$ the complex refractive index of the film, and $\theta$ the scattering angle. Equation 6.8 can be rewritten as

$$
\sin ^{2} \theta=\frac{\lambda^{2} n^{2}}{4 D^{2}}-\left(\eta^{2}-1\right),
$$

and now gives a linear relationship between $n^{2}$ and $\sin ^{2} \theta$. By plotting them against each other, the slope of the curve can be used for calculating the film thickness. For multilayer samples, which can be considered as one dimensional analogues of 3D crystals with reflections occuring at each interface, $D$ corresponds to the multilayer period, and $\eta$ is then the mean refractive index of the multilayer. ${ }^{166}$

\section{DENSITY AND SURFACE ROUGHNESS MEASUREMENTS}

XRR can also be used for density measurements. The reflectivity curve of a sample is directly related to material parameters of the sample, among other the electron density, $\rho_{e}$. The electron density in turn can be converted into the mass density $\rho$. By recording the reflectivity curve of a sample, and fitting that with a theoretical profile, the density can be derived if the composition is known. ${ }^{166}$ In addition, the surface roughness of the sample can be determined by fitting the same curve. A rough surface will cause imperfect interference and the reflected intensity will divert from the theoretical one given by the law of Fresnel reflectivity.

Determining the density and surface roughness of a sample is nowadays very straight-forward, as there are several computer programs available for fitting a recorded reflectivity curve. There are basically three parts of the curve that has to be considered, see Figure 6.5. The first part of the curve shows increasing intensity. The shape of this part is very sensitive to the size of the specimen, or the so-called sample length. The sample length also affects the 
FIGURE 6.5: Typical x-ray reflectivity scans for two Ti-B-Si$\mathrm{N}$ samples showing the critical angle, $\theta_{c}$, and the three regions that have to be fitted for determining the density and surface roughness.

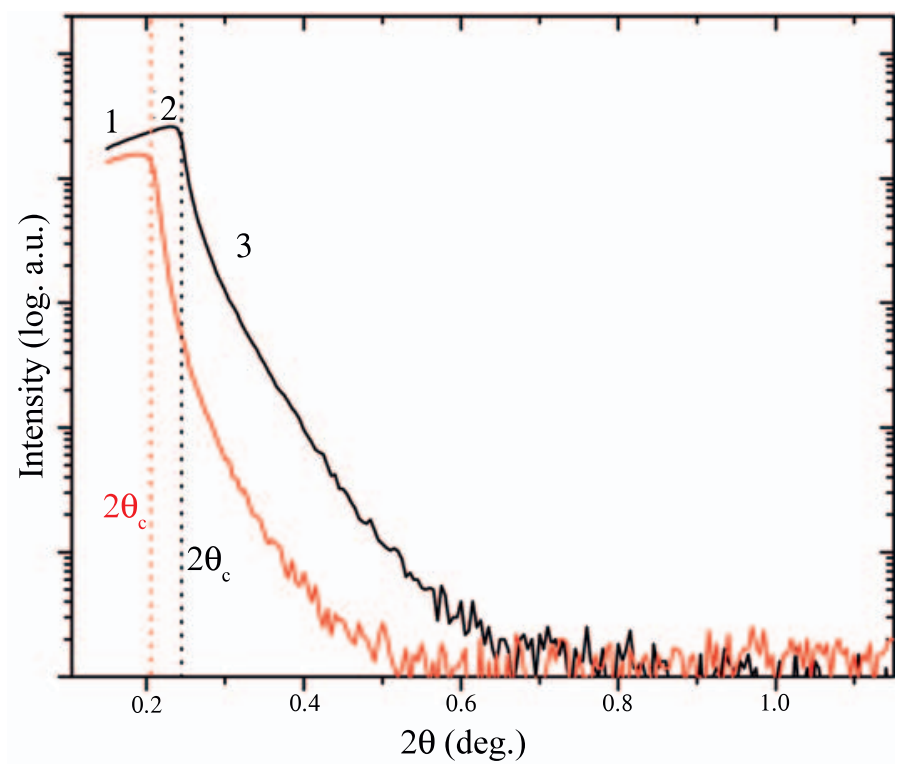

intensity in both the first and second part of the curve, and if the specimen is too small, the critical angle $\theta_{c}$, can not be correctly positioned.

The second part is an intensity plateau, which is caused by total reflection of the primary beam. Close to the critical angle, there is a transition region. The shape of the transition region depends on the $\mathrm{x}$-ray absorption coefficient, $\mu$. Without absorption there would be a sharp drop in intensity at the critical angle. ${ }^{170}$

The critical angle separates the second and third part of the curve. The third part is characterized by a steep decrease in intensity. The decrease is affected by the surface roughness, where a rough surface will cause a steeper decrease than a smooth one.

\section{Electron microscopy}

In electron microscopy the beam that illuminates the sample consists of electrons instead of visible light, as in the case of visible light microscopes (often also referred to as light optical microscopes). The resolution of a microscope can be described by the Rayleigh criterion which states the smallest distance between two objects that can be resolved:

$$
d=0.62 \frac{\lambda}{n \sin \theta},
$$

where $d$ is the resolution, $\lambda$ the wavelength, $n$ the refractive index of the medium, and $\theta$ the angle of the collected light. For an electron microscope operating at an acceleration voltage of $200 \mathrm{kV}$, 
as used here, gives a wavelength in the range of picometers. The best electron microscopes can achieve better than $50 \mathrm{pm}$ resolution $^{171}$ and magnification up to about $50.000 .000 \mathrm{x}$, as compared to the best visible light microscopes that are limited to about 200 $\mathrm{nm}$ resolution and magnifications below 2000x.

In an electron microscope electrostatic and electromagnetic lenses are used to control the electron beam and to focus it to create an image. They have the same task as the glass lenses that are used in visible light microscopes to focus the light.

\section{TEM}

In transmission electron microscopy (TEM) electrons are emitted by an electron gun and accelerated at a voltage of $\sim 200 \mathrm{kV}$ towards the sample. The sample is thin, less than $100 \mathrm{~nm}$, and the beam is partly transmitted through, and partly scattered from the sample. This gives rise to an outgoing beam with different electron intensities, that holds information about the structure of the sample. The various electron intensities are translated into contrast, and the image is projected on a fluorescent screen or recorded by sensors of a CCD camera, which can be displayed on a computer monitor. ${ }^{172}$

If the electron beam only interacts with the sample and then is transferred to the screen, the result will be a low contrast image. To improve contrast, apertures can be placed in the back focal plane of the objective lens to filter away scattered electrons. Only the transmitted electrons now contribute to the image, and a bright field (BF) image with better contrast is obtained. The dominating contrast mechanism in bright field mode is the massthickness contrast that arises from elastic and incoherent scattering of the electrons by the atoms in the sample. Areas that are thick, and that consist of atoms with high mass and high density will scatter more electrons, and will appear dark in a BF image.

The electrons can also be filtered in such a manner that only scattered electrons form the image. The contrast will now be in-
FIGURE 6.6: Setup in bright field (BF) and dark field (DF) mode with corresponding images for a Hf-Al-Si-N sample grown with four layers of different composition.
Bright Field

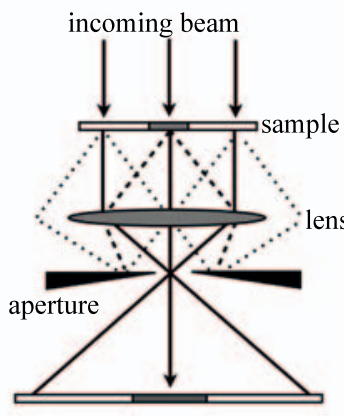

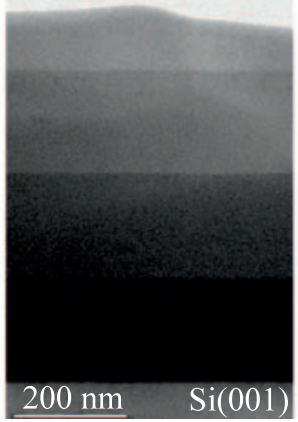

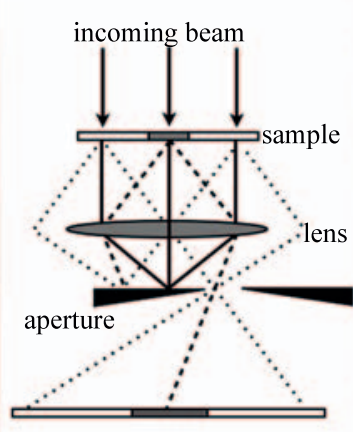

Dark Field

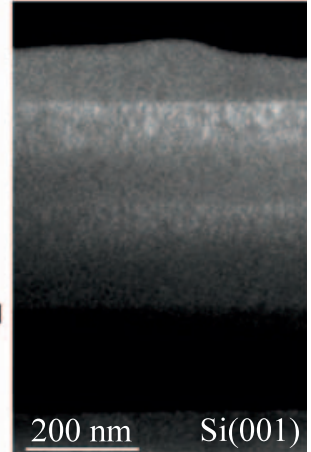


FIGURE 6.7: Typical SAED patterns for a) single-crystal TiC (image courtesy of O. Tengstrand), b) a 200 textured polycrystalline $\mathrm{Hf}-\mathrm{Al}-\mathrm{Si}-\mathrm{N}$ sample, and c) an electron diffraction amorphous Ti-B-Si-N sample showing the characteristic diffuse halo. verse, and the image mode is called dark field (DF). In dark field mode the contrast occurs due to coherent scattering of the electrons at certain Bragg angles. See Figure 6.6 for a schematic image of the different operation modes.

The third contrast mechanism is phase contrast. It requires more than one beam, and is used in high resolution (HR) TEM by using a combination of the transmitted and the diffracted beam. The contrast comes from the pathway difference between the two beams when one of them is scattered. HR-TEM makes it possible to get lattice-resolved images.

Electron diffraction can be used to obtain crystallographic information of the sample. Diffraction occurs in the TEM in a similar manner as in XRD, but a great benefit of electron diffraction compared to $\mathrm{x}$-ray diffraction is that the short wavelength of the electrons makes it possible to probe very small volumes of the sample. ${ }^{172}$ This was the case in Paper I, where the crystallization of h-AlN could not be detected by XRD, but was later detected using electron diffraction in TEM.

When the electron beam is diffracted by the atoms in the sample, and Bragg's law is fulfilled, it gives rise to a diffraction pattern in the back focal plane. By placing an aperture in the back focal plane, certain areas on the sample can be chosen to obtain a diffraction pattern from that specific region by so-called selected area electron diffraction (SAED). SAED patterns can help to determine whether a sample is amorphous, single crystalline or polycrystalline. This is done by studying the shape of the diffraction pattern, where an amorphous sample would yield a diffuse ring pattern, a polycrystalline sample gives a clear or speckled ring pattern, and a single crystal sample would give a dotted pattern, see Figure 6.7. By aligning the central beam along the zone axis, the distance between the rings or dots in the diffraction pattern and the central spot can be used to relate the diffractions based on the Miller indices of the planes from which the respective diffraction origins.

In scanning transmission electron microscopy (STEM), the electron beam is focused to a probe that is scanned across the sam-
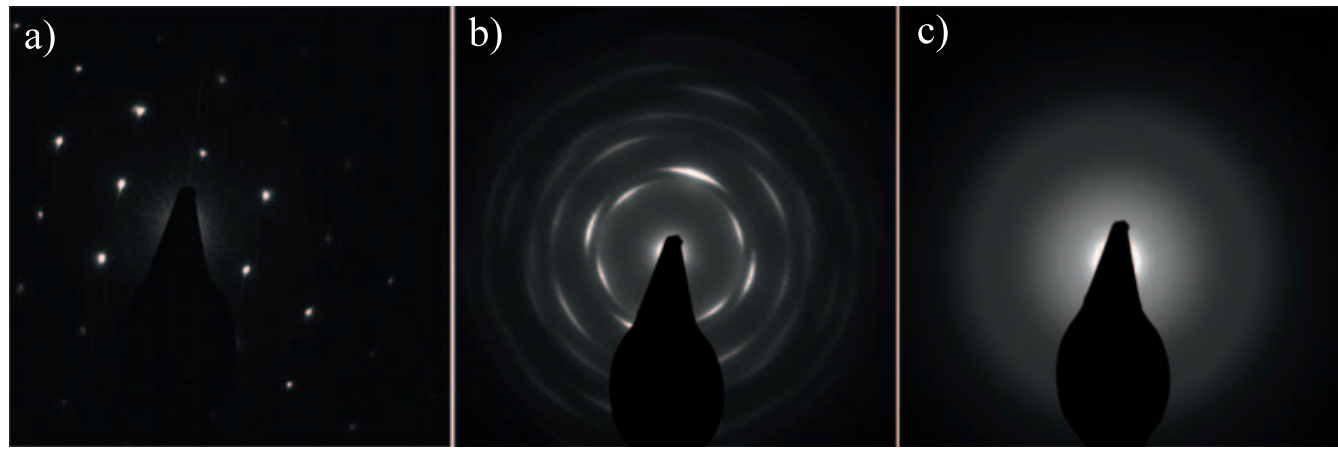
ple. The information is collected in each spot and in combination with a high-angle annular dark-field detector (HAADF), that enhances the Z-contrast, and EDX, this can be used to map areas and determine elemental composition. This is especially useful for samples with both heavy and light elements, and was used in Paper I to investigate the diffusion path of heavy Co and W metals into the Ti-Al-Si-N film after annealing, and in Paper III to evidence the TiN-rich layering.

\section{SAMPLE PREPARATION FOR TEM}

TEM sample preparation can be tedious work, and depending on the sample characteristics different techniques can be used. The most common ones for preparation of ceramic materials include ion beam thinning, focused ion beam (FIB) thinning, crushing or cleaving of samples. In this work I have exclusively been working with mechanical polishing followed by ion beam thinning for both cross-sectional and for plan-view samples. The aim of all TEM sample preparation is to create samples that are so thin that they are electron transparent, meaning that their thickness must be less than $\sim 100 \mathrm{~nm}$. The sample preparation for cross-sectional samples is divided into three steps:

- Sample mounting according to the sandwich method.

- Mechanical polishing.

- Ion beam thinning.

\section{Step 1 - The Sandwich Method}

The so-called sandwich method is used, as it allows for mounting of two different specimens in one sample. The first step is to cut thin strips of the film, using a diamond wheel. The maximum size of one piece should not exceed (W x L x H): $0.3 \mathrm{~mm} \times 1.8 \mathrm{~mm}$ $x$ 0.3-0.5 mm. The height of the sample can vary slightly due to the possibility to use grids of different size $(0.6,0.8$ or $1.0 \mathrm{~mm})$. The small pieces are thoroughly cleaned whereafter they are put together, two-by-two, with the film side facing each other, like a sandwich in the grid, see Figure 6.8. The sides of the grid are pushed together, both from the front and from the back to clamp the sample together. For brittle substrate material, special care has to be taken in order not to break the specimen. When the clamps are holding the pieces together, the grid is placed on $\mathrm{Al}$ foil, covered with a 3:1 powder mixture of an epoxy resin and carbon, and put on a heating plate $\left(180^{\circ} \mathrm{C}\right.$ for 2 hours) for melting the powder and harden the glue.

\section{Step 2 - Mechanical Polishing}

The second step is to mechanically polish the sample to a thickness of $\sim 50 \mu \mathrm{m}$. The mechanical polishing is a preparatory step so that the sample can be further processed by other techniques. 

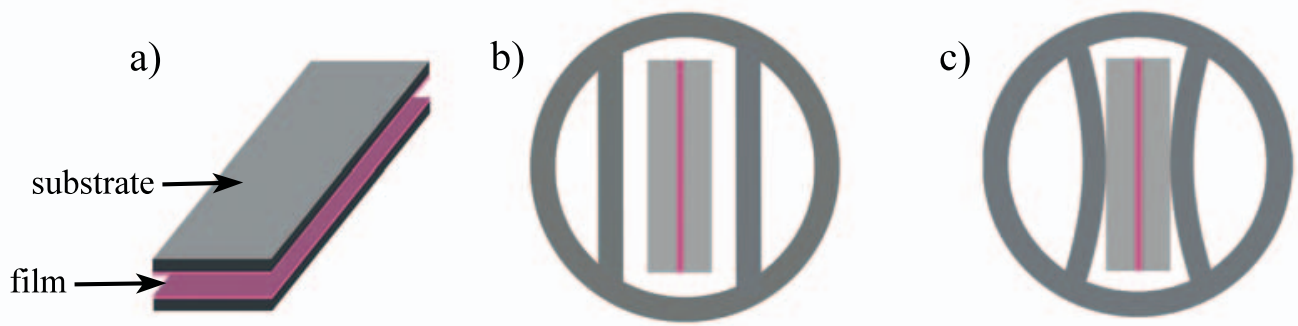

FIGURE 6.8: Sample mounting using the sandwich method with a) two specimens put together with film sides facing, b) inserted into a Ti-grid, and c) clamped together using the transversal bars.
The goal is to obtain a flat and scratch-free surface with little mechanical damage. ${ }^{173}$

First, the sample is removed from the $\mathrm{Al}$ foil, and excess glue surrounding the grid is mechanically removed using a razor blade or a small rasp. The sample is waxed onto a glass slide. First, the sample is thinned by hand to $\sim 300 \mu \mathrm{m}$ using a coarse $(30 \mu \mathrm{m})$ diamond grinding paper with water as a lubricant and coolant. This is followed by finer grinding using $6 \mu \mathrm{m}$-paper for another $30 \mu \mathrm{m}, 3 \mu \mathrm{m}$-paper for $10 \mu \mathrm{m}$, and finally to a mirror-like surface using a $1 \mu \mathrm{m}$-paper. Between each step, the sample is rinsed in water, and blown dry with compressed air, and observed in a visible light microscopy to ensure that scratches from the previous step are removed before continuing. Continuously the thickness of the sample is controlled using a digital gauge, see Figure $6.9 \mathrm{~b}$ ).

When the first side is finished, the sample is turned upside down, and the procedure is repeated. The first grinding step with the coarse paper is continued until a thickness of $96 \mu \mathrm{m}$ is achieved. The following three polishing steps will lead to a final sample thickness of $50 \mu \mathrm{m}$.

\section{Step 3 - Ion Beam Thinning}

The final step of TEM sample preparation is the ion beam thinning or ion milling, where the electron transparency is obtained. The operation principle is simply that when an accelerated ion beam interacts with a specimen, surface atoms of the specimen will be removed. This technique can be used both for crosssectional samples, plan-view samples, and for thinning wedges after cleaving.

The apparatus that I have used is a so-called Precision Ion Polishing System - PIPS. A thorough description of the instrument was published by Alani \& Swann. ${ }^{174}$ In short, the system consists of a chamber with a vacuum in the $10^{-6}$ Torr range, connected to two ion guns, positioned $120^{\circ}$ apart, see Figure 6.10 for a schematic.

The ions are $\mathrm{Ar}^{+}$operated at an energy of 1-6 keV. The thinning rate is maximized by correct alignment of the ion beams, and by adjustment of the gas flow to the beams. The beams can be individually controlled. The angles of the incident beams can 

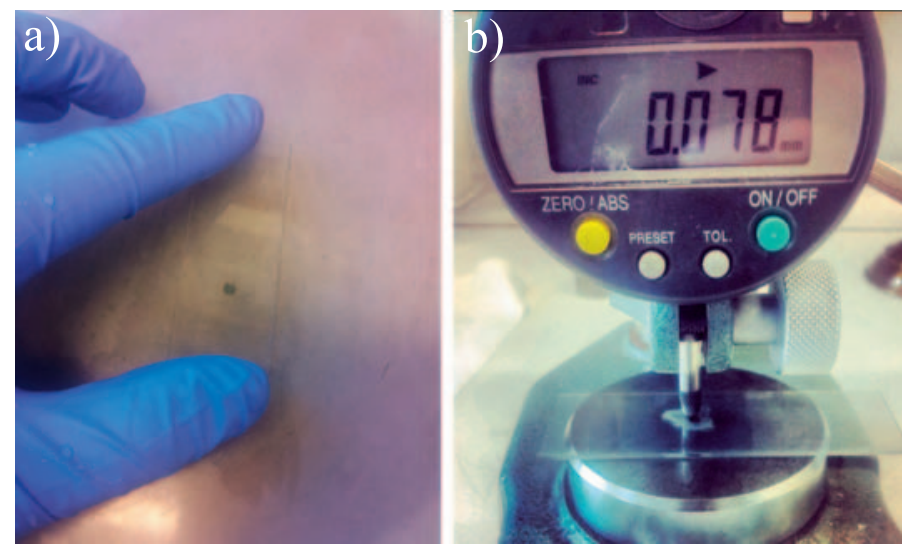

FIGURE 6.9: a) Mechanical polishing by hand, and b) thickness control measurement of a sample glued onto a glass slide.

be adjusted from $-10^{\circ}$ to $+10^{\circ}$. Higher angles will give higher thinning rates, while lower angles give a larger thin region of high quality at the expense of longer milling times.

The system also offer the possibility of beam modulation which is mainly used for cross-sectional samples. ${ }^{175}$ By sequentially turning the guns on and off at various positions along one revolution, the effect of different thinning rates of the specimens in the sample can be minimized. In addition, beam modulation also limits the contamination of sputtered material from parts of the ion miller itself that is in line-of-sight of the ion beams during rotation. There are two options; single-beam and double-beam modulation.

Single beam-modulation uses only one of the guns, and can be used for polishing one sector from one side, or two sectors using different rotation speed within the sectors.

Double beam uses both guns, and the milling occur from both sides. This can be advantageous if the sample is fragile, since milling from only one side can induce stresses in the sample that might break it. There is also a third setting (off) which means that the beam modulation is turned off, and there is continuous milling going on.

When the gas flow to the ion beams have been adjusted, and the proper angle has been selected, the position of the ion beams must be aligned using a fluorescent screen. The sample is then positioned in a special holder that clamps it from both sides, and mounted in the instrument (aligned with the glue-line parallel to the front panel of the instrument so that polishing sectors are $\pm 30^{\circ}$ normal to the sample interface), and lowered into the vacuum chamber.

The sample can be rotated during the operation, and the ongoing process can be observed using the visible light microscope that is placed above the sample holder position. For cross-sectional samples, the milling goes on until there is a small hole in 
FIGURE 6.10: Schematic of ion milling setup showing a) topview, and b) side-view of the system with the two ion guns marked with arrows.

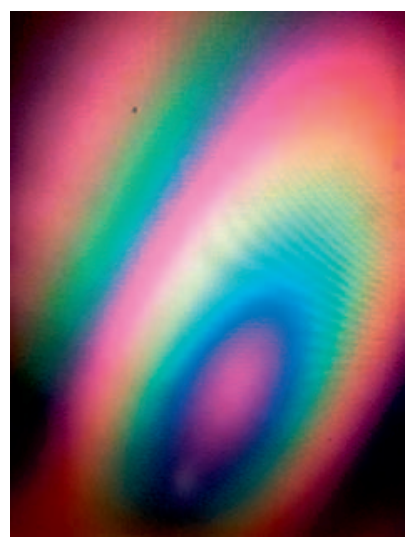

FIGURE 6.11: Interference fringes during ion milling of a plan-view Ti-B-Si-N sample. a)

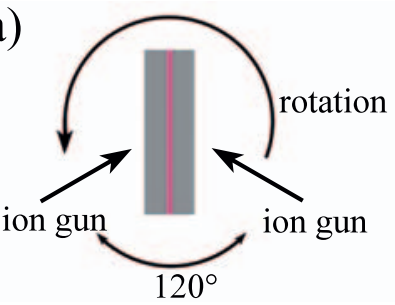

b)

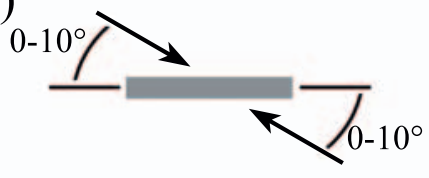

the center of the sample, covering both sides of the interface. By this, there will be very thin regions around the hole that are electron transparent. The last step consists of final polishing of the sample using a lower energy.

For all my cross-sectional TEM samples, I have used an ion energy of $5 \mathrm{keV}$, double-beam modulation, 3 r.p.m. rotation speed, and $6^{\circ}$ gun angles. With this setting I have been running the system until a small hole has formed, then I have decreased the energy to $<1 \mathrm{keV}$ and changed to single-beam modulation for the final polishing step.

\section{Preparation of plan-view samples}

Plan-view samples are prepared by cutting out 3-mm discs from the specimen, either by using an ultrasonic disc cutter, or by hand from a $4 \times 4 \mathrm{~mm}^{2}$ piece that is shaped into a 3-mm disc using abrasive paper. The mechanical polishing is following the same steps as described above, but of course only from the substrate side of the sample, and with thicknesses adjusted accordingly so that the final sample has a thickness of $\sim 50 \mu \mathrm{m}$. There is no need for a Ti grid for a plan-view sample, and instead of using the holder with clamps the sample is either glued onto a circular holder, or just put on top of a special holder with a thin lip to keep it in place. The ion milling is performed with single-beam modulation from the substrate side of the sample. For plan-view samples, it is often not necessary to continue the milling until a hole is created. Thanks to the visible light microscope, it is possible to monitor the final stages of the thinning by the interference fringes that arise and where each new colored fringe represents a thickness change of a few hundred $\AA$. When no new fringes appear, the sample is thin enough. Figure 6.11 shows a typical example of interference fringes for a Ti-B-Si-N sample on a Si substrate from Paper II. 

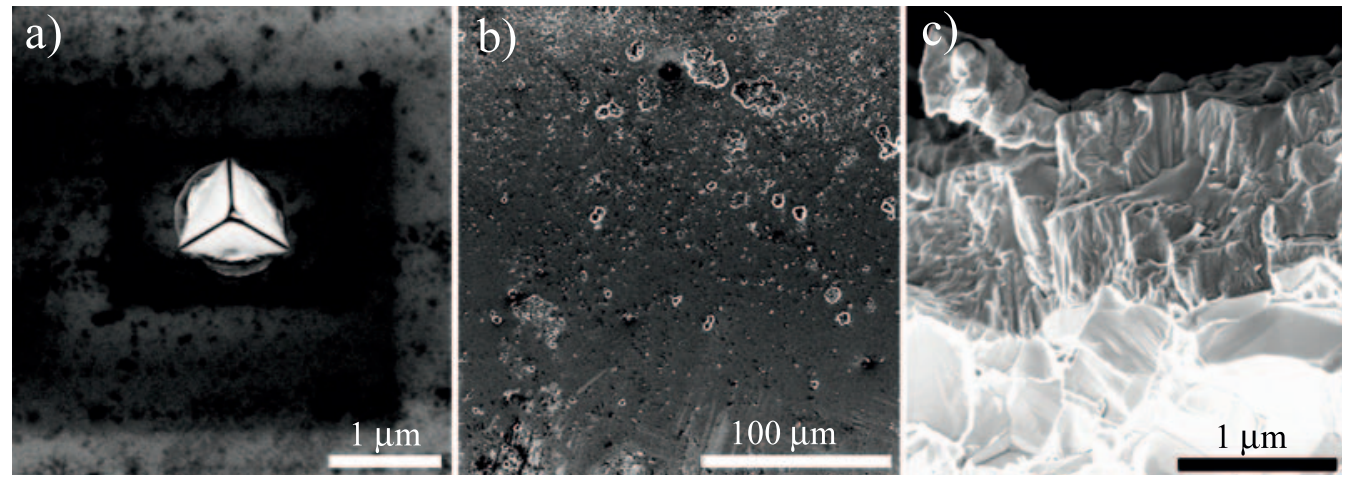

SEM

In the same way as in TEM, scanning electron microscopy (SEM) utilizes an electron beam to illuminate the sample, but the beam in a SEM is focused and scanned across an area on the sample. When the beam hits the sample, the electrons in the beam interact with the sample and lose energy that is converted into heat, secondary electrons, backscattered electrons, Auger electrons, light, and x-rays, among other. The image is created by displaying the various intensities for the selected signal at the position the beam was when the image was created. The resolution of a SEM is $\sim 2 \mathrm{~nm}$, i.e., about an order of magnitude lower than that of a TEM. On the other hand it has a great depth of field, so it can produce images that well represents three-dimensional shapes. Also, sample preparation is in most cases not needed, besides ensuring conducting samples.

The main use of SEM is to investigate topography of the surface of a sample, or to study the microstructure of a cross-sectional sample, see Figure 6.12. The SEM can also be equipped with several spectroscopic tools for compositional analysis. In this thesis energy dispersive $\mathrm{x}$-ray spectroscopy was used, described in detail below.

\section{Chemical and elemental analysis}

There are several characterization techniques available for the chemical and elemental analysis of thin films. Common for them is that they can give information on composition including compositional gradients, thickness, contamination, and for some also information on the bonding state. In the work presented in this thesis I have used a number of different techniques, both ion scattering techniques like Rutherford backscattering spectrometry (RBS) and elastic recoil detection analysis (ERDA), and also spectroscopic techniques like energy dispersive $\mathrm{x}$-ray spectrosco-

FIGURE 6.12: a) A resulting impression after nanoindentation with a cube corner tip of a magnetron-sputtered $\mathrm{Hf}-\mathrm{Al}$ Si-N film, b) plan-view image of the topography of an arcevaporated Ti-B-Si-N film, and c) a cross-sectional view of an arc-evaporated Ti-Al-Si-N film. 
TABLE 6.1: Comparison between different chemical analysis techniques used in this thesis. Data is gathered from Bubert \& Riviére, 176 Jensen, ${ }^{177}$ Saha \& Barron, ${ }^{178}$ and Brundl. ${ }^{179}$ Please note that the elements that can be detected, the sensitivity, and the compositional precision is dependent on both the sample characteristics and the instrument, and can vary greatly.

\begin{tabular}{llll}
\hline \hline Method & Incident particle & Outgoing particle & Elements detected \\
\hline RBS & Ion & Ion & $\operatorname{Be}-\mathrm{U}\left(Z>Z_{\text {ion }}\right)$ \\
ERDA & Ion & Atom & $\mathrm{H}-\mathrm{U}\left(Z<Z_{\text {ion }}\right)$ \\
EDX & Electron & X-ray photon & Be-U $(\mathrm{Na}-\mathrm{U})$ \\
XPS & X-ray photon & Electron & He-U (Li-U) \\
Method & Depth probed & Sensitivity & Precision (composition) \\
\hline RBS & $1-2 \mu \mathrm{m}$ & $0.01-10$ at. $\%$ & $<1$ at. $\%$ \\
ERDA & $\sim 1 \mu \mathrm{m}$ & $10^{-4}-10^{-6}$ at. $\%$ & 1 at. $\%$ \\
EDX & $\sim 2 \mu \mathrm{m}$ & $0.01-0.1$ at. $\%$ & 2 at. $\%$ \\
XPS & $5-10 \mathrm{~nm}$ & $0.1-1$ at. $\%$ & $\sim 2$ at. $\%$ \\
\hline
\end{tabular}

py (EDX) and x-ray photoelectron spectroscopy (XPS). Table 6.1 presents a comparison of different chemical analysis techniques.

The ion beam techniques, RBS and ERDA, are both based on the elastic scattering of ions, where the principle of conservation of energy and momentum during a collision applies. When a projectile with mass $M_{1}$, energy $E_{1}$, and atomic number $Z_{1}$ collides with a target atom of mass $M_{2}$, and atomic number $Z_{2}$, it will transfer parts of its energy to the target atom. The energy transfer can be derived from laws of conservation of energy and momentum and is given by:

$$
E_{2}=\frac{4 M_{1} M_{2} \cos ^{2} \theta}{\left(M_{1}+M_{2}\right)^{2}} E_{1}
$$

By impinging the surface of the sample with an ion beam, there will be backscattered projectiles, but also forward scattered projectiles and recoils. The backscattered projectiles, scattered by angles $\theta>90^{\circ}$ are analyzed in RBS. As a consequence of the conservation law, also the other participant in the collision, namely the recoiled target atoms, contain the same kind of information. These recoiled atoms are detected and analyzed in ERDA. ${ }^{180}$ Figure 6.13 show a schematic of a RBS and ERDA setup. The techniques are described in further detail below.

RBS

Backscattering from sample atoms with mass $M_{2}$ can only occur for projectiles with mass $M_{1}$ if $M_{1}<M_{2}$. Therefore, light ions like $\mathrm{He}^{+}$or protons are used in RBS, with energies in the range from $0.5-3 \mathrm{MeV}$. Heavier ions will give high backscattered energies and large backscattering cross-sections. ${ }^{181}$ RBS is well suited for analysis of heavy elements, but the sensitivity for light elements is poor.

The energy of the backscattered ions is recorded, and an energy spectrum is obtained, where the backscattered ions with the 


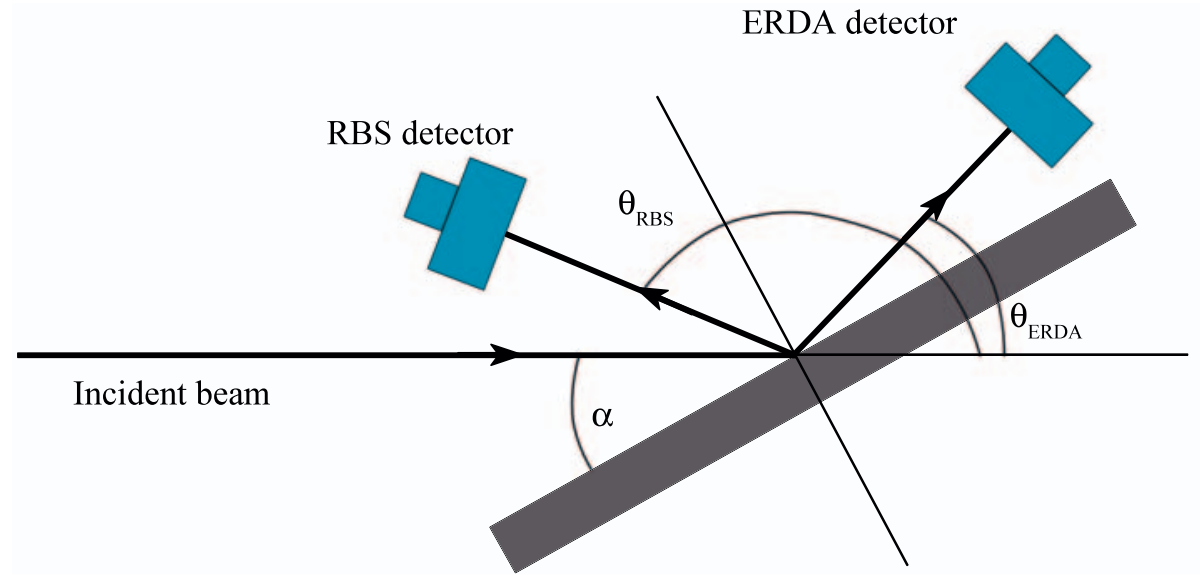

highest energy have collided with the heaviest elements in the sample. The ion energy is, however, also dependent on the distance travelled in the sample, meaning that ions scattered by an atom deeper in the sample has lower energy.

The measured backscattering energy spectra can be fitted to a simulation, here using the simulation program SIMNRA, ${ }^{182}$ where the fit is based on composition and thickness of the sample in order to yield an elemental depth profile. RBS is suitable for analysis of thin films up to $\sim 500 \mathrm{~nm}$. Preferably, the films should consist of medium to heavy elements on light-element substrates. A typical RBS spectrum from a Hf-Al-Si-N sample can be seen in Figure 6.14.

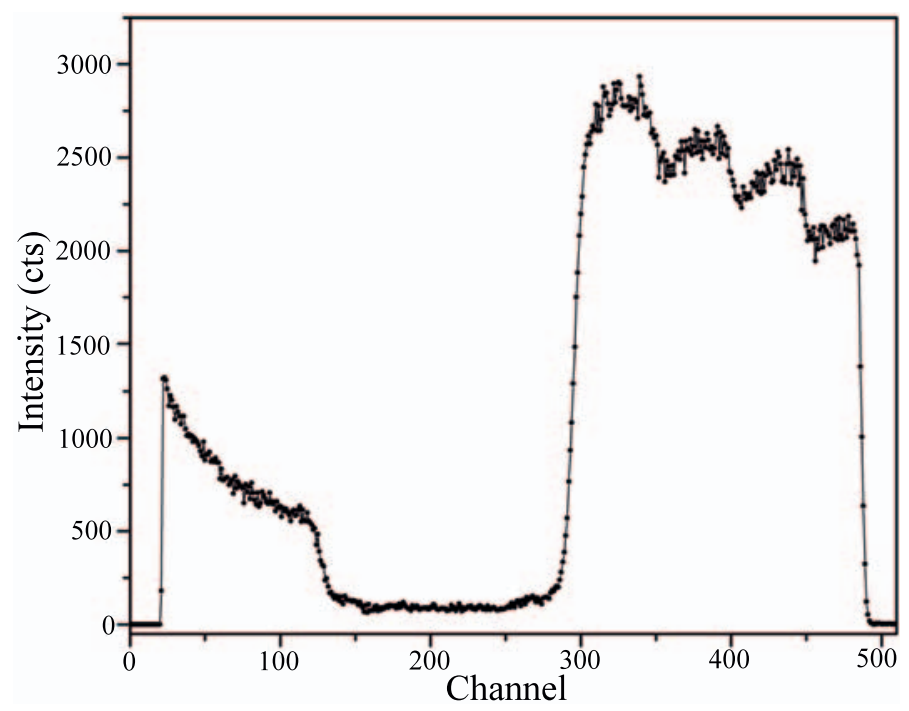

FIGURE 6.13: A schematic of RBS and ERDA setup.

FIGURE 6.14: A typical RBS energy spectrum from a Hf-AlSi-N sample grown with four layers with different composition. 
ERDA

ERDA and RBS are often used complementary since ERDA is especially suited for detection of light elements. Depending on what information that is sought for, different projectiles can be chosen. Often heavy projectiles $\left({ }^{129} \mathrm{I}^{9+}\right.$ or $\left.{ }^{35} \mathrm{Cl}^{9+}\right)$ with energies of 2-100 MeV are used, which makes it possible to analyze a broad range of light and intermediate elements. The choice of projectile will influence the sensitivity and depth resolution. The sensitivity for ERDA is approximately the same for all elements. ${ }^{181}$ Here, all experiments were performed using a $36 \mathrm{MeV}$ ${ }^{127} I^{8+}$ beam.

A drawback with ERDA is that it can be difficult to separate elements that are close in mass. This has been the case in this thesis, where $\mathrm{Al}(27 \mathrm{amu})$ and $\mathrm{Si}(28 \mathrm{amu})$ are too close to be resolved.

Since there will be both recoiled atoms and scattered projectiles with a forward motion according to the law of conservation of momentum, they will continue to the detector where they will be simultaneously detected. This means that the recorded energy spectra will contain contributions from both recoiled atoms and scattered projectiles, leading to a complex spectrum and a demand for heavy data analysis. The data evaluation for all ERDA measurements in this thesis was done using the Contes program. ${ }^{183}$

XPS

X-ray photoelectron spectroscopy (XPS) can be used for compositional analysis, but has become popular since it also can provide chemical bonding information. The basis of XPS is the photoelectric effect that was discovered by Heinrich Rudolf Hertz and later

FIGURE 6.15: A typical ERDA time-of-flight energy spectrum from a Ti-B-Si-N sample.

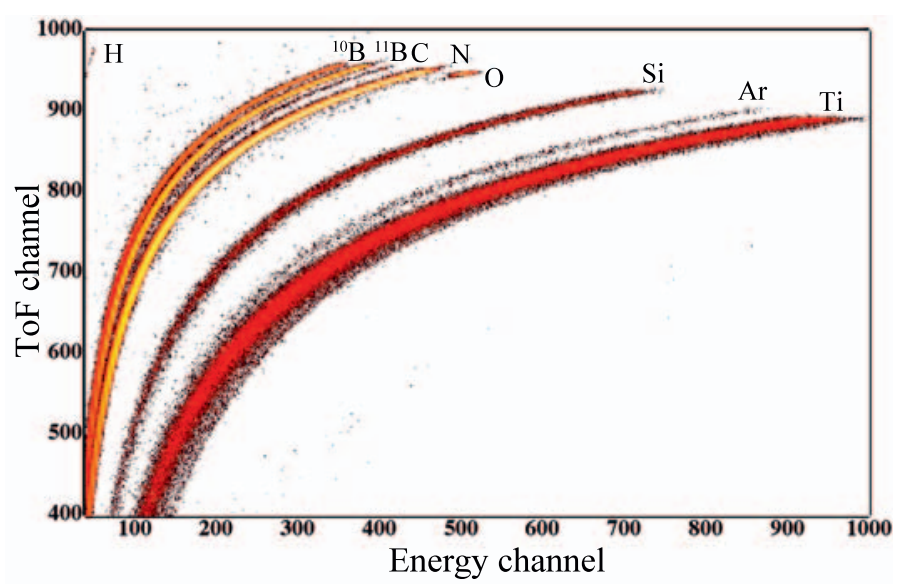




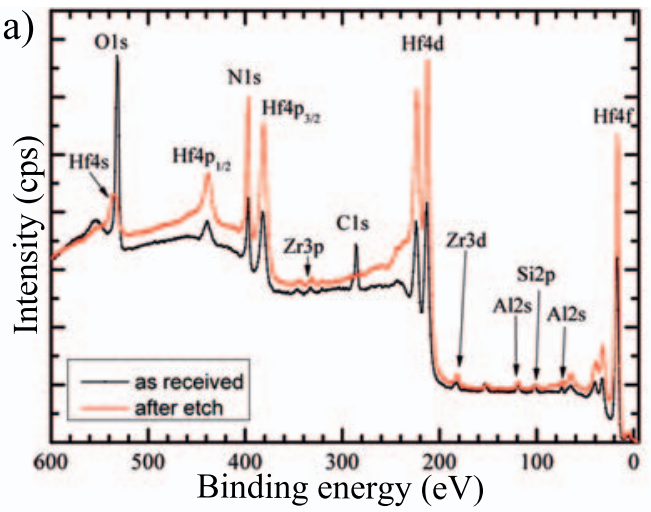

explained by Albert Einstein in 1905, which awarded him the Nobel Prize in Physics in 1921. Kai Siegbahn, a Swedish physicist, and his group at Uppsala University worked with development of XPS equipment and were the first ones to record a highenergy-resolution XPS spectrum. In 1981, Siegbahn was awarded the Nobel Prize in Physics for his contributions to the development of high-resolution electron spectroscopy. XPS is sometimes called ESCA - Electron Spectroscopy for Chemical Analysis, a name that Siegbahn and his co-workes used, and that nowadays primarily refers to when XPS is used for analysis of chemical bonding.

The sample under investigation is irradiated with soft $\mathrm{x}$-rays with energies ranging from $0.1 \mathrm{MeV}$ to $10 \mathrm{keV}$. The most common x-ray sources are $\mathrm{Al} \mathrm{K}_{\alpha}(1486.6 \mathrm{eV})$ and $\mathrm{Mg} \mathrm{K}_{\alpha}(1253.6 \mathrm{eV}) .{ }^{176}$

A photon with energy $h \nu$ interacts with an electron with a binding energy $E_{B}$. The energy of the photon is transferred to the electron, and a photoelectron is ejected with a kinetic energy, $E_{k i n}$, given by:

$$
E_{k i n}=h \nu-E_{B}-\Phi_{s} .
$$

$\Phi_{s}$ is a measure of the potential that the photoelectron will be affected by during passing from the sample to the spectrometer. $\Phi_{s}$ is given by the difference between the sample work function and the spectrometer work function. The photoelectron can come from a core level, or from an occupied portion of the valence band. The valence electrons are involved with the chemical bonding, and lower energy photons can be used to create spectra associated with these more loosely bound electrons. They, however, do not provide elemental information. Since the electronic binding energies are unique for all elements, measurement of the kinetic energy of photoelectrons stemming from the core levels give information that is significant for the atom with which the photon has interacted.

The position of the peaks in the energy spectra is thus dependent on the element from which it originates, and the intensity is
FIGURE 6.16: a) A typical XPS survey spectrum from a Hf-AlSi-N sample with the black line showing the signal from the film as received and the red signal after $2 \mathrm{~min}$. etching with $500 \mathrm{eV} \mathrm{Ar}^{+}$ions. b) A narrow spectrum showing the $\mathrm{Hf} 4 \mathrm{f}$ signal composed of the $\mathrm{Hf}_{4} \mathrm{f}_{5 / 2}$ and $\mathrm{Hf}_{4 / 2} \mathrm{f}_{7 / 2}$ spin-split doublets. 
related to the elemental concentration. The exact binding energy and thereby peak position is also influenced by the surrounding chemical environment. Changes in the chemical environment of an element causes a redistribution of valence electron charges that in turn affects the core electron binding energies. Changes in binding energy lead to so-called chemical shifts, that are tabulated for many elements, and thereby make the elemental analysis easier.

A typical example of an energy survey spectrum from a HfAl-Si-N sample can be seen in Figure 6.16. The peaks correspond to the energies of characteristic electrons which have been ejected from the sample without energy loss. The tails, towards higher binding energies, correspond to electrons, which have undergone inelastic scattering and suffered from loss of kinetic energy on their way out of the sample. The black line in Figure 6.16a) shows the results initially, before etching the sample with $500 \mathrm{eV}$ $\mathrm{Ar}^{+}$ions for $2 \mathrm{~min}$. The red line show the results after etching. This exemplifies the surface sensitivity of XPS, where e.g., the Hf4f peak, located at $\sim 534 \mathrm{eV}$, is initially drowned in the $\mathrm{O} 1 \mathrm{~s}$ signal. The tested depth is limited by the inelastic mean free path of the photoelectron which is only of the order of 5-10 nm, and therefore XPS measurements are very sensitive to surface contamination and require UHV conditions for operation. Samples are often sputter cleaned, as the Hf-Al-Si-N sample above, but the same technique can also be used for depth profiling of samples.

Depth profiling is a destructive method, where the surface is removed by ion bombardment. The surface is sequentially sputtered and analyzed, which is very time consuming, but can give important information of compositional variations, or variations in chemical bonding state. This was utilized in Paper V, where depth profiling of a multilayer sample showed variations in the Si bonding state between different layers. The complete measurement over a depth of $28 \mathrm{~nm}$ took 65 hours.

EDX

In energy dispersive $x$-ray spectroscopy (EDS or EDX) x-rays emitted from the sample are detected. An EDX detector is often operated in conjunction with a SEM or TEM. The principles for generation of $x$-rays and the detection is mainly the same in SEM and TEM. ${ }^{179}$

In EDX the electron beam is used to irradiate the sample. The incident electrons excite an electron from a core level and eject it, creating an electron hole. An electron from a higher-energy level fills the hole and at the same time an x-ray photon is released with an energy that corresponds to the energy difference between the two electron levels. The x-rays that are emitted from the sample surface are dependent on the electronic structure of 
the atoms from which they were generated, and their energy is specific for each element. This enables identification and quantification of the elements in the sample. A detector is used to convert the energy of the $x$-rays into voltage signals, that are then analyzed. Light elements, for example nitrogen, have low detection efficiency since the emitted $x$-rays have low energy and high probability of being absorbed before they reach the detector.

The accuracy can be affected by several factors, e.g., overlapping peaks of some elements, but also the homogeneity of the sample, since the probability that an $x$-ray escapes the sample and is detected is dependent on the energy of the $x$-ray and the amount and density of the material is has to escape from. ${ }^{184}$

In SEM, the x-rays are emitted from a large volume of the sample, and both the spatial and depth resolution is of the order of a few microns. In the case of thin films the substrate can influence the measurements if the penetration depth of the beam is too large. The spatial resolution depends on the size of the interaction volume, which is determined by the accelerating voltage and the mean atomic number of the sample. In TEM, where the accelerating voltage is higher, less spreading of the beam give a better spatial resolution than in SEM. The depth resolution is limited by the thickness of the sample.

For quantification of an element in EDX, the intensities of each element are counted in the detector at certain beam currents, and the count rates are compared to standards, containing a known amount of the element of interest. X-rays show matrix effects that have to be encountered for by so-called ZAF-correction; atomic number (Z), absorption (A), and fluorescence (F). This is usually done automatically in the computer program. For quantification of composition, EDX is well suited, but it lacks the precision needed for detection of trace elements.

EDX is normally considered to be a non-destructive technique, but in reality most samples suffer from some kind of damage under the electron beam. In both SEM and TEM, scanning of the electron beam over the sample surface can be used for elemental mapping.

\section{Mechanical characterization}

\section{NANOINDENTATION}

Indentation techniques are the most commonly used techniques for determining the mechanical properties of a material, such as hardness and elastic modulus. In the case of thin films, special consideration is needed since what is measured is a thin film on a substantially thicker substrate. This requires a method that ensures that it is the film that is measured, without contribution from the substrate. The most common method for evaluating hardness and elastic modulus of a thin film is nanoinden- 


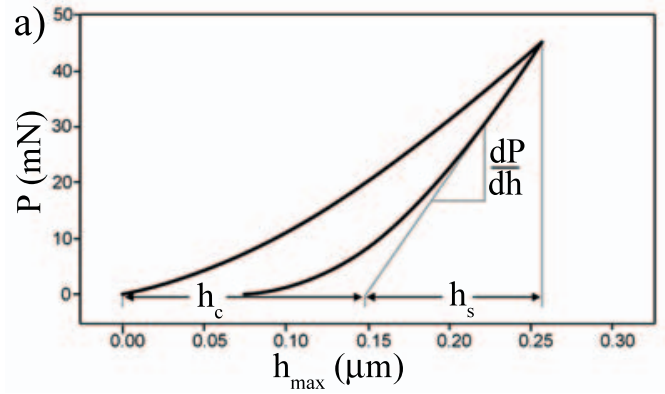

b)

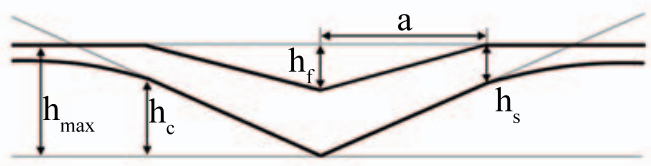

FIGURE 6.17: a) A typical nanoindentation loadingunloading curve, and b) schematic illustration of a cross-section through an indent. Based on a figure by Oliver and Pharr. ${ }^{186}$ tation, where an indenter with a sharp diamond tip is pressed into the film. ${ }^{185}$ By controlling the applied load and evaluating the deformed area, hardness and elastic modulus can be determined by applying the evaluation method developed by Oliver and Pharr. ${ }^{186}$

The hardness of a material is defined as the resistance to plastic deformation. In nanoindentation the hardness, $H$, is equal the applied load, $P$, divided by the contact area of the tip, $A$.

$$
H=\frac{P}{A}
$$

The residual indents are usually too small to be measured by optical means, so the contact area has to be calculated. For a pyramid shaped diamond Berkovich tip (that was used in all measurements in this thesis), the contact area is given by:

$$
A=24.49 h_{c}^{2}
$$

During indentation, the applied load, $P$, and the indentation depth, $h$, is recorded continuously. The relation between the maximum indentation depth, $h_{\max }$, the surface displacement, $h_{s}$, and the contact depth, $h_{c}$, is shown in the cross-sectional schematic illustration of an indentation in Figure 6.17. After removal of the load the material recovers elastically and the resulting indent, due to plastic deformation, have a depth, $h_{f}$.

The reduced modulus $\mathrm{E}_{r}$ is given by the equation

$$
E_{r}=\frac{1}{2} \sqrt{\frac{\pi}{A}}\left(\frac{d P}{d h}\right)
$$

where $(d P / d h)$ is the contact stiffness that can be determined from the gradient of the first part of the unloading curve, see Figure 6.17. The elastic modulus of the sample can be calculated if Poisson's ratio $(\nu)$ is known, as well as the elastic modulus $\left(E_{i}\right)$ and Poisson's ratio $\left(\nu_{i}\right)$ of the indenter:

$$
\frac{1}{E_{r}}=\frac{1-\nu^{2}}{E}+\frac{1-\nu_{i}^{2}}{E_{i}}
$$




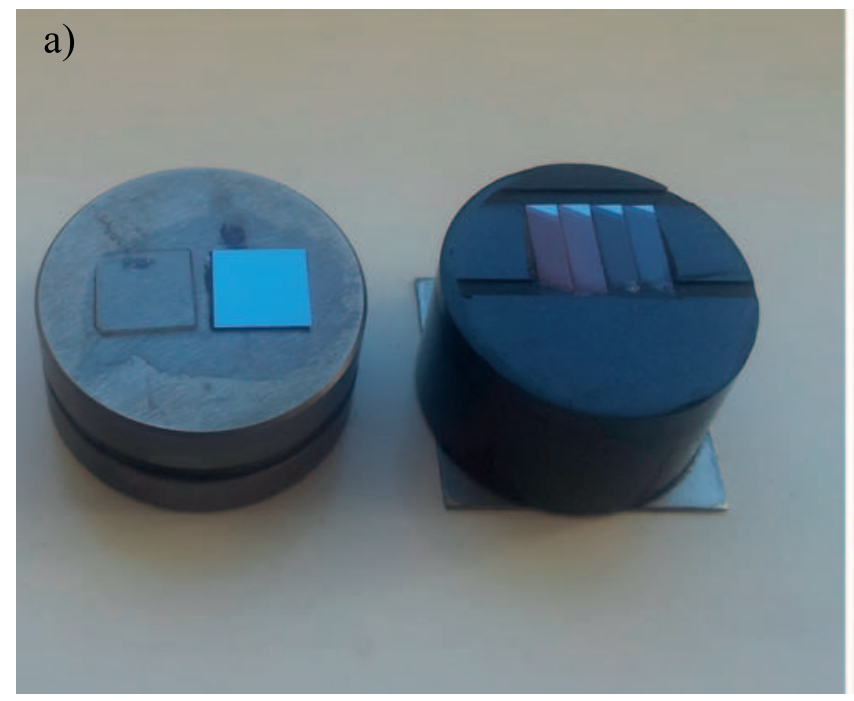

To avoid influence from substrate the penetration depth should not exceed $10 \%$ of the film thickness. The shape of the tip is crucial for correct evaluation of the acquired data. The tip wears with time, and therefore the tip contact area is calibrated with respect to a sample with known hardness and elastic modulus. Here, fused quartz has been used as reference material.

The hardness data acquired is also affected by material-dependent properties, such as microstructure, stress, grain size and grain boundaries, etc, but also on conditions during measurements such as temperature and humidity. The arc evaporated films in Paper I and Paper III, have a rough surface that can influence the measurements. Therefore, they have been polished before the measurements, and to avoid reduction of the film thickness, the samples were placed in tapered cross-sections, see Figure 6.18. The data has been evaluated using a statistical approach, and in these studies, the samples have been indented 25-50 times, and the average values of hardness and elastic modulus with their standard deviation has been reported.

\section{FRACTURE TOUGHNESS}

Fracture toughness is defined as the highest stress intensity that a material can withstand without fracture in the presence of a flaw. For thin films, however, traditional methods for determining toughness such as measuring the maximum stress intensity factor under plane strain conditions, does not work since the thickness usually ranges from nanometers to a few micrometers, meaning that the plane strain condition is not met. ${ }^{187}$

For thin films, nanoindentation can be used to create cracks. The crack formation and propagation is then characterized as a

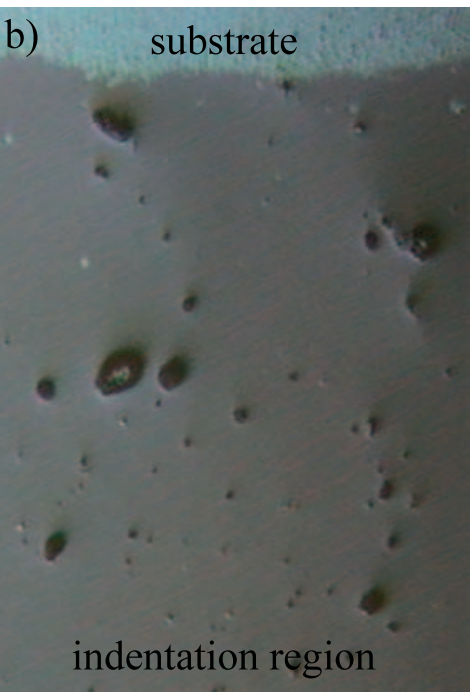

FIGURE 6.18: a) Sample mounting by waxing the samples directly onto a holder and by placing the sample is tapered cross-section. b) A typical overview of an arc evaporated sample with the substrate and nanoindentation regions indicated. 
measure of the fracture toughness. Crack propagation in a thin film bonded to a substrate is a three-dimensional process. The cracks are initiated at a flaw, and spreads through the material by channeling. The propagation of a crack in a material is attributed to a release of energy. ${ }^{188}$

The type of cracking and the crack movement through the film is affected by a number of factors. For example, if the substrate is very stiff compared to the film, the crack may propagate through parts of the film without reaching the substrate. In other cases, the crack penetrates through the film-substrate interface and continues into the substrate. Also, if the film-substrate interface toughness is low, delamination of the film might occur due to the shear stress at the interface outside the contact region during loading, or due to tensile stress at the interface in the contact region during unloading. ${ }^{189}$

There are mainly three types of cracking that can result after indenting a thin film; radial cracking, circumferential cracking, and lateral cracking. The exact type of cracking, and how it will propagate through the material is dependent on film and substrate properties, the indenter geometry, and the peak contact load.

Radial corner cracks are common for thin films on stiff substrates. Even if no large geometrical cracks are visible, a great number of nanoscale and microscale cracks are expected to occur following indentation, due to the hard coatings' inability to yield large plastic deformation. ${ }^{190}$ Visible cracks are originating at the edges of the indent, and a hemispherical plastic zone is generated underneath the impression. If the load is further increased the shape of the plastic zone changes to cylindrical and the radial cracks transform into so-called channel cracks. ${ }^{187}$ Channel cracking means that the crack goes all the way through the film down to the substrate. These type of cracks are often confused with circumferential cracking, which are formed inside an impression after indentation using a spherical indenter with a large radius.

Lateral cracks form beneath the deformation zone parallel to the surface, but can also form inside impressions parallel to the contact edge.

By analyzing radial cracks that form after indentation using a sharp edge indenter, e.g., a Vickers or Berkovich indenter, the fracture toughness $\left(K_{c}\right)$ is given by: ${ }^{187}$

$$
K_{c}=\alpha\left(\frac{E}{H}\right)^{1 / 2}\left(\frac{P}{c^{3 / 2}}\right),
$$

in which $c$ is the crack lenght, $P$ is the peak load at indentation, and $\alpha$ is an empirical constant which depends on the geometry of the indenter ( $\alpha=0.016$ for both Berkovich and Vickers type indenters). $E$ and $H$ are the elastic modulus and hardness of the material, respectively. 


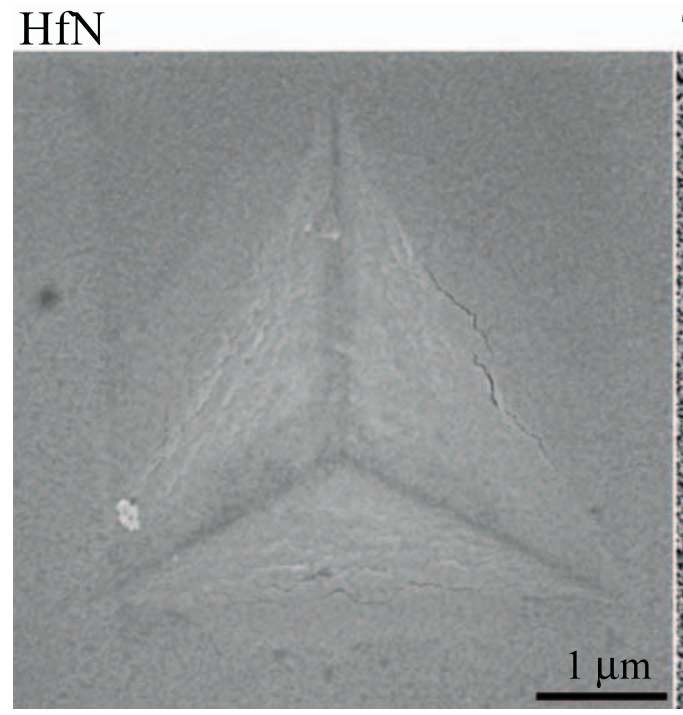

\section{TiN}

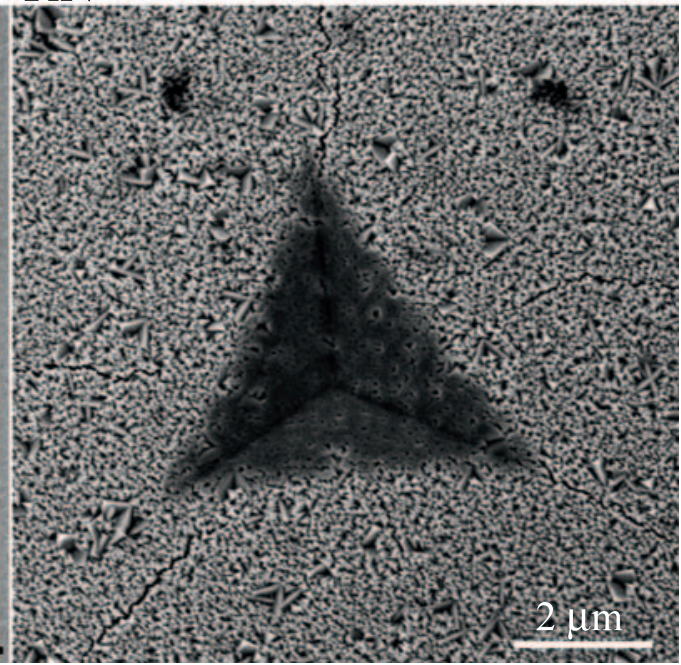

For Equation 6.17 to be valid, it is required that a so-called half-penny cracking pattern is formed around and underneath the impression. This implies that $c \geq 2 a$, where $a$ is the radius of the impression, and that $d$, which is the depth of the halfpenny crack is less than $10 \%$ of the film thickness. The derivation of Equation 6.17 assume unlimited sample thickness, since it is initially proposed for bulk materials. In order to produce visible cracks, there is a threshold load of $250 \mathrm{mN}$ or more for most ceramic materials, ${ }^{191,192}$ and the corresponding impressions are several micrometers in depth. Even with a shaper indenter (like the cube corner), the impressions range a few hundred nanometers in depth. ${ }^{193}$ Thus, for thin films, it is very hard to introduce well-defined radial cracks and meet the depth limitation of nanoindentation to exclude substrate effects.

To still be able to characterize fracture toughness of Hf-Al-Si$\mathrm{N}$ thin films in Paper $\mathrm{V}$, a fixed load was used for all indentations, and only films with the same thickness grown on the same type of substrate were evaluated. Thereby, the general trends could be studied, and the films could also be compared with reference samples measured in the same way.
FIGURE 6.19: Typical lateral crack formation in a HfN reference sample, and radial cracking in a TiN sample, following indentation with $100 \mathrm{mN}$ and $50 \mathrm{mN}$ loads, respectively, using a Berkovich diamond probe. 



\section{SUMMARY OF RESULTS AND CONTRIBUTIONS TO THE FIELD}

\section{Paper I}

This study was initiated as an extension of a study by Flink et al., where it was reported that arc evaporated $\left(\mathrm{Ti}_{0.33} \mathrm{Al}_{0.67}\right)_{1-x} \mathrm{Si}_{x} \mathrm{~N}$ coatings were $x$-ray amorphous for $x \geq 0.17$. ${ }^{194}$ The aim was to distort crystallinity into an electron-diffraction amorphous state.

In the paper, I report on the growth of amorphous Ti-Al-Si$\mathrm{N}$ coatings by industrial cathodic arc evaporation. The coatings were grown from $\mathrm{Ti}_{75} \mathrm{Al}_{25}, \mathrm{Ti}_{75} \mathrm{Si}_{25}$, and $\mathrm{Ti}_{23} \mathrm{Al}_{47} \mathrm{Si}_{30}$ cathodes in a $\mathrm{N}_{2}$ atmosphere. It was shown that the microstructure changes from nanocrystalline to predominantly amorphous with few separated 2-3 nm crystallites by addition of $\mathrm{Al}$ and $\mathrm{Si}$ to TiN. Figure 7.1 shows a cross-sectional SEM image of one of the amorphous coatings.

We show that the initially amorphous coatings start to crystallize at $900-1000{ }^{\circ} \mathrm{C}$ by coarsening of nanocrystallites, preferentially in Ti-rich layers that are induced by substrate rotation during deposition. At $1100{ }^{\circ} \mathrm{C}$ inter-diffusion of $\mathrm{Co}$ and $\mathrm{W}$ from the substrate occurs, and the films crystallize into c-TiN and h-AlN.

In the as-deposited state the amorphous coatings have a hardness of $\sim 19 \mathrm{GPa}$. They exhibit age hardening with an increase in hardness by $40 \%$ up to $\sim 27 \mathrm{GPa}$, which is accompanied with a change from a mainly amorphous to a nanocrystalline state.

The promising results in Paper I convinced me that it would be possible to distort crystallinity into a fully amorphous state even with the limitations stated by the industrial arc evaporation sys-

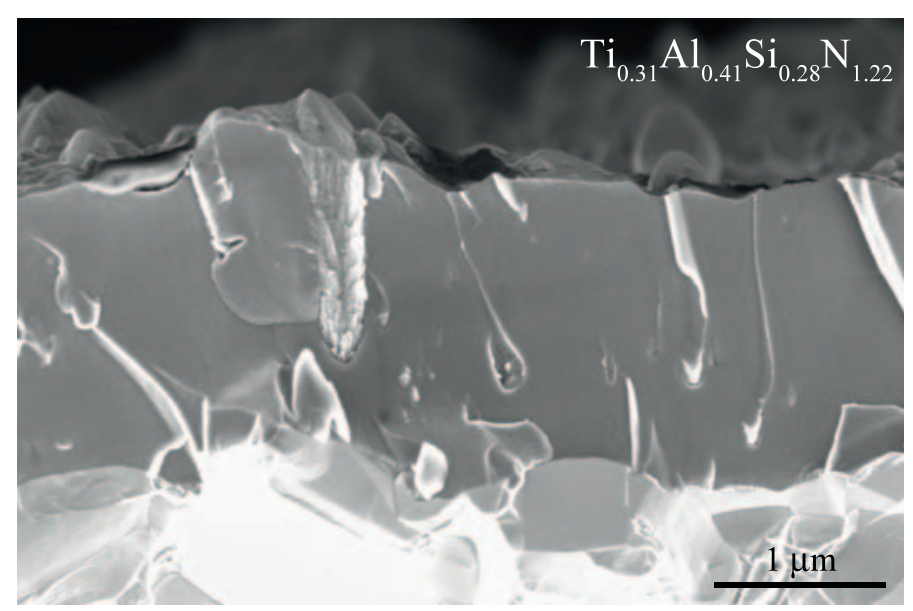

FIGURE 7.1: Fractured SEM cross-section of one of the amorphous coatings in Paper I. 

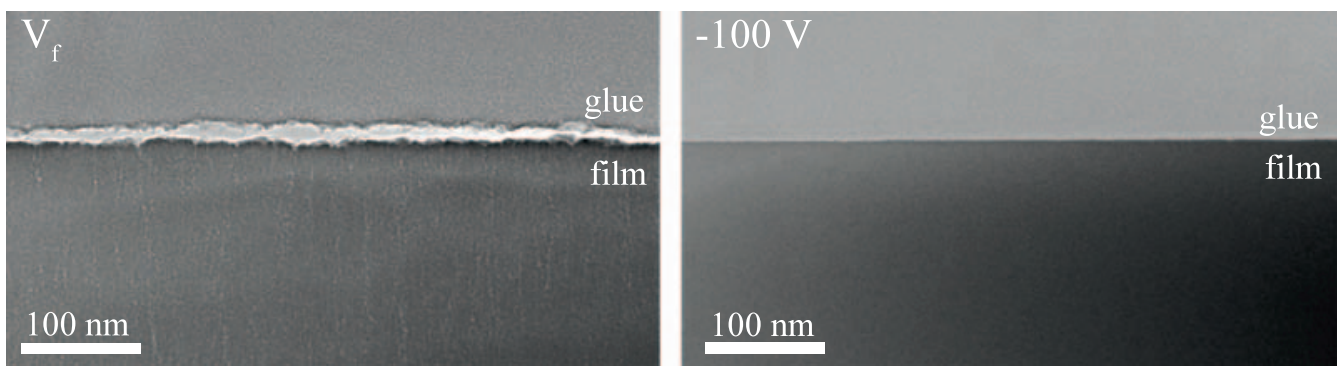

FIGURE 7.2: BF-TEM crosssections of the film surfaces, illustrating the decrease in surface roughness when a substrate bias voltage of $-100 \mathrm{~V}$ is applied, compared to a film grown at floating potential, $\mathrm{V}_{f}$. tem. The major issue was to increase the Si content, which is difficult to do in industrial arc cathodes, due to the brittleness that come with increasing amounts of Si. The benefit of using silicon is that silicon nitride can be grown amorphous at temperatures as high as $1100{ }^{\circ} \mathrm{C}^{195}$ and that it possesses a structural flexibility owing to the fourfold coordination with nitrogen, which is an advantage when it comes to distorting otherwise crystalline structures. B is another well known grain refiner, and has been suggested to be an even better choice for formation of amorphous phases, since B can be both three- and fourfold coordinated with nitrogen. We therefore decided to exchange $\mathrm{Al}$ for $\mathrm{B}$, to be able to deposit amorphous films without the need for high Si-content cathodes.

\section{Paper II}

As an initial study for Ti-B-Si-N, I used dc magnetron sputtering for a systematic study over a wide range of deposition parameters. The results from this study served as a starting point for both Paper III and Paper IV.

In Paper II, I report on $\left(\mathrm{Ti}_{0.25} \mathrm{~B}_{0.75}\right)_{1-x} \mathrm{Si}_{x} \mathrm{~N}_{y}$ films, $0 \leq \mathrm{x} \leq$ $0.89,0.9 \leq \mathrm{y} \leq 1.25$, grown by reactive dc magnetron sputtering from compound $\mathrm{TiB}_{2}$ and elemental Si targets. We show that films can be grown in a fully electron-diffraction amorphous state with $\mathrm{x}>0.46$, evidenced by XRD and HR-TEM investigations. In films grown without $\mathrm{Si}, \mathrm{BN}$ form onion-like sheets that surrounds TiN nanocrystallites.

The substrate temperature, varied from 100 to $600{ }^{\circ} \mathrm{C}$, including the contribution from plasma heating, shows only minor effects on the microstructure of the films, and on the mechanical properties, due to the limited surface diffusion at these temperatures.

A substrate bias voltage, on the other hand, drastically improves the mechanical properties of the films, due to nanoscale densification. In addition, the surface roughness is decreased, illustrated in Figure. 7.2. A maximum hardness value of $\sim 27 \mathrm{GPa}$ was found for an amorphous $\left(\mathrm{Ti}_{0.25} \mathrm{~B}_{0.75}\right)_{0.39} \mathrm{Si}_{0.61} \mathrm{~N}_{1.15}$ film gro- 
wn at a substrate temperature of $400{ }^{\circ} \mathrm{C}$ and a substrate bias voltage of $-100 \mathrm{~V}$.

\section{Paper III}

In this paper I report on the thermal stability and mechanical properties of amorphous Ti-B-Si-N and Ti-B-Si-Al-N coatings grown in the same industrial system as the coatings in Paper I. By using three different cathodes; $\mathrm{Ti}_{85} \mathrm{Si}_{15}, \mathrm{TiB}_{2}$, and $\mathrm{Ti}_{33} \mathrm{Al}_{67}$, we could deposit coatings over a wide range of compositions. We show that the microstructure of the as-deposited coatings changes from nanocrystalline to $\mathrm{x}$-ray amorphous with addition of either $(\mathrm{B}+\mathrm{Si}+\mathrm{Al})$ or high amounts of $(\mathrm{B}+\mathrm{Si})$ to $\mathrm{TiN}$, illustrated in Figure 7.3. The amorphous coatings are dense and homogeneous, and have unusually few macroparticles. The same type of Tirich layering that was seen in the coatings in Paper I could be observed also in these coatings. TEM observation also reveal that Ti-B-Si-Al-N coatings are mainly amorphous with only a few nanocrystalline grains, while the Ti-B-Si-N contains a larger number of nanocrystals.

Annealing experiments, performed at temperatures between $700{ }^{\circ} \mathrm{C}$ and $1100{ }^{\circ} \mathrm{C}$ result in crystallization of the coatings by clustering of TiN grains. The hardness of the amorphous asdeposited samples are $\sim 17 \mathrm{GPa}$, and increases to $\sim 21 \mathrm{GPa}$ with annealing temperatures up to $800{ }^{\circ} \mathrm{C}$. At annealing temperatures of $1000^{\circ} \mathrm{C}$ and above the hardness decreases due to inter-diffusion of $\mathrm{W}$ and $\mathrm{Co}$ from the substrate to the coating.

\section{Paper IV}

The hybrid dc magnetron sputtering (DCMS) and high power impulse magnetron sputtering (HIPIMS) system used in Paper IV enables bombardment of the growing film by energetic target ions. This promotes near-surface mixing, and can distort emerging crystallites, but the increased mobility of the species as they land on the substrate might cause crystallization.

I report on films with an almost constant $\mathrm{Ti} / \mathrm{B}$ ratio (0.54), with increasing Si contents. Thanks to the use of an elemental $\mathrm{Si}$ target, it was possible to grow films with as much as 20 at.\% Si $(x=0.43)$. All films are $x$-ray amorphous, but for low Si contents, the films are porous, and have a nanocrystalline structure with 2-4 $\mathrm{nm}$ TiN grains separated by BN-rich amorphous phase channels, inclined with respect to the substrate normal. With $x \geq 0.22$, the films are fully electron diffraction amorphous, see Figure 7.4. The hardness is shown to increase linearly with increasing Si content, from $\sim 9 \mathrm{GPa}$ to $\sim 17 \mathrm{GPa}$.

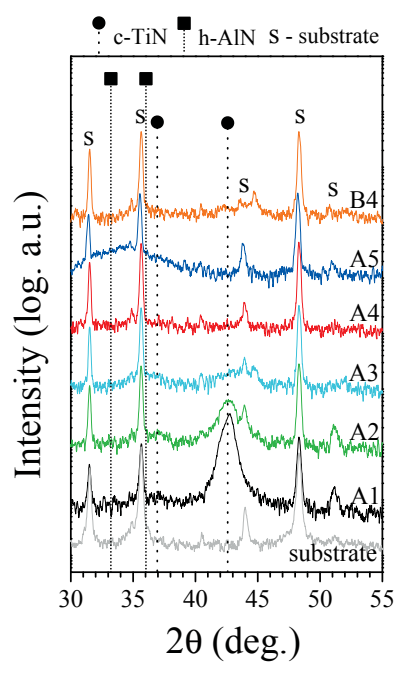

FIGURE 7.3: X-ray diffractograms from Ti-B-Si-N (A1, A2, and $\mathrm{B} 4)$, Ti-B-Si-Al-N (A3 and A4), and Ti-B-Al-N (A5) coatings in Paper III. Coatings A4 and B4 are x-ray amorphous. An uncoated substrate is shown as reference. 
FIGURE 7.4: Selected area electron diffraction (SAED) patterns and corresponding HRTEM images from a nanocrystalline Ti-B-Si-N films with 4 at.\% Si, and a fully electron diffraction amorphous films with 10 at. \% Si. Modified from Paper IV.
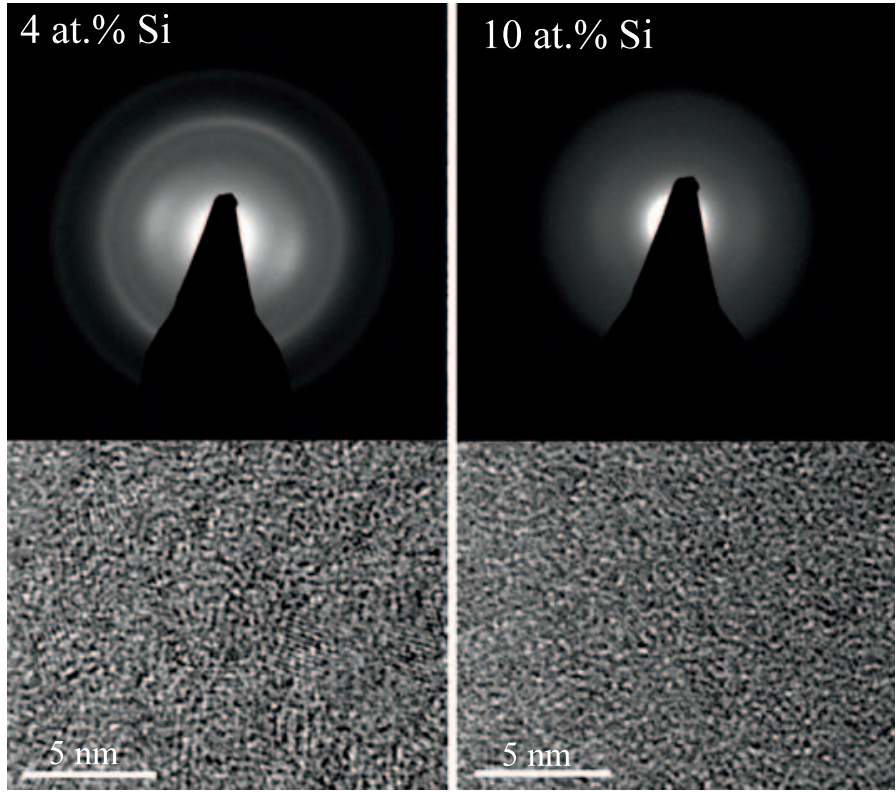

\section{Paper V}

Paper V follows a study by Howe et al., where real-time control of the AlN concentration in epitaxial $\mathrm{Hf}_{1-x} \mathrm{Al}_{x} \mathrm{~N}(001)$ layers was demonstrated by growth from a single $\mathrm{Hf}_{0.7} \mathrm{Al}_{0.3}$ alloy target using tunable magnetically-unbalanced reactive magnetron sputtering. By bombardment of the growing films with highflux, low-energy ions during deposition, the $\mathrm{Al}$ resputter yield is amplified, and the AlN incorporation probability is changed. The preferential removal of lighter $\mathrm{Al}$ atoms is explained by forward sputtering by recoiled $\mathrm{Ar}^{+}$ions that are neutralized and backscattered from heavy $\mathrm{Hf}$ atoms. ${ }^{44,196}$

In our study, we wanted to extend this technique to vary both the AlN and $\mathrm{SiN}$ concentrations in $\mathrm{Hf}_{1-x-y} \mathrm{Al}_{x} \mathrm{Si}_{y} \mathrm{~N}$, and grow amorphous films. Then, I would grow alternating amorphous Hf-Al-Si-N and nanocrystalline HfN layers using a single $\mathrm{Hf}_{0.6^{-}}$ $\mathrm{Al}_{0.2} \mathrm{Si}_{0.2}$ alloy target, by just varying the ion energy.

Figure 7.5a) shows a cross-sectional overview BF-TEM image of a four-layer $\mathrm{Hf}_{1-x-y} \mathrm{Al}_{x} \mathrm{Si}_{y} \mathrm{~N}$ film in which the ion-to-metal flux ratio $J_{i} / J_{M e}$ was varied from eight (layers 1-3), to one in the top layer. The film growth temperature $T_{s}$ was decreased stepwise, from $450{ }^{\circ} \mathrm{C}$ for the bottom layer to $350{ }^{\circ} \mathrm{C}$ for the second layer to $250{ }^{\circ} \mathrm{C}$ for the third layer, and $150{ }^{\circ} \mathrm{C}$ for the top layer. Each layer was deposited for five min and the temperature was equilibrated for $15 \mathrm{~min}$ between each deposition.

The BF-TEM image reveals a homogenous structure within each of the four layers, with sharp interfaces and clear contrast 


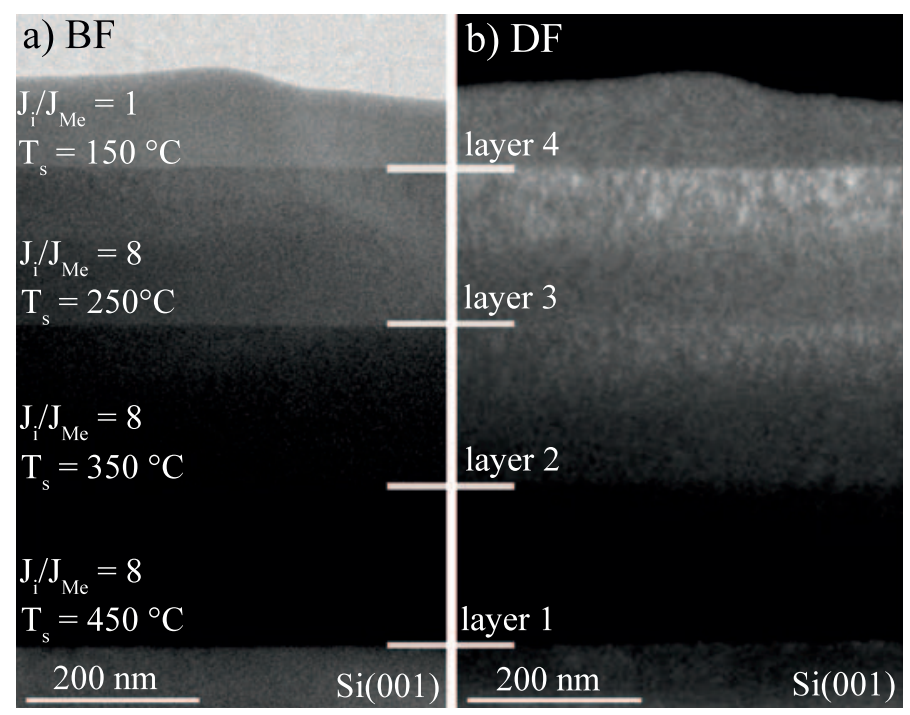

differences. In the DF-TEM image in Figure 7.5b), the bottom layer grown with $J_{i} / J_{M e}=8$ and $T_{s}=450{ }^{\circ} \mathrm{C}$ exhibits speckle contrast in the upper part. The interface between the bottom layer and layer 2, which is grown with $J_{i} / J_{M e}=8$ and $T_{s}=350{ }^{\circ} \mathrm{C}$, is abrupt and defined by the change in contrast. Layer 2 exhibits speckle contrast throughout and there is an increasing number of bright areas near the interface with the layer 3 . The interface between layer 2 and layer 3 , which is grown with the same $J_{i} / J_{M e}$, but with $T_{s}=250{ }^{\circ} \mathrm{C}$, is smooth with less change in contrast. The transition to the homogeneous amorphous top layer, grown with $J_{i} / J_{M e}=1$ and $T_{s}=150^{\circ} \mathrm{C}$, is sharp.

The layer formation that is visible in Figure 7.5 is mainly the result of diffraction contrast. The clear interfaces show that the contrast changes are mainly due to differences in composition and not in thickness of the sample. The composition of the first three layers are the same, $\mathrm{Hf}_{0.76} \mathrm{Al}_{0.12} \mathrm{Si}_{0.12} \mathrm{~N}$, within the error limits of the characterization technique. However, even a slight change in Hf content would give a drastic change in diffraction contrast due to the heavy mass of Hf. The fourth layer grown with $T_{s}=150{ }^{\circ} \mathrm{C}$ with $J_{i} / J_{M e}=1$ is, however, different than the other three layers. The lower ion-to-metal-flux ratio changes the nanostructure of the layer from nanocrystalline to amorphous. This change is attributed with an increase in $\mathrm{Si}$ and $\mathrm{Al}$ in the layer, and the composition is $\mathrm{Hf}_{0.72} \mathrm{Al}_{0.14} \mathrm{Si}_{0.14} \mathrm{~N}$. Also, the nitrogen content in this layer is higher and it is slightly nitrogen overstoichiometric with a ratio $\mathrm{N} /(\mathrm{Hf}+\mathrm{Al}+\mathrm{Si})=1.05$, compared to $\mathrm{N} /(\mathrm{Hf}+\mathrm{Al}+\mathrm{Si})=0.99$ for the other layers.

The sharp interfaces between the layers that is observed in Figure 7.5 are formed when the deposition process is stopped
FIGURE 7.5: a) BF-TEM and b) DF-TEM images of a four layer Hf-Al-Si-N film in which the ion-to-metal flux ratio is eight during growth of layer one to three, and equal one for the fourth layer. The substrate temperature is sequentially reduced from $450{ }^{\circ} \mathrm{C}$ to $350{ }^{\circ} \mathrm{C}$ to $250^{\circ} \mathrm{C}$ to $150^{\circ} \mathrm{C}$. The ion energy is $10 \mathrm{eV}$ for all four layers. 


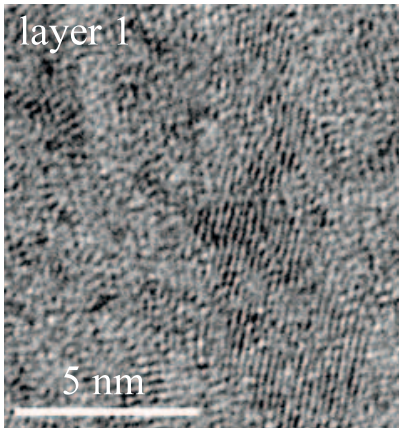

FIGURE 7.6: HR-TEM image showing nanocrystalline grains in layer 1.

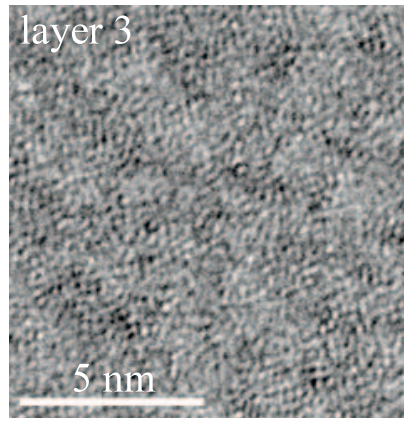

FIGURE 7.7: Typical HR-TEM image showing the nanostructure in layers 2 and 3, here shown for layer 3.

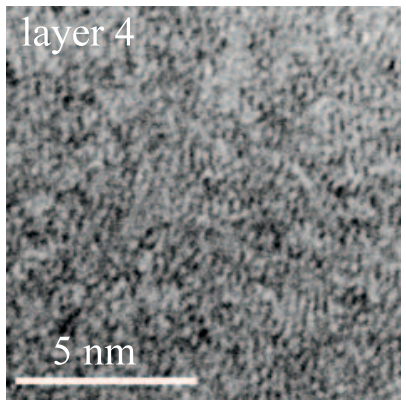

FIGURE 7.8: HR-TEM image showing the amorphous structure of layer 4 . between growth of each layer. In the DF-TEM image, an increasing number of nanocrystalline grains are visible closer to the top of each individual layer. This is especially clear close to the interface between the layer 3 and layer 4 . This could possibly be due to formation of $\mathrm{SiO}_{x}$ at the surface when the deposition is stopped.

Figure 7.6 is a high-resolution TEM (HR-TEM) micrograph of the bottom layer grown with $J_{i} / J_{M e}=8$ at $T_{s}=450{ }^{\circ} \mathrm{C}$. It clearly consists of $\sim 5 \mathrm{~nm}$-sized grains encapsulated in an amorphous matrix.

Layers 2 and 3 are equal in nanostructure. The typical appearance is shown for layer 3 in Figure 7.7. The layers consist of 1-2 nm sized nanocrystalline grains, with lattice fringes visible inside, encapsulated in an otherwise amorphous matrix.

Figure 7.8 shows the nanostructure of the amorphous top layer. The layer is fully amorphous, without any evidence of grain formation. Thus, I conclude that it is possible to grow fully amorphous Hf-Al-Si-N films from a single alloy $\mathrm{Hf}_{0.6} \mathrm{Al}_{0.2} \mathrm{Si}_{0.2}$-target with $E_{i}=10 \mathrm{eV}, J_{i} / J_{M e}=1$ and $T_{s}=150{ }^{\circ} \mathrm{C}$.

The difference in substrate temperature between layer $3\left(250{ }^{\circ} \mathrm{C}\right)$ and layer $4\left(150{ }^{\circ} \mathrm{C}\right)$ is only an effect of the increased ion-tometal flux ratio towards the substrate, since the external heating was switched off during growth of both layers. However, the increased temperature during growth of layer 3 is enough to cause crystallization. Our results show that a very low substrate temperature $\left(150{ }^{\circ} \mathrm{C}\right)$, is needed for growth of fully amorphous films at this composition. I concluded that it would not be possible to grow alternating amorphous and nanocrystalline layers using the $\mathrm{Hf}_{0.6} \mathrm{Al}_{0.2} \mathrm{Si}_{0.2}$-target, since a high flux is needed for the preferential resputtering of lighter elements. However, I discovered that films grown with $J_{i} / J_{M e}=8$ at $T_{s}=250{ }^{\circ} \mathrm{C}$ and $E_{i}=10-50 \mathrm{eV}$ have different $\mathrm{Si}$-bonding structure, depending on the ion energy.

In Paper V I report on multilayers grown by sequentially alternating the ion energy between $10 \mathrm{eV}$ (floating potential) and $40 \mathrm{eV}$, which yields nanocrystalline multilayers with layers that are alternating hard and ductile, with essentially the same composition.

The hardness of the multilayers decrease monotonically from $\sim 27 \mathrm{GPa}$ to $\sim 20 \mathrm{GPa}$ as the bilayer period $\Lambda$ is increased from 2 to $20 \mathrm{~nm}$. However, the fracture toughness, characterized by direct crack length measurements following $50-150 \mathrm{mN}$ peak load nanoindentations, increases with $\Lambda$. Multilayers with $\Lambda=10 \mathrm{~nm}$ are shown to be both hard, $\sim 24 \mathrm{GPa}$, and fracture tough. 




\section{B I B L I O G R A P H Y}

[1] Sandvik Coromant. Modern Metal Cutting - A Practical Handbook. AB Sandvik Coromant, 1994.

[2] C. Kittel. Introduction to Solid State Physics. John Wiley \& Sons, Inc., 2005.

[3] M. Ohring. The Materials Science of Thin Films. Academic Press, 1992.

[4] R. Zallen. The Physics of Amorphous Solids. John Wiley \& Sons, Inc., 1983.

[5] K.J. Saji. Amorphous Oxide Transparent Thin Films: Growth, Characterization and Applications to Thin Films Transistors. PhD thesis, Department of Physics, Cochin University of Science and Technology, India, 2008.

[6] R.W. Douglas and S. Frank. History of Glassmaking. G.T. Foulis \& Co. Ltd., 1972.

[7] J. Henderson. Ancient glass: an interdisciplinary exploration. Cambridge University Press, 2013.

[8] B. Cottrell and J. Kamminga. Mechanics of pre-industrial technology: An introduction to the mechanics of ancient and traditional material culture. Cambridge University Press, 1990.

[9] L.A.B. Pilkington. Review lecture. The float glass process. Proceedings of the Royal Society A, 314:1, 1969.

[10] A. Lindsay Greer and N. Mathur. Changing face of the chameleon. Nature, 437:1246, 2005.

[11] S.M. Kosslyn. Through the glass lightly. Science, 267:1615, 1995.

[12] M. W. Barsoum. Fundamentals of Ceramics. Taylor \& Francis Group, 2003.

[13] G.S. Fulcher. Analysis of recent measurements of the viscosity of glasses. Journal of the American Ceramic Society, 75:1043, 1992.

[14] W. Klement Jr., R.H. Willens, and P. Duwez. Non-crystalline structure in solidified gold-silicon alloys. Nature, 187:869, 1960.

[15] H.S. Chen and D. Turnbull. Formation, stability and structure of palladium-silicon based alloy glasses. Acta Materialia, 17:1021, 1969.

[16] T. Zhang, A. Inoue, and T. Masumoto. Amorphous Zr-Al-TM $(\mathrm{TM}=\mathrm{Co}, \mathrm{Ni}, \mathrm{Cu}$ ) alloys with significant supercooled liquid region of over 100 K. Materials Transactions, JIM, 32:1005, 1991.

[17] W.H. Wang, C. Dong, and C.H. Shek. Bulk metallic glasses. Materials Science and Engineering R, 44:45, 2004. 
[18] H.S. Chen. Thermodynamic consideration on the formation and stability of metallic glasses. Acta Materialia, 22:1505, 1974.

[19] A.J. Drehman, A.L. Greer, and D. Turnbull. Bulk formation of a metallic glass: $\mathrm{Pd}_{40} \mathrm{Ni}_{40} \mathrm{P}_{20}$. Applied Physics Letters, 41:716, 1982.

[20] H.W. Kui, A.L. Greer, and D. Turnbull. Formation of bulk metallic glass by fluxing. Applied Physics Letters, 45:615, 1984.

[21] A. Inoue, T. Zhang, and T. Masumoto. Al-La-Ni amorphous alloys with a wide supercooled liquid region. Materials Transactions, JIM, 30:965, 1989.

[22] A. Peker and W.L. Johnson. A highly processable metallic glass: $\mathrm{Zr}_{41.2} \mathrm{Ti}_{13.8} \mathrm{Cu}_{12.5} \mathrm{Ni}_{10.0} \mathrm{Be}_{22.5}$. Applied Physics Letters, 63:2342, 1993.

[23] A. Inoue, N. Nishiyama, and H. Kimura. Preparation and thermal stability of bulk amorphous $\mathrm{Pd}_{40} \mathrm{Cu}_{30} \mathrm{Ni}_{10} \mathrm{P}_{20}$ alloy cylinder of 72 mm diameter. Materials Transactions, JIM, 38:179, 1997.

[24] W.L. Johnson. Bulk glass-formning metallic alloys: science and technology. MRS Bulletin, 24:42, 1999.

[25] J.F. Löffler. Bulk metallic glasses. Intermetallics, 11:529, 2003.

[26] W.L. Johnson. Thermodynamic and kinetic aspects of the crystal to glass transformation in metallic materials. Progress in Materials Science, 30:81, 1986.

[27] J. P. Chu, J.S.C. Jang, J.C. Huang, H.S. Chou, Y. Yang, J.C. Ye, Y.C. Wang, J.W. Lee, F.X. Liu, P.K. Liaw, Y.C. Chen, C.M. Lee, C.L. Li, and C. Rullyani. Thin film metallic glasses: Unique properties and potential applications. Thin Solid Films, 520:5097, 2012.

[28] S. Hata, K. Sato, and A. Shimokohbe. Fabrication of thin film metallic glass and its application to microactuator. SPIE, 3892:97, 1999.

[29] Y. Liu, S. Hata, K. Wada, and A. Shimokohbe. Thermal, mechanical and electrical properties of Pd-based thin-film metallic glass. Japanese Journal of Applied Physics, 40:5382, 2001.

[30] P.-T. Chiang, G.-J. Chen, S.-R. Jian, Y.-H. Shih, J.S.-C. Jang, and C.-H. Lai. Surface antimicrobial effects of $\mathrm{Zr}_{61} \mathrm{Al}_{7.5} \mathrm{Ni}_{10} \mathrm{Cu}_{17.5} \mathrm{Si}_{4}$ thin film metallic glasses on Escherichia coli, Staphylococcus aureus, Pseudomonas aeruginosa, Acinetobacter baumannii and Candida albicans. Fooyin Journal of Health Sciences, 2:12, 2010.

[31] K. Nomura, H. Ohta, A. Takagi, T. Kamiya, M. Hirano, and $\mathrm{H}$. Hosono. Room-temperature fabrication of transparent flexible thin-film transistors using amorphous oxide semiconductors. Nature, 432:488, 2004.

[32] D.B. Buchholz, L. Zeng, M.J. Bedzyk, and R.P.H. Chang. Differences between amorphous indium oxide thin films. Progress in Materials Science: Materials International, 23:475, 2013. 
[33] J.B. Kortright and D.L. Windt. Amorphous silicon carbide coatings for extreme ultraviolet optics. Applied Optics, 27:2841, 1988.

[34] B. García, M. Estrada, K.F. Albertin, M-N-P. Carreño, I. Pereyra, and L. Resendiz. Amorphous and excimer laser annealed SiC films for TFT fabrication. Solid-State Electronics, 50:241, 2006.

[35] M. Magnuson, M. Andersson, J. Lu, L. Hultman, and U. Jansson. Electronic structure and chemical bonding of amorphous chromium carbide thin films. Journal of Physics: Condensed Matter, 24:225004, 2012.

[36] M. Andersson, J. Högström, S. Urbonaite, A. Furlan, L. Nyholm, and U. Jansson. Deposition and characterization of magnetron sputtered amorphous Cr-C films. Vacuum, 86:1408, 2012.

[37] K. Kádas, M. Andersson, E. Holmström, H. Wende, O. Karis, S. Urbonaite, S. M. Butorin, S. Nikitenko, K. O. Kvashnina, U. Jansson, and O. Eriksson. Structural properties of amorphous metal carbides: theory and experiment. Acta Materialia, 60:4720, 2012.

[38] J.E. Krzanowski and J. Wormwood. Microstructure and mechanical properties of $\mathrm{Mo}-\mathrm{Si}-\mathrm{C}$ and $\mathrm{Zr}-\mathrm{Si}-\mathrm{C}$ thin films: Compositional routes for film densification and hardness enhancement. Surface $\mathcal{E}$ Coatings Technology, 201:2942, 2006.

[39] S.Q. Wang. Copper diffusion into silicon and drift through silicon dioxide. MRS Bulletin, 19:30, 1994.

[40] F.M. Penning. Die Glimmentladung bei niedrigem Druck zwischen koaxialen Zylindern in einem axialen Magnetfeld. Physica, 3:873, 1936.

[41] E. Kay. Magnetic field effects on an abnormal truncated glow discharge and their relation to sputtered thin-film growth. Journal of Applied Physics, 34:760, 1963.

[42] W.D. Gill and E. Kay. Efficient low pressure sputtering in a large inverted magnetron suitable for film synthesis. The Review of Scientific Instruments, 36:277, 1965.

[43] R.K. Waits. Planar Magnetron Sputtering. Published in Thin Films Processes, edited by J.L. Vossen and W. Kern. Academic Press, 1978.

[44] I. Petrov, F. Adibi, J.E. Greene, W.D. Sproul, and W.-D. Münz. Use of an externally applied axial magnetic field to control ion/neutral flux ratios incident at the substrate during magnetron sputter deposition. Journal of Vacuum Science \& Technology A, 10:3283, 1992.

[45] J.E. Greene, S.A. Barnett, J.-E. Sundgren, and A. Rockett. Low-energy Ion/Surface Interactions During Film Growth From the Vapor Phase. Published in Ion Beam Assisted Film Growth, edited by T. Itoh. Elsevier Science Publisher, 1989. 
[46] S. Berg and I. Katardjiev. Resputtering effects during ion beam assisted deposition and the sputter yield amplification effect. Surface E Coatings Technology, 84:353, 1996.

[47] J.L. Vossen and J.J. Cuomo. Glow Discharge Sputter Deposition. Published in Thin Film Processes, edited by J.L. Vossen and W. Kern. Academic Press, 1978.

[48] O. Almén and G. Bruce. Collection and sputtering experiments with noble gas ions. Nuclear Instruments and Methods, 11:257, 1961.

[49] O. Almén and G. Bruce. Sputtering experiments in the high energy region. Nuclear Instruments and Methods, 11:279, 1961.

[50] N. Laegreid and G. K. Wehner. Sputtering yields of metals for $\mathrm{Ar}^{+}$ and $\mathrm{Ne}^{+}$ions with energies from 50 to $600 \mathrm{eV}$. Journal of Applied Physics, 32:365, 1961.

[51] A.H. Eltoukhy and J.E. Greene. Diffusion enhancement due to low-energy ion bombardment during sputter etching and deposition. Journal of Applied Physics, 51:4444, 1980.

[52] I. Petrov, A. Myers, J.E. Greene, and J.R. Abelson. Mass and energy resolved detection of ions and neutral sputtered species incident at the substrate during reactive magnetron sputtering of $\mathrm{Ti}$ in mixed $\mathrm{Ar}+\mathrm{N}_{2}$ mixtures. Journal of Vacuum Science \& Technology A, 12:2846, 1994.

[53] R. Behrisch. Sputtering by Particle Bombardment: I. Physical Sputtering of Single-Element Solids. Springer-Verlag, 1981.

[54] S.P. Bugaev, N.N. Koval, N.S. Sochugov, and A.N. Zakharov. Investigation of a high-current pulsed magnetron discharge initiated in the low-pressure diffuse arc plasma. Proceedings of the XVIIth International Symposium on Discharges and Electrical Insulation in Vacuum, page 1074, 1996.

[55] D.V. Mozgrin, I.K. Fetisov, and G.V. Khodachenko. Pulsed probe technique for determining the plasma parameters of a high-current low-pressure diffuse discharge. Plasma Physics Reports, 25:255, 1999.

[56] I.K. Fetisov, A.A. Filippov, G.V. Khodachenko, D.V. Mozgrin, and A.A. Pisarev. Impulse irradiation plasma technology for film deposition. Vacuum, 53:133, 1999.

[57] V. Kouznetsov, K. Macák, J.M. Schneider, U. Helmersson, and I. Petrov. A novel pulsed magnetron sputter technique utilizing very high target power densities. Surface E Coatings Technology, 122:290, 1999.

[58] J. Böhlmark, J. Alami, C. Christou, A.P. Ehiasarian, and U. Helmersson. Ionization of sputtered metals in high power pulsed magnetron sputtering. Journal of Vacuum Science E Technology A, 23:18, 2005. 
[59] K. Macák, V. Kouznetsov, J.M. Schneider, U. Helmersson, and I. Petrov. Ionized sputter deposition using an extremely high plasma density pulsed magnetron discharge. Journal of Vacuum Science $\mathcal{E}$ Technology A, 18:1533, 2000.

[60] U. Helmersson, M. Lattemann, J. Böhlmark, A.P. Ehiasarian, and J.T. Gudmundsson. Ionized physical vapor deposition (IPVD): A review of technology and applications. Thin Solid Films, 513:1, 2006.

[61] J. Böhlmark, J.T. Gudmundsson, J. Alami, M. Lattemann, and U. Helmersson. Spatial electron density distribution in a high-power pulsed magnetron discharge. IEEE Transactions on Plasma Science, 33:346, 2005.

[62] C. Christou and Z.H. Barber. Ionization of sputtered material in a planar magnetron discharge. Journal of Vacuum Science \& Technology A, 18:2897, 2000.

[63] J.T. Gudmundsson. The high power impulse magnetron sputtering discharge as an ionized physical vapor deposition tool. Vacuum, 84:1360, 2010.

[64] G. Greczynski and L. Hultman. Time and energy resolved ion mass spectroscopy studies of the ion flux during high power pulsed magnetron sputtering of $\mathrm{Cr}$ in $\mathrm{Ar}$ and $\mathrm{Ar} / \mathrm{N}_{2}$ atmospheres. Vacuum, 84:1159, 2010.

[65] J.T. Gudmundsson, J. Alami, and U. Helmersson. Spatial and temporal behavior of the plasma parameters in a pulsed magnetron discharge. Surface \& Coatings Technology, 161:249, 2002.

[66] B.M. DeKoven, P.R. Ward, R.E. Weiss, D.J. Christie, R.A. Scholl, W.D. Sproul, F. Tomasel, and A. Anders. Carbon thin film deposition using high power pulsed magnetron sputtering. Annual Technical Conference Proceedings, Society of Vacuum Coaters, 46:158, 2003.

[67] J. Alami, P.O.Å. Persson, D. Music, J.T. Gudmundsson, J. Böhlmark, and U. Helmersson. Ion-assisted physical vapor deposition for enhanced film properties on nonflat surfaces. Journal of Vacuum Science E Technology A, 23:278, 2005.

[68] A.P. Ehiasarian, P.E. Hovsepian, L. Hultman, and U. Helmersson. Comparison of microstructure and mechanical properties of chromium nitride-based coatings deposited by high power impulse magnetron sputtering and by the combined steered cathodic arc/unbalanced magnetron technique. Thin Solid Films, 457:270, 2004.

[69] E. Wallin and U. Helmersson. Hysteresis-free reactive high power impulse magnetron sputtering. Thin Solid Films, 516:6398, 2008.

[70] D. Depla and R. De Gryse. Target poisoning during reactive magnetron sputtering: Part I: the influence of ion implantation. Surface \& Coatings Technology, 183:184, 2004. 
[71] S.M. Rossnagel. Gas density reduction effects in magnetrons. Journal of Vacuum Science \& Technology A, 6:19, 1988.

[72] K. Sarakinos, J. Alami, and M. Wuttig. Process characteristics and film properties upon growth of $\mathrm{TiO}_{x}$ films by high power pulsed magnetron sputtering. Journal of Physics D: Applied Physics, 40:2108, 2007.

[73] K. Sarakinos, J. Alami, and S. Konstantinidis. High power pulsed magnetron sputtering: A review on scientific and engineering state of the art. Surface \& Coatings Technology, 204:1661, 2010.

[74] K. Bobzin, N. Bagcivan, P. Immich, S. Bolz, J. Alami, and R. Cremer. Advantages of nanocomposite coatings deposited by high power pulse magnetron sputtering technology. Journal of Materials Processing Technology, 209:165, 2009.

[75] T.F. Zhang, Q.M. Wang, J. Lee, P. Ke, R. Nowak, and K.H. Kim. Nanocrystalline thin films synthesized from a $\mathrm{Ti}_{2} \mathrm{AlN}$ compound target by high power impulse magnetron sputtering technique. Surface E Coatings Technology, 212:199, 2012.

[76] J. Alami, Z. Maric, H. Busch, F. Klein, U. Grabowy, and M. Kopnarski. Enhanced ionization sputtering: A concept for superior industrial coatings. Surface \& Coatings Technology, http://dx.doi.org/10.1016/j.surfcoat.2013.11.040:xxx-xxx, 2013.

[77] D.J. Christie. Target material pathways model for high power pulsed magnetron sputtering. Journal of Vacuum Science \& Technology A, 23:330, 2005.

[78] U. Helmersson, M. Lattemann, J. Alami, J. Böhlmark, A.P. Ehiasarian, and J.T. Gudmundsson. High power impulse magnetron sputtering discharges and thin film growth: A brief review. Annual Technical Conference Proceedings, Society of Vacuum Coaters, 48:458, 2005.

[79] J. Böhlmark, M. Östbye, M. Lattemann, H. Ljungcrantz, T. Rosell, and U. Helmersson. Guiding the deposition flux in an ionized magnetron discharge. Thin Solid Films, 515:1928, 2006.

[80] A. Anders. Deposition rates of high power impulse magnetron sputtering: Physics and economics. Journal of Vacuum Science $\mathcal{E}$ Technology A, 28:783, 2010.

[81] A. Anders. Ion charge state distributions of vacuum arc plasmas: The origin of species. Physical Review E, 55:969, 1997.

[82] A. Anders. Approaches to rid cathodic arc plasmas of macro- and nanoparticles: A review. Surface E Coatings Technology, 120-121:319, 1999.

[83] R. L. Boxman, D. M. Sanders, P. J. Martin, and J. M. Laferty. Handbook of Vacuum Arc Science, Fundamentals and Applications. Noyes Publications, 1995. 
[84] A. Eriksson, J.Q. Zhu, N. Ghafoor, M.P. Johansson, J. Sjölén, J. Jensen, M. Odén, L. Hultman, and J. Rosén. Ti-Si-C-N thin films grown by reactive arc evaporation from $\mathrm{Ti}_{3} \mathrm{SiC}_{2}$ cathodes. Journal of Materials Research, 26:874, 2011.

[85] A.O. Eriksson, J.Q. Zhu, N.Ghafoor, M.P. Johansson, J. Sjölén, J. Jensen, M. Odén, L. Hultman, and J. Rosén. Layer formation by resputtering in Ti-Si-C hard coatings during large scale cathodic arc deposition. Surface E Coatings Technology, 205:3923, 2011.

[86] O. Knotek, F. Löffler, M. Böhmer, R. Breidenbach, and C. Stößel. Ceramic cathodes for arc-physical vapour deposition: development and application. Surface E Coatings Technology, 49:263, 1991.

[87] J.A. Thornton. Diagnostic methods for sputtering plasmas. Journal of Vacuum Science and Technology, 15:188, 1978.

[88] I. H. Hutchinson. Principles of Plasma Diagnostics. Cambridge University Press, 2002.

[89] B. Chapman. Glow Discharge Processes. John Wiley \& Sons, Inc., 1980.

[90] M.A. Lieberman and A.J. Lichtenberg. Principles of Plasma Discharges and Materials Processing. John Wiley \& Sons, Inc., 1994.

[91] J. G. Laframboise. Studies Report No. 100. PhD thesis, University of Toronto Institute for Aerospace, 1966.

[92] I. Petrov. Probes in negative glow discharges. Lecture Notes, 1994.

[93] NIST ITS-90. Thermocouple Database. < http://srdata.nist.gov/its90/main/ >, visited 20 Mar, 2014.

[94] D. Ng and G. Fralick. Use of a multiwavelength pyrometer in several elevated temperature aerospace applications. Review of Scientific Instruments, 72:1522, 2001.

[95] J. C. Slater. Atomic radii in crystals. Journal of Chemical Physics, 41:3199, 1964.

[96] L.E. Toth. Transition Metal Carbides and Nitrides. Academic Press, 1971.

[97] J.-E. Sundgren, B.O. Johansson, A. Rockett, S.A. Barnett, and J.E. Greene. TiN: A review of the present understanding of the atomic and electronic structure and recent results on the growth and physical properties of epitaxial $\operatorname{TiN}_{x}(0.6<\mathrm{x}<1.2)$ layers. American Institute of Physics Series 149, 1986.

[98] P. H. Mayrhofer, C. Mitterer, and H. Clemens. Self-organized nanostructures in hard ceramic coatings. Advanced Engineering Materials, 7:1071, 2005.

[99] N.W. Ashcroft and N.D. Mermin. Solid State Physics. Brooks/Cole, 1976. 
[100] R.S. Pease. An X-ray study of boron nitride. Acta Crystallographica, 5:356, 1952.

[101] R.H. Wentorf Jr. Cubic form of boron nitride. The Journal of Chemical Physics, 26:956, 1957.

[102] F.P. Bundy and R.H. Wentorf Jr. Direct transformation of hexagonal boron nitride to denser forms. The Journal of Chemical Physics, 38:1144, 1963.

[103] H. Holleck. Material selection for hard coatings. Journal of Vacuum Science \& Technology A, 4:2661, 1986.

[104] C.Y. Ting. TiN formed by evaporation as a diffusion barrier between $\mathrm{Al}$ and Si. Journal of Vacuum Science E Technology, 21:14, 1982.

[105] S.-K. Rha, S.-Y. Lee, W.-J. Lee, Y.-S. Hwang, C.-O. Park, D.-W. Kim, Y.-S. Lee, and C.-N. Whang. Characterization of TiN barriers against $\mathrm{Cu}$ diffusion by capacitance-voltage measurement. Journal of Vacuum Science \& Technology B, 16:2019, 1998.

[106] P. Roquiny, F. Bodart, and G. Terwagne. Colour control of titanium nitride coatings produced by reactive magnetron sputtering at temperature less than $100{ }^{\circ} \mathrm{C}$. Surface \& Coatings Technology, 116-119:278, 1999.

[107] J.-E. Sundgren. Structure and properties of TiN coatings. Thin Solid Films, 128:21, 1985.

[108] H. Ljungcrantz, M. Odén, L. Hultman, J. E. Greene, and J.-E. Sundgren. Nanoindentation studies of single-crystal (001)- (011)and (111)-oriented TiN layers on MgO. Journal of Applied Physics, 80:6725, 1996.

[109] H. Ljungcrantz, C. Engström, M. Olsson, X. Chu, M.S. Wong, W.D. Sproul, and L. Hultman. Nanoindentation hardness, abrasive wear, and microstructure of TiN/NbN polycrystalline nanostructured multilayer films grown by reactive magnetron sputtering. Journal of Vacuum Science E Technology A, 16:3104, 1998.

[110] A. Flink, T. Larsson, J. Sjölén, L. Karlsson, and L. Hultman. Influence of $\mathrm{Si}$ on the microstructure of arc evaporated $(\mathrm{Ti}, \mathrm{Si}) \mathrm{N}$ thin films; evidence for cubic solid solutions and their thermal stability. Surface $\mathcal{E}$ Coatings Technology, 200:1535, 2005.

[111] H. Ichimura and A. Kawana. High-temperature oxidation of ion-plated TiN and TiAIN films. Journal of Materials Research, 8:1093, 1993.

[112] P. Panjan, B. Navinšek, A. Cvelbar, A. Zalar, and I. Milošev. Oxidation of TiN, ZrN, TiZrN, erN, TiCrN and TiN/CrN multilayer hard coatings reactively sputtered at low temperature. Thin Solid Films, 281-282:298, 1996. 
[113] TiN. Powder Diffraction File TiN: 00-038-1420. JCPDS International Centre for Diffraction Data, 2010.

[114] I. Suni, M. Mäenpää, and M.-A. Nicolet. Thermal stability of hafnium and titanium nitride diffusion barriers in multilayer contacts to silicon. Journal of The Electrochemical Society, 130:1215, 1983.

[115] B. M. Howe. Growth, Physical Properties, and Nanostructuring of Epitaxial Metastable Hafnium Aluminum Nitride. PhD thesis, University of Illinois at Urbana-Champaign, 2010.

[116] H.-S. Seo, T.-Y. Lee, J.G. Wen, I. Petrov, J.E. Greene, and D. Gall. Growth and physical properties of epitaxial HfN layers on $\mathrm{MgO}(001)$. Journal of Applied Physics, 96:878, 2004.

[117] N. Kumar, W. Noh, S.R. Daly, G.S. Girolami, and J.R. Abelson. Low temperature chemical vapor deposition of hafnium nitride-boron nitride nanocomposite films. Chemistry of Materials, 21:5601, 2009.

[118] H.-S. Seo, T.-Y. Lee, I. Petrov, J.E. Greene, and D. Gall. Epitaxial and polycrystalline $\mathrm{HfN}_{x}(0.8 \leq \mathrm{x} \leq 1.5)$ layers on $\mathrm{MgO}(001)$ : Film growth and physical properties. Journal of Applied Physics, 97:083521, 2005.

[119] D.S. Yee, J.J. Cuomo, M.A. Frisch, and D.P.E. Smith. Reactive radio frequency sputter deposition of higher nitrides of titanium, zirconium, and hafnium. Journal of Vacuum Science \& Technology A, 4:381, 1986.

[120] A. Zerr and G. Miehe amd R. Riedel. Synthesis of cubic zirconium and hafnium nitride having $\mathrm{Th}_{3} \mathrm{P}_{4}$ structure. Nature Materials, 2:185, 2003.

[121] HfN. Powder Diffraction File HfN: 00-033-0592. JCPDS International Centre for Diffraction Data, 2010.

[122] W.M. Yim, E.J. Stofko, P.J. Zanzucchi, J.I. Pankove, M.Ettenberg, and S.L. Gilbert. Epitaxially grown AIN and its optical band gap. Journal of Applied Physics, 44:292, 1973.

[123] Y. Baik and R.A.L. Drew. Aluminium nitride: Processing and applications. Key Engineering Materials, 122-124:553, 1996.

[124] P. Limsuwan, N. Udomkan, S. Meejoo, and P. Winotai. Surface morphology of submicron crystals in aluminum nitride films grown by DC magnetron sputtering. International Journal of Modern Physics B, 19:2073, 2005.

[125] A. Kumar, H.L. Chan, J.J. Weimer, and L. Sanderson. Structural characterization of pulsed laser-deposited AlN thin films on semiconductor substrates. Thin Solid Films, 308-309:406, 1997.

[126] AlN. Powder Diffraction File AlN: 00-025-1133. JCPDS International Centre for Diffraction Data, 2010. 
[127] I. Petrov, E. Mojab, R. C. Powell, J. E. Greene, L. Hultman, and J.-E. Sundgren. Synthesis of metastable epitaxial zinc-blende structure AlN by solid-state reaction. Applied Physics Letters, 60:2491, 1992.

[128] F. Adibi, I. Petrov, L. Hultman, U. Wahlström, T. Shimizu, D. McIntyre, J. E. Greene, and J.-E. Sundgren. Defect structure and phase transitions in epitaxial metastable cubic $\mathrm{Ti}_{0.5} \mathrm{Al}_{0.5} \mathrm{~N}$ alloys grown on $\mathrm{MgO}(001)$ by ultra-high-vacuum magnetron sputter deposition. Journal of Applied Physics, 69:6437, 1991.

[129] S. Hampshire. Silicon nitride ceramics - review of structure, processing and properties. Journal of Achievements in Materials and Manufacturing Engineering, 24:43, 2007.

[130] P. Walsh, A. Omeltchenko, R.K. Kalia, A. Nakano, and P. Vashishta. Nanoindentation of silicon nitride: A multimillion-atom molecular dynamics study. Applied Physics Letters, 82:118, 2003.

[131] J.Z. Jiang, F. Kragh, D.J. Frost, K. Ståhl, and H. Lindelov. Hardness and thermal stability of cubic silicon nitride. Journal of Physics: Condensed Matter, 13:L515, 2001.

[132] I. Tomaszkiewicz. Thermodynamics of silicon nitride. Standard molar enthalpy of formation of amorphous $\mathrm{Si}_{3} \mathrm{~N}_{4}$ at $298.15 \mathrm{~K}$. Journal of Thermal Analysis and Calorimetry, 65:425, 2001.

[133] A. Zerr, G. Miehe, G. Serghiou, E. Kroke, R. Riedel, H. Fuesz, P. Kroll, and R. Boehler. Synthesis of cubic silicon nitride. Nature, 400:340, 1999.

[134] S.R. Elliot. Physics of Amorphous Materials. Longman Scientific \& Technical, 1990.

[135] N. Wada, S.A. Solin, J. Wong, and S. Prochazka. Raman and IR absorption spectroscopic studies on $\alpha, \beta$, and amorphous $\mathrm{Si}_{3} \mathrm{~N}_{4}$. Journal of Non-Crystalline Solids, 43:7, 1981.

[136] H.O. Pierson and E. Randich. Titanium diboride coatings and their interaction with the substrates. Thin Solid Films, 54:119, 1978.

[137] C. Pfohl, A. Bulak, and K.-T. Rie. Development of titanium diboride coatings deposited by PACVD. Surface E Coatings Technology, 131:141, 2000.

[138] B. Basu, G.B. Raju, and A.K. Suri. Processing and properties of monolithic $\mathrm{TiB}_{2}$ based materials. International Materials Reviews, 51:352, 2006.

[139] J. Fjellstedt, A.E.W. Jarfors, and L. Svendsen. Experimental analysis of the intermediary phases $\mathrm{AlB}_{2}, \mathrm{AlB}_{12}$ and $\mathrm{TiB}_{2}$ in the $\mathrm{Al}-\mathrm{B}$ and Al-Ti-B systems. Journal of Alloys and Compounds, 283:192, 1999.

[140] $\mathrm{TiB}_{2}$. Powder Diffraction File $\mathrm{TiB}_{2}$ : 00-035-0741. JCPDS International Centre for Diffraction Data, 2010. 
[141] B.F. Decker and J.S. Kasper. The crystal structure of TiB. Acta Crystallographica, 7:77, 1954.

[142] K.E. Spear, P. McDowell, and F. McMahon. Experimental evidence for the existence of the $\mathrm{Ti}_{3} \mathrm{~B}_{4}$ phase. Journal of the American Ceramic Society, 69:C4, 1983.

[143] W.B. Pearson. A Handbook of Lattice Spacings and Structures of Metals and Alloys, Vol.2. 1958-1967 International Series of Monographs in Metal Physics and Physical Metallurgy, 1967.

[144] $\mathrm{AlB}_{2}$. Powder Diffraction File $\mathrm{AlB}_{2}$ : 00-039-1483. JCPDS International Centre for Diffraction Data, 2010.

[145] I. Higashi. Crystal chemistry of $\alpha-\mathrm{AlB}_{12}$ and $\gamma-\mathrm{AlB}_{12}$. Journal of Solid State Chemistry, 154:168, 2000.

[146] M. Engler, C. Lesniak, R. Damasch, B. Ruisinger, and J. Eichler. Hexagonal boron nitride (hBN) - Applications from metallurgy to cosmetics. cfi/Ber. DKG, 84:E49, 2007.

[147] BN. Powder Diffraction File h-BN: 00-049-1327. JCPDS International Centre for Diffraction Data, 2010.

[148] Y. Tian, B. Xu, D. Yu, Y. Ma, Y. Wang, Y. Jiang, W. Hu, C. Tang, Y. Gao, K. Luo, Z. Zhao, L.-M. Wang, B. Wen, J. He, and Z. Liu. Ultrahard nanotwinned cubic boron nitride. Nature, 493:385, 2013.

[149] T. Ishii, T. Sato, Y. Sekikawa, and M. Iwata. Growth of whiskers of hexagonal boron nitride. Journal of Crystal Growth, 52:285, 1981.

[150] R. Zedlitz, M. Heintze, and M.B. Schubert. Properties of amorphous boron nitride thin films. Journal of Non-Crystalline Solids, 198-200:403, 1996.

[151] C.H. Henager Jr. and W.T. Pawlewicz. Thermal conductivities of thin, sputtered optical films. Applied Optics, 32:91, 1993.

[152] S. Weissmantel, G. Reisse, B. Keiper, and S. Schulze. Microstructure and mechanical properties of pulsed laser deposited boron nitride films. Diamond and Related Materials, 8:377, 1999.

[153] N.G. Chopra, R.J. Luyken, K. Cherrey, V.H. Crespi, M.L. Cohen, S.G. Louie, and A. Zettl. Boron nitride nanotubes. Science, 269:966, 1995.

[154] R. Tenne. Doped and heteroatom-containing fullerene-like structures and nanotubes. Advanced Materials, 7:965, 1995.

[155] T. Oku, M. Kuno, H. Kitahara, and I. Narita. Formation, atomic structures and properties of boron nitride and carbon nanocage fullerene materials. International Journal of Inorganic Materials, 3:597, 2001.

[156] J. Thomas Jr., N.E. Weston, and T.E. O'Connor. Turbostratic boron nitride, thermal transformation to ordered-layer-lattice boron nitride. Journal of the American Ceramic Society, 84:4619, 1963. 
[157] M.P. Johansson, L. Hultman, S. Dauud, K. Bewilgua, H. Lüthje, A. Schütze, S. Kouptsidis, and G.S.A.M. Theunissen. Microstructure of BN:C films deposited on Si substrates by reactive sputtering from a B ${ }_{4} \mathrm{C}$ target. Thin Solid Films, 287:193, 1996.

[158] D.A. Porter and K.E. Easterling. Phase Transformations in Metals and Alloys $2^{\text {nd }}$ Edition. Taylor \& Francis Group, 2004.

[159] B. A. Movchan and A. V. Demchishin. Study of the structure and properties of thick vacuum condensates of nickel, titanium, tungsten, aluminium oxide and zirconium dioxide. Physics of Metals and Metallography, 28:83, 1969.

[160] J.A. Thornton. Influence of apparatus geometry and deposition conditions on the structure and topography of thick sputtered coatings. Journal of Vacuum Science and Technology, 11:666, 1974.

[161] A. Anders. A structure zone diagram including plasma-based deposition and ion etching. Thin Solid Films, 518:4087, 2010.

[162] C. Michaelsen, C. Gente, and R. Bormann. The thermodynamics of amorphous phases in immiscible systems: The example of sputter-deposited Nb-Cu alloys. Journal of Applied Physics, 81:6024, 1997.

[163] H. Hecht, G. Weigang, S. Eickert, and U. Geyer. Formation area of thin amorphous $\mathrm{Zr}-\mathrm{Mn}$ and $\mathrm{Zr}$-Ta films prepared by cocondensation. Zeitschrift für Physik B, 100:47, 1996.

[164] R.A.L. Jones. Soft Condensed Matter. Oxford University Press, 2002.

[165] A. Hörling, L. Hultman, M. Odén, J. Sjölén, and L. Karlsson. Mechanical properties and machining performance of $\mathrm{Ti}_{1-x} \mathrm{Al}_{x} \mathrm{~N}$-coated cutting tools. Surface $\mathcal{E}$ Coatings Technology, 191:384, 2005.

[166] M. Birkholz. Thin Film Analysis by X-Ray Scattering. Wiley-VCH Verlag GmbH \& Co., 2006.

[167] The Nobel Prize in Physics 1915. Nobel Media AB 2013. $<$ http: //www.nobelprize.org >, visited Jan 8, 2014.

[168] I.C. Noyan and J.B. Cohen. Residual Stress - Measurements by Diffraction and Interpretation. Springer-Verlag, 1987.

[169] J.A. Sue. X-ray elastic constants and residual stress of textured titanium nitride coating. Surface \& Coatings Technology, 54-55:154, 1992.

[170] L. G. Parratt. Surface studies of solids by total reflection of X-rays. Physical Review, 95:359, 1954.

[171] R. Erni, M. D. Rossell, C. Kisielowski, and U. Dahmen. Atomic-resolution imaging with a sub-50-pm electron probe. Physical Review Letters, 102:096101, 2009. 
[172] D.B. Williams and C.B. Carter. Transmission Electron Microscopy. Springer Science, 2009.

[173] A. Barna. Topographic Kinetics and Practice of Low Angle Ion Beam Thinning. Published in Specimen Preparation for Transmission Electron Microscopy of Materials - III. Materials Research Society Symposium Proceedings Vol. 254, 1992.

[174] R. Alani and P.R. Swann. Precision Ion Polishing System - A new instrument for TEM specimen preparation of materials. Published in Specimen Preparation for Transmission Electron Microscopy of Materials - III. Materials Research Society Symposium Proceedings Vol. 254, 1992.

[175] Gatan. Precision Ion Polishing System User's Guide. Gatan, Inc., 1998.

[176] H. Bubert and J.C Riviére. Photoelectron Spectroscopy. Published in Surface and Thin Film Analysis: Principles, Instrumentation, Applications, edited by H. Bubert and H. Jenett. Wiley-VCH Verlag $\mathrm{GmbH}, 2002$.

[177] J. Jensen. Ion Beam Analysis in Material Science. Lecture Notes, 2012.

[178] A. Saha and A.R. Barron. Rutherford Backscattering of Thin Films. The Connexions Project, 2009.

[179] C.R. Brundle, C.A. Evans Jr., and S. Wilson. Encyclopedia of Materials Characterization. Butterworth-Heinemann, 1992.

[180] W.M.A. Bik and F.H.P.M. Habraken. Elastic recoil detection. Reports on Progress in Physics, 56:859, 1993.

[181] O. Benka. Elastic Recoil Detection Analysis (ERDA). Published in Surface and Thin Film Analysis: Principles, Instrumentation, Applications, edited by H. Bubert and H. Jenett. Wiley-VCH Verlag $\mathrm{GmbH}, 2002$.

[182] M. Mayer. SIMNRA, a simulation program for the analysis of NRA, RBS and ERDA. American Institute of Physics Conference Proceedings, 475:541, 1999.

[183] M.S. Janson. CONTES conversion of time-energy spectra - a program for ERDA data analysis. Internal Report, Uppsala University, 2004.

[184] J.I. Goldstein, D.E. Newbury, P. Echlin, D.C. Joy, C.E. Lyman, E. Lifshin, L. Sawyer, and J.R. Michael. Scanning Electron Microscopy and X-ray Microanalysis. Springer Science+Business Media, Inc., 2003.

[185] R.W. Armstrong, W.L. Elban, and S.M. Walley. Elastic, plastic, cracking aspects of the hardness of materials. International Journal of Modern Physics B, 27:1330004, 2013.

[186] W.C. Oliver and G.M. Pharr. An improved technique for determining hardness and elastic modulus using load and displacement sensing indentation experiments. Journal of Materials Research, 7:1564, 1992. 
[187] S. Zhang and X. Zhang. Toughness evaluation of hard coatings and thin films. Thin Solid Films, 520:2375, 2012.

[188] Z.C. Xia and J.W. Hutchinson. Crack patterns in thin films. Journal of Mechanics and Physics of Solids, 48:1107, 2000.

[189] A. Abdul-Baqi and E. Van der Giessen. Numerical analysis of indentation-induced cracking of brittle coatings on ductile substrates. International Jorunal of Solids and Structures, 39:1427, 2002.

[190] A. Karimi, Y. Wang, T. Cselle, and M. Morstein. Fracture mechanisms in nanoscale layered hard thin films. Thin Solid Films, 420-421:275, 2002.

[191] G.M. Pharr. Measurement of mechanical properties by ultra-low load indentation. Materials Science and Engineering: A, 253:151, 1998.

[192] J. Lankford and D. L. Davidson. Indentation plasticity and microfracture in silicon carbide. Journal of Materials Science, 14:1669, 1979.

[193] X. Li, D. Diao, and B. Bhushan. Fracture mechanisms of thin amorphous carbon films in nanoindentation. Acta Materialia, 45:4453, 1997.

[194] A. Flink, J. M. Andersson, B. Alling, R. Daniel, J. Sjölén, L. Karlsson, and L. Hultman. Structure and thermal stability of arc evaporated $\left(\mathrm{Ti}_{0.33} \mathrm{Al}_{0.67}\right)_{1-x} \mathrm{Si}_{x} \mathrm{~N}$ thin films. Thin Solid Films, 517:714, 2008.

[195] S. Veprek. The search for novel, superhard materials. Journal of Vacuum Science \& Technology A, 17:2401, 1999.

[196] B.M. Howe, E. Sammann, J.G. Wen, T. Spila, J.E. Greene, L. Hultman, and I. Petrov. Real-time control of AlN incorporation in epitaxial $\mathrm{Hf}_{1-x} \mathrm{Al}_{x} \mathrm{~N}$ using high-flux, low-energy (10-40 eV) ion bombardment during reactive magnetron sputter deposition from a $\mathrm{Hf}_{0.7} \mathrm{Al}_{0.3}$ alloy target. Acta Materialia, 59:421, 2011. 


\section{LIST OF FIGURES}

2.1 Specific volume change when a glass is cooled through $T_{g} \ldots 6$

3.1 The magnetron sputtering process . . . . . . . . . . . . . . . . 12

3.2 Balanced and unbalanced magnetrons . . . . . . . . . . . . . . 13

3.3 Unbalanced magnetrons with external coils . . . . . . . . . . . . . 14

3.4 Sputter yield amplification (SYA) $\ldots \ldots \ldots \ldots$

3.5 The arc evaporation process . . . . . . . . . . . . . . . 19

3.6 Industrial cathodic arc evaporation system . . . . . . . . . . . 20

3.7 Typical IV-curve . . . . . . . . . . . . . . . . . . . . . . 22

3.8 Logarithmic IV-curve . . . . . . . . . . . . . . . . . . . . . . . . 24

3.9 Thermocouple . . . . . . . . . . . . . . . 26

4.1 Hard ceramic materials classified after chemical bonding . . . . 28

4.2 Rock-salt crystal structure . . . . . . . . . . . . . . . . 30

4.3 Wurtzite crystal structure . . . . . . . . . . . . . . . . 31

4.4 Silicon nitride network . . . . . . . . . . . . . . . 32

$4.5 \mathrm{AlB}_{2}$ crystal structure . . . . . . . . . . . . . . . 33

4.6 Hexagonal crystal structure . . . . . . . . . . . . 33

5.1 Schematic illustration of metastability . . . . . . . . . . . 36

5.2 Free energy diagram of a binary alloy . . . . . . . . . . . 36

5.3 Free energy change in homogeneous nucleation . . . . . . . . . 37

5.4 Structure zone diagram . . . . . . . . . . . . . . . . . . . . . 39

5.5 Binary phase diagram with eutectic point . . . . . . . . . . . . 40

5.6 Spinodal decomposition . . . . . . . . . . . . . . . 41

6.1 X-ray diffraction from lattice planes . . . . . . . . . . . . . . . . . 44

6.2 X-ray diffractogram . . . . . . . . . . . . . . . . . . . . . . . 44

6.3 Sample related stress tensors . . . . . . . . . . . . . . . . . . 45

6.4 Relation between angles $\theta, \Phi$, and $\Psi \ldots \ldots \ldots \ldots$. . . . . . . . . . . . . . . . . . . .

6.5 X-ray reflectivity scan . . . . . . . . . . . . . . . . . . . 48

6.6 Bright field and dark field TEM . . . . . . . . . . . . . . . . . . 49

6.7 Selected area diffraction patterns . . . . . . . . . . . . 50

6.8 Sandwich method for TEM sample preparation . . . . . . . . 52

6.9 Mechanical polishing of a TEM sample . . . . . . . . . . . 53

6.10 Ion milling of a TEM sample . . . . . . . . . . . . . . . 54

6.11 Plan-view TEM sample interference fringes . . . . . . . . . . 54

6.12 Examples of SEM images . . . . . . . . . . . . . . . . . 55

6.13 Schematic of a combined RBS and ERDA setup . . . . . . . . . 57

6.14 Typical RBS spectrum . . . . . . . . . . . . . . . . . . . . 57

6.15 Typical ERDA spectrum . . . . . . . . . . . . . . . . . . 58

6.16 Typical XPS spectra . . . . . . . . . . . . . . . . . . . 59

6.17 Typical nanoindentation loading-unloading curve . . . . . . . 62

6.18 Sample mounting for nanoindentation . . . . . . . . . . . 63

6.19 Crack formation in HfN and TiN samples . . . . . . . . . 65 

Papers 


\section{LIST OF PAPERS AND MY CONTRIBUTIONS}

Paper I The project was initiated and planned jointly. I participated during the depositions and did all characterization, except TEM where I participated. I took part in the evaluation and interpretation of the results. I was responsible for writing the manuscript.

Paper II I initiated the project, planned and carried out all the depositions. I did all characterization, except for TEM where I participated, and ERDA where I initiated the measurement and took part in the evaluation and interpretation of the results. I was responsible for writing the manuscript.

Paper III The project was initiated jointly. The depositions were planned and performed by Dr. Andersson and me. I did all characterization, except TEM where I participated. I initiated the ERDA measurement, and I participated in the evaluation and interpretation of the results. I was responsible for writing the manuscript.

Paper IV The project was initiated jointly, and planned by me and Dr. Greczynski. I performed all depositions. I did all characterization, except TEM where I participated, and ERDA and XPS measurements were I initiated the studies and took part in evaluating and interpreting the results. I was responsible for writing the manuscript.

Paper V The project was initiated and planned by Dr. Howe and me. I did all depositions and all characterization, except TEM where I participated, and RBS and XPS studies, where I took part in the evaluation and interpretation of the results. I was responsible for writing the manuscript.

RELATED BUT NOT INCLUDED PAPERS

Paper VI A. Fallqvist, N. Ghafoor, H. Fager, L. Hultman, and P.O.Å. Persson.

Self-organization during growth of $\mathrm{ZrN} / \mathrm{SiN}_{x}$ multilayers by epitaxial lateral overgrowth.

Journal of Applied Physics, 114:224302, 2013. 


\section{Papers}

The articles associated with this thesis have been removed for copyright reasons. For more details about these see:

http://urn.kb.se/resolve?urn=urn:nbn:se:liu:diva-106576 